\title{
REGULATION OF GLUTAMATE DEHYDROGENASE IN HYPOMETABOLIC STATES
}

\author{
By \\ Ryan Bell \\ B.Sc. (Hons.), 2006
}

A Thesis Submitted to the Faculty of Graduate Studies and Research in partial fulfilment of the requirements for the degree of

\author{
Master of Science \\ Department of Biology
}

Carleton University

Ottawa, Ontario, Canada

(C) copyright 2008 


$\begin{array}{ll}\begin{array}{l}\text { Library and } \\ \text { Archives Canada }\end{array} & \begin{array}{l}\text { Bibliothèque et } \\ \text { Archives Canada }\end{array} \\ \begin{array}{l}\text { Published Heritage } \\ \text { Branch }\end{array} & \begin{array}{l}\text { Direction du } \\ \text { Patrimoine de l'édition }\end{array} \\ \begin{array}{l}\text { 395 Wellington Street } \\ \text { Ottawa ON K1A 0N4 } \\ \text { Canada }\end{array} & \begin{array}{l}\text { 395, rue Wellington } \\ \text { Ottawa ON K1A 0N4 } \\ \text { Canada }\end{array}\end{array}$

Your file Votre référence ISBN: 978-0-494-44117-6 Our file Notre référence ISBN: 978-0-494-44117-6

NOTICE:

The author has granted a nonexclusive license allowing Library and Archives Canada to reproduce, publish, archive, preserve, conserve, communicate to the public by telecommunication or on the Internet, loan, distribute and sell theses worldwide, for commercial or noncommercial purposes, in microform, paper, electronic and/or any other formats.

The author retains copyright ownership and moral rights in this thesis. Neither the thesis nor substantial extracts from it may be printed or otherwise reproduced without the author's permission.
AVIS:

L'auteur a accordé une licence non exclusive permettant à la Bibliothèque et Archives Canada de reproduire, publier, archiver, sauvegarder, conserver, transmettre au public par télécommunication ou par l'Internet, prêter, distribuer et vendre des thèses partout dans le monde, à des fins commerciales ou autres, sur support microforme, papier, électronique et/ou autres formats.

L'auteur conserve la propriété du droit d'auteur et des droits moraux qui protège cette thèse. $\mathrm{Ni}$ la thèse ni des extraits substantiels de celle-ci ne doivent être imprimés ou autrement reproduits sans son autorisation.
In compliance with the Canadian Privacy Act some supporting forms may have been removed from this thesis.

While these forms may be included in the document page count, their removal does not represent any loss of content from the thesis.
Conformément à la loi canadienne sur la protection de la vie privée, quelques formulaires secondaires ont été enlevés de cette thèse.

Bien que ces formulaires aient inclus dans la pagination, il n'y aura aucun contenu manquant.

\section{Canada}




\begin{abstract}
Glutamate dehydrogenase (GDH) is a key enzyme in nitrogen metabolism and has significant roles in amino acid catabolism and urea biosynthesis. The role of this enzyme in important metabolic processes suggests that it may be regulated in animals that survive in unforgiving environments. Such animals typically respond to harsh environmental conditions with strong overall metabolic rate suppression as well as species- and tissuespecific metabolic alterations. To better understand the role of amino acid metabolism in hypometabolism, GDH was investigated in hibernating Richardson's ground squirrels (Spermophilus richardsonii), anoxia-tolerant freshwater turtles (Trachemys scripta elegans), and estivating land snails (Otala lactea). Studies analyzed GDH substrate affinities, effects of metabolite activators and inhibitors, $\mathrm{pH}$ and/or temperature effects, and the actions of protein kinases and protein phosphatases in modifying enzyme properties. Liver GDH from ground squirrels was regulated by reversible protein phosphorylation in a manner that could activate the oxidation of glutamate to assist in energy production and contribute to gluconeogenesis during hibernation. Similarly, foot muscle GDH from land snails was regulated by reversible phosphorylation with the subsequent activation of the glutamate-oxidizing reaction to aid in energy production and urea biosynthesis in the estivating state. Conversely, under conditions of oxygen deprivation, the freshwater turtle utilizes reversible phosphorylation to inactivate both the glutamate-oxidizing and glutamate-synthesizing reactions of GDH. Thus, it appears that GDH and its effects on amino acid metabolism play an important role in animals during hypometabolism.
\end{abstract}




\section{ACKNOWLEDGEMENTS}

First and foremost, I must thank my family for getting me through my academic career and really my whole life. Thanks to my Mom and Dad for their love and support throughout all of my endeavors, without which I could not have accomplished what I have in my life. A special thanks needs to go out to my brother, Matt, who has guided me throughout my academic career and always been there to show me the right path and help me whenever I needed. I could not have made it through undergrad, let alone my Masters without your help.

I must thank Dr. Ken Storey and Jan Storey for all of their help and guidance over the past few years. Thanks to Dr. Storey for teaching me the skills necessary for me to succeed in science as well as giving me a push from time to time to think more like a scientist. You truly are the best supervisor. Thanks to Jan for all of her editing, insightful suggestions and encouragement throughout my time in the Storey lab. I must also thank my fellow enzymologists, Chris D., Chris Ram, and Khalil, who helped me countless number of times over the years.

Next I have to thank Judeh. Once again we have made it through another level of schooling literally laughing all the way through. Thanks for all of the help over the years as well as the constant Seinfeld jokes, lunchtime sitcoms/video games, hangman, and all of the random sporting events that we held in the lab throughout the years.

And last but not least, thanks to the Storey lab members for making my grad studies so much fun. Special mention has to go out to Ben, Jacques, Oscar, and all of the Storey lab boys. Whether it was playing short hop, watching Chappelle/curb/The Office etc., pulling pranks, or playing intramurals, we had some great times.Thanks to everyone. 


\section{TABLE OF CONTENTS}

Title Page

Page

Abstract

ii

Acknowledgements $\quad$ iii

Table of Contents $\quad$ iv

List of Abbreviations $\quad$ v

List of Tables $\quad$ vii

List of Figures $\quad$ ix

Chapter 1: General Introduction 1

Chapter 2: Regulation of liver glutamate dehydrogenase from a hibernating $\quad 12$ mammal

Chapter 3: Regulation of liver glutamate dehydrogenase from an anoxiatolerant freshwater turtle

Chapter 4: Regulation of foot muscle glutamate dehydrogenase from an estivating land snail

$\begin{array}{ll}\text { Chapter 5: General Discussion } & 102\end{array}$

$\begin{array}{ll}\text { References } & 116\end{array}$

$\begin{array}{ll}\text { Appendix } & 126\end{array}$ 


\section{LIST OF ABBREVIATIONS}

AMP, ADP, ATP - adenosine mono-, di-, or triphosphate

AMPD - AMP deaminase

AMPK - AMP activated protein kinase

$\boldsymbol{\beta}$-GP - $\beta$-glycerol phosphate

CaMK - calmodulin- and $\mathrm{Ca}^{2+}$ - dependent protein kinase

CAMP - 3', 5'-cyclic adenosine monophosphate

cGMP - 3', 5' -cyclic guanosine monophosphate

CM - carboxymethyl

CPSI - carbamoyl phosphate synthase I

DEAE - diethylaminoethyl

$\mathbf{E}_{\mathbf{a}}$ - Activation energy

EDTA - ethylenediamine tetraacetate

EGTA - ethyleneglycol bis tetraacetate

ETC - electron transport chain

FADH $_{2}-$ reduced flavin adenine dinucleotide

GDH - glutamate dehydrogenase

GTP - guanosine triphosphate

HEPES - (4-(2-hydroxyethyl)-1-piperazineethanesulfonic acid )

HPLC - high performance liquid chromatography

$\mathbf{I}_{\mathbf{5 0}}$ - inhibitor concentration reducing enzyme velocity by $50 \%$

kDa - kiloDalton

$\mathbf{K}_{\mathbf{a}}$ - activator concentration producing half-maximal enzyme activation 
$\mathbf{K}_{\mathrm{m}}$ - substrate concentration producing half maximal enzyme activity

MES - 2-(N-morpholino)ethanesulfonic acid

$\mathrm{NAD}^{+}, \mathbf{N A D H}$ - oxidized and reduced nicotinamide adenine dinucleotide

$\mathbf{N A D P}^{+}, \mathbf{N A D P H}$ - oxidized and reduced nicotinamide adenine dinucleotide phosphate

$\mathrm{NaF}$ - sodium fluoride

$\mathrm{Na}_{3} \mathrm{VO}_{4}$ - sodium orthovanadate

PAGE - polyacrylamide gel electrophoresis

PDC - pyruvate dehydrogenase complex

PEP - phosphoenolpyruvate

PEPCK - phosphoenolpyruvate carboxykinase

PKA - cAMP-dependent protein kinase

PKC $-\mathrm{Ca}^{2+}-$ and phospholipid-dependent protein kinase

PK - pyruvate kinase

PKG - protein kinase G

PMA - phorbol myristate acetate

PMSF - phenylmethylsulfonyl fluoride

$\mathrm{pCO}_{2}$ - partial pressure of carbon dioxide

$\mathbf{p O}_{2}$ - partial pressure of oxygen

PP1 - protein phosphatase type-1

PP2A, PP2B, PP2C - protein phosphatase type-2A, -2B and -2C

SDS - sodium dodecyl sulfate

Tris - Tris[hydroxymethyl]aminomethane

$\mathbf{V}_{\max }$ - maximal enzyme velocity 


\section{LIST OF TABLES}

TABLE

PAGE

2.1 Comparison of liver GDH kinetic parameters in the forward (glutamate-utilizing) direction using $\mathrm{NAD}^{+}$as the cofactor at $5^{\circ} \mathrm{C}$ and $23^{\circ} \mathrm{C}$ for euthermic and hibernator enzymes.

2.2 Comparison of liver GDH kinetic parameters in the forward (glutamate-utilizing) direction using $\mathrm{NADP}^{+}$as the cofactor at $5^{\circ} \mathrm{C}$ and $23^{\circ} \mathrm{C}$ for both euthermic and hibernator enzymes.

2.3 Kinetic parameters of liver GDH from euthermic and hibernating ground squirrels in the reverse (glutamate-synthesizing) direction using NADH as the cofactor with assay at $23^{\circ} \mathrm{C}$.

2.4 The enzyme efficiency, represented as $V_{\max } / K_{m}$, for both euthermic and hibernator GDH derived from $S$. richardsonii crude liver extracts.

3.1 Purification of GDH from the liver of control T.s. elegans

3.2 Comparison of the kinetic parameters of purified liver GDH from control and $20 \mathrm{~h}$ anoxic turtles. GDH was assayed in the glutamateutilizing (forward) direction using $\mathrm{NAD}^{+}$as the cofactor.

3.3 Comparison of the kinetic parameters for purified liver GDH from control and $20 \mathrm{~h}$ anoxic turtles. GDH was assayed in the glutamateproducing (reverse) direction using NADH as the cofactor.

3.4 The $\mathrm{V}_{\max }$ for the forward and reverse reactions, and the resulting $\mathrm{V}_{\max }$ ratio (forward/reverse reaction) for purified control and $20 \mathrm{~h}$ anoxic GDH from $T$. s. elegans liver extracts. The velocities were determined at specific $\mathrm{pH}$ values characteristic of normoxic $(\mathrm{pH}$ 7.4) and anoxic conditions ( $\mathrm{pH}$ 6.6) in vivo.

4.1 Comparison of foot muscle GDH kinetic parameters from control and 10 day estivated $O$. lactea assayed in the glutamate-utilizing (forward) direction using $\mathrm{NAD}^{+}$as the cofactor.

4.2 Comparison of foot muscle GDH kinetic parameters from control and 10 day estivated $O$. lactea assayed in the glutamatesynthesizing (reverse) direction using NADH as the cofactor. 
4.3 The ratios of maximal activity in the glutamate-oxidizing (forward) reaction to the maximal activity in the glutamate-synthesizing (reverse) reaction for GDH from the foot muscle of active and $10 \mathrm{~d}$ estivated $O$. lactea.

4.4 The effect of various metabolites on foot muscle GDH activity from 89 control and 10 day estivated $O$. lactea. GDH was assayed in the glutamate-synthesizing (reverse) direction using NADH as the cofactor. 


\section{LIST OF FIGURES}

FIGURE

PAGE

1.1 The tricarboxylic acid cycle showing the input of glutamate and the reactions that produce $\mathrm{NADH}, \mathrm{FADH}, \mathrm{GTP}$, and $\mathrm{CO}_{2}$.

1.2 The urea cycle showing the amino group being removed from glutamate via the glutamate dehydrogenase reaction in the mitochondrial matrix.

2.1 Arrhenius plots for liver GDH (using $\mathrm{NADP}^{+}$as the cofactor) from euthermic and hibernating $S$. richardsonii.

2.2 Effects of in vitro incubations to stimulate the activities of endogenous protein phosphatases on $\mathrm{K}_{\mathrm{m}}$ glutamate of $S$. richardsonii liver GDH.

2.3 Effects of in vitro incubations to stimulate the activities of endogenous protein kinases on $\mathrm{K}_{\mathrm{m}}$ glutamate for liver $\mathrm{GDH}$.

2.4 $\mathrm{CM}^{-}$cellulose elution profiles for GDH activity from liver of euthermic and hibernating ground squirrels.

2.5 The relative band intensity of purified liver GDH from euthermic and hibernating $S$. richardsonii as assessed on a SDS-PAGE gel stained with ProQ Diamond stain.

3.1 SDS-PAGE with Coomassie blue staining of samples taken at every step in the purification of GDH from the liver of control $T$. s. elegans.

3.2 The relative band intensity of purified liver GDH from control and $20 \mathrm{~h}$ anoxic $T$. s. elegans as assessed on a SDS-PAGE gel stained with ProQ Diamond phosphoprotein stain.

3.3 Effects of in vitro incubations to stimulate (A) the activities of exogenous alkaline and acid phosphatases, and (B) exogenous PKA on $\mathrm{K}_{\mathrm{m}} \alpha$-ketoglutarate for liver GDH from control (only the phosphatases) and $20 \mathrm{~h}$ anoxic (only PKA) T. s. elegans.

3.4 Arrhenius plots for liver GDH from control and $20 \mathrm{~h}$ anoxic $T$. $s$. elegans. 
4.1 The relative band intensity of purified foot muscle GDH from active and $10 \mathrm{~d}$ estivated $O$. lactea, as assessed on a SDS-PAGE gel stained with ProQ Diamond phosphoprotein stain.

4.2 Representative $\mathrm{DEAE}^{+}$Sephadex elution profiles for GDH activity from the foot muscle of control and $10 \mathrm{~d}$ estivated $O$. lactea. 
Chapter 1

General Introduction 


\section{Metabolic Rate Depression}

There are typically three general strategies for animals to survive harsh environmental conditions: (1) migrating away from the particularly unforgiving environment (i.e. Canadian geese); (2) changing the environment to make it more habitable (i.e. humans); and (3) developing adaptations that allow survival in these harsh environments. Those animals that use the latter strategy typically have to cope with a dramatic decrease in resource availability (i.e. food, water and sometimes oxygen) or a major change in an environmental parameter (e.g. temperature, salinity). To survive under these conditions, animals often go into a hypometabolic or dormant state, during which the organism must be able to sustain general metabolic functioning over the long term through the use of endogenous fuel reserves compiled during more favourable conditions. To this end, these organisms have the ability to lower their metabolic rate below the typical resting rate in order to extend their survival period. This is essential since normal metabolic rates would likely burn through fuel reserves in a very short period of time, making long term survival impossible. The ability to depress metabolic rate during periods of environmental stress is found throughout the animal kingdom and includes both vertebrates and invertebrates. For instance, some small mammals and reptiles drop their metabolic rate to $<20 \%$ of the resting rate to survive cold winter conditions (Storey and Storey, 1990). Similarly, some molluscs are capable of decreasing their metabolic rate by as much as $90 \%$ in order to survive in unfavourable environments for prolonged periods of time (Storey and Storey, 1990).

Metabolic rate depression requires dramatic behavioural, physiological and biochemical changes. Typical behavioural and physiological responses include the 
cessation of movement, feeding, digestion, absorption, as well as substantial decreases in breathing, heart rate, and kidney filtration rates (Storey, 2004a). Furthermore, the animals that cope with these harsh environments typically attempt to protect themselves from direct contact with the environment by seeking shelter (i.e. withdrawing into a shell, hiding in a burrow, etc.). It is also interesting to note that metabolic rate is suppressed by certain factors that tend to accompany dormant states, such as decrease in $\mathrm{pO}_{2}$, increase in $\mathrm{pCO}_{2}$, decrease in $\mathrm{pH}$, and sometimes cold temperatures (Storey, 2004a).

Although a strong reduction in many physiological processes contributes significantly to a depressed metabolic rate, it is believed that at least half of an animal's energy savings are due to significant alterations in cellular biochemistry (Storey, 2004a). Essentially the biochemical changes that occur during hypometabolism work toward establishing a new balance between ATP-consuming and ATP-producing processes. In order for this to occur, there must be a reduction in the activity of most cellular processes, however, these reductions are not the same throughout all tissues and all organisms. For instance, protein synthesis, which is a very energy-expensive process, is intrinsically suppressed to varying degrees in ground squirrel organs during hibernation. In organs such as the brain and liver protein synthesis is negligible during hibernation (Whitten et al., 1970; Frerichs et al., 1998); however, brown adipose tissue seems to retain the biosynthetic capacity of an active squirrel throughout hibernation (Storey, 2004b). The magnitude of suppression of particular cellular processes also depends on the animal and the corresponding stress that they encounter. For instance, urea synthesis, which is suppressed by $70 \%$ during anaerobiosis in freshwater turtles (Hochachka et al., 1996), is greatly increased during land snail estivation (Hiong et al., 2005). It is important to note 
that although the majority of metabolic processes are shutdown during hypometabolism, there are selected processes, such as urea synthesis in the land snail, that are essential during this hypometabolic state and are enhanced. Another example is gluconeogenesis, which is turned off in anoxic turtle hepatocytes, but is increased by $60-100 \%$ during ground squirrel hibernation in comparison to gluconeogenesis in active squirrels. Taken together, these examples indicate that metabolic rate depression is not uniform in all organs for all cases of hypometabolism, but is highly dependent on the tissue-specific needs of the organism.

Although the metabolic changes during hypometabolism are drastic, they must be induced and reversed relatively quickly since alterations in environmental conditions can take place in a short time period. For instance, estivating spadefoot toads are immediately alert when dug out of their burrows, and estivating land snails awaken in as little as 5 minutes after being misted with water (Storey, 2002). Thus, it makes sense that transition into a dormant state does not require global changes in gene expression, and typically involves the regulation of key metabolic enzymes that alter the activities of metabolic pathways. One of the major regulatory mechanisms that could be responsible for such changes is reversible protein phosphorylation.

\section{Reversible Protein Phosphorylation}

Protein phosphorylation is mediated by protein kinases which transfer the $\gamma$ phosphate of ATP to the target protein. The phosphate group is covalently linked to the target protein via an amino acid (serine, threonine, or tyrosine) hydroxyl group, and this modification is stable unless cleaved by a protein phosphatase. There are several ways in 
which phosphorylation can affect an enzyme or functional protein, including (1) an increase/decrease in activity, (2) alteration in kinetic or regulatory properties, and (3) changes in protein binding to other macromolecules (Storey, 2004c). These changes come about because the addition of a highly negative phosphate group to a protein changes protein conformation and charge, which subsequently changes its properties.

The mechanism that mediates the transition of an animal to and from a hypometabolic state is required to be (a) rapid, and (b) involve little de novo protein synthesis and metabolic reorganization (Storey, 2002). Reversible phosphorylation fits these criteria, and is a very powerful regulatory mechanism that has been shown to have a prominent role during hypometabolism. Phosphorylation patterns and levels of second messenger compounds change within minutes or hours of the animal's exposure to harsh environmental conditions. Phosphorylation is known to play a key role in transcriptional and translational controls, as well as ion-channel arrest, fuel metabolism and signal transduction in a wide variety of species that suppress their metabolic rate (Storey and Storey, 2004). For instance, protein phosphorylation controls the key enzymes in glycolysis in anoxia-tolerant marine molluscs, estivating land snails, anoxia-tolerant vertebrates, and hibernating ground squirrels (Storey, 2004a; Storey, 2004b).

Furthermore, hormone-sensitive lipase, a key enzyme in fat metabolism, is regulated by reversible phosphorylation during hibernation (Frank et al., 1998). Although the regulation of carbohydrate and fatty acid metabolism has been investigated in some hypometabolic states, the regulation of amino acid metabolism has remained relatively unexplored.

\section{Glutamate Dehydrogenase}


Glutamate dehydrogenase (GDH; E.C. 1.4.1.3) is a key enzyme that links amino acid and carbohydrate metabolism within eukaryotic cells. This enzyme is present in the mitochondrial matrix and catalyzes the reversible $\mathrm{NAD}(\mathrm{P})^{+}$-linked oxidative deamination of L-glutamate to $\alpha$-ketoglutarate and ammonium ion (note: this reaction will be regarded arbitrarily as the forward reaction of GDH). GDH is a hexamer whose molecular weight varies between 250-400 kDa depending on the species (Eisenberg and Reisler, 1970). The subunits are identical and each subunit has two domains separated by an active site cleft (Nakasako, 2001). However, it is important to note that the monomers by themselves have no catalytic activity (Schmidt and Schmidt, 1988). In addition to the active site clefts, each domain has allosteric binding sites for ADP/GDP, and GTP/ATP. Typically, the high-energy molecules (i.e. GTP and ATP) act as inhibitors, whereas ADP and GDP act as activators of GDH activity. The affinity of GDH for these effector molecules is likely also dependent on factors such as $\mathrm{pH}$, coenzyme type and the substrate present (Schmidt and Schmidt, 1988).

GDH operating in the amino acid catabolizing direction produces $\alpha$-ketoglutarate, which gets taken up into the Krebs cycle and goes on to produce NADH and $\mathrm{FADH}_{2}$ which contributes to ATP production by oxidative phosphorylation. Furthermore, the $\alpha$ ketoglutarate input into the cycle can be drained off as oxaloacetate and used as a substrate for gluconeogenesis. Gluconeogenesis from amino acids involves the conversion of oxaloacetate to phosphoenolpyruvate (PEP) via phosphoenolpyruvate carboxykinase (PEPCK), followed by PEP export into the cytoplasm and the eventual production of glucose by the gluconeogenic enzymes (essentially a reversal of glycolysis) (Garrett and Grisham, 2005a). Gluconeogenesis occurs most prominently in the liver 
and, to some degree, the kidney. Figure 1.1 outlines the components of the Krebs cycle and the point of entry of glutamate into the cycle.

The ammonia produced via the forward GDH reaction is toxic, and can damage tissues if it is allowed to react with body water. To prevent tissue damage, animals either directly release ammonia into the surrounding environment, or convert it into the less toxic nitrogenous wastes, urea or uric acid. Direct release of ammonia into the environment is usually only seen in aquatic animals, whereas uric acid is produced by many terrestrial reptiles, birds, and land snails (Campbell and Reece, 2002). Both aquatic and terrestrial species may produce and excrete urea. Urea is synthesized by the urea cycle, which mainly occurs in the liver. The urea cycle typically begins in the mitochondria of hepatocytes and starts with the formation of carbamoyl phosphate from the addition of ammonia to bicarbonate, with the use of ATP. This molecule is then combined with ornithine and, following cleavage of the phosphate, citrulline is formed. Citrulline is subsequently transported out of the mitochondria and into the cytoplasm. In the cytosol, citrulline is converted back to ornithine, and in the process releases urea (Fig. 1.2; Storey, 2004d). Urea is then transported to the kidneys where it is excreted through the urine.

GDH is present in most organs and is therefore considered a ubiquitous enzyme. That being said, GDH is distributed amongst the organs unevenly, with some organs expressing much higher levels than others (i.e. liver has much higher GDH levels in comparison to the heart; Schmidt and Schmidt, 1988). 


\section{Objectives}

Some animals exposed to stressful environmental conditions are capable of suppressing their metabolic rate in order to survive. This typically requires coordinated biochemical changes that are often mediated by reversible protein phosphorylation. Examples of enzymes that are regulated by this mechanism have been identified in many species capable of entering into hypometabolism, including the hibernating Richardson's ground squirrel (Spermophilus richardsonii), the anoxia-tolerant freshwater turtle (Trachemys scripta elegans), and the estivating land snail (Otala lactea). Each of these animals are exposed to different environmental stresses (e.g. cold temperatures, anoxia, and arid conditions), however, each animal survives by depressing their metabolic rate. One of the most important aspects of hypometabolism is the need to regulate fuel metabolism and sustain long term viability by slowly catabolising endogenous fuel reserves during their dormant state. Lipids and carbohydrates are typically the first fuels that are catabolised to fuel hypometabolism whereas proteins are preserved for as long as possible. Ultimately, however, as other fuels run out or as specific conditions demand (e.g. a critical level of body water loss can trigger urea synthesis), proteins become an important fuel source. The carbon skeletons from a variety of amino acids are fed into the Krebs cycle via GDH whereas associated $\mathrm{NH}_{4}{ }^{+}$that is released is the primary nitrogen source for urea biosynthesis. The research described in this thesis is aimed at determining if GDH, a key enzyme in the catabolism of amino acids as a fuel source, is regulated by reversible phosphorylation and differentially controlled in normal versus hypometabolic states. To explore this question, three different hypometabolic states are examined - 
hibernation, anaerobiosis, and estivation - using three different model organisms ground squirrels, turtles, and land snails, respectively.

\section{Hypotheses and Predictions}

I hypothesized that regulation of GDH by reversible phosphorylation is important for survival of animals in hypometabolic states. The following predictions were tested. 1. The activity of liver GDH in the glutamate-oxidizing direction is enhanced during hibernation in the ground squirrel, Spermophilus richardsonii, to permit the aerobic oxidation of protein as a fuel source and the mechanism of GDH regulation is reversible phosphorylation.

2. The activity of liver GDH in the glutamate-oxidizing direction is suppressed during anoxia in the freshwater turtle, Trachemys scripta elegans, as part of the overall suppression of oxygen-based fuel catabolism and the mechanism of regulation is reversible phosphorylation.

3. The activity of muscle GDH in the glutamate-oxidizing direction is enhanced during estivation in the land snail, Otala lactea, to support the synthesis of urea as an osmolyte which helps to retain body water under dessicating conditions and the mechanism of regulation is reversible phosphorylation. 
Figure 1.1. The tricarboxylic acid cycle showing the input of glutamate and the reactions that produce $\mathrm{NADH}, \mathrm{FADH}{ }_{2}, \mathrm{GTP}$, and $\mathrm{CO}_{2}$. The enzymes within the cycle are (1) citrate synthase, (2) aconitase, (3) isocitrate dehydrogenase, (4) $\alpha$-ketoglutarate dehydrogenase, (5) succinyl thiokinase, (6) succinate dehydrogenase, (7) fumarase, and (8) malate dehydrogenase. The exit of oxaloacetate for gluconeogenesis is also shown (modified from Storey, 2004e). 


\section{Figure 1.1}

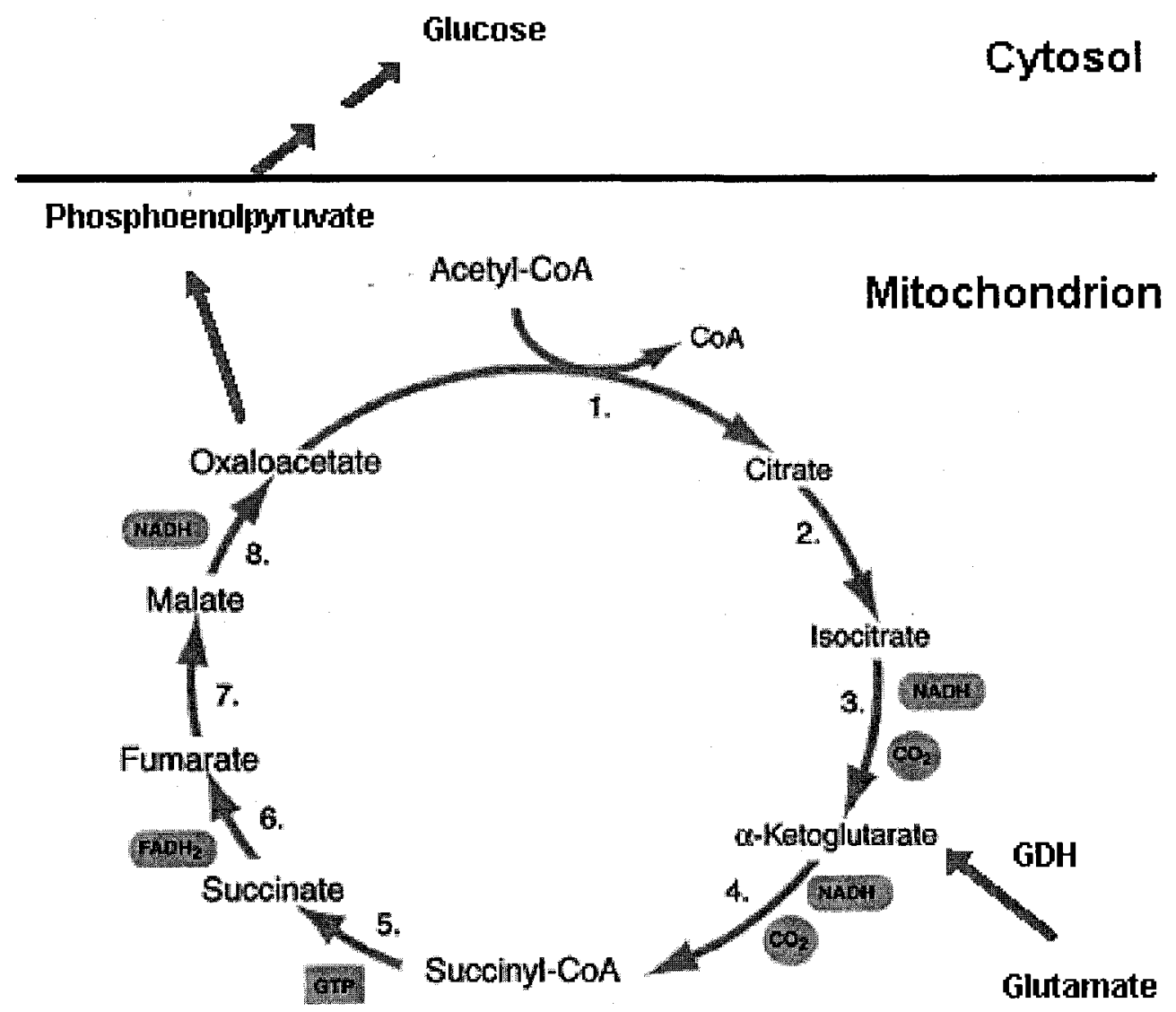


Figure 1.2. The urea cycle showing the amino group being removed from glutamate via the glutamate dehydrogenase reaction in the mitochondrial matrix. (1) Carbamoyl phosphate synthetase catalyzes the first reaction of the urea cycle, and condenses $\mathrm{NH}_{4}{ }^{+}$ and $\mathrm{HCO}_{3}{ }^{-}$to form carbamoyl phosphate (CP). (2) This molecule then condenses with ornithine (ORN) to form citrulline (CIT), which is catalyzed by ornithine transcarbamoylase. (3) Citrulline is then exported to the cytosol where arginosuccinate synthetase combines aspartate (ASP) with CIT to form arginosuccinate (ASA). (4) This compound is then hydrolyzed by arginosuccinate lyase into fumarate and arginine. (5) Lastly, arginine is cleaved by arginase into urea and ORN. The urea produced is then exported from the liver to the kidneys where it is eventually excreted (modified from Storey, 2004d). 
Figure 1.2

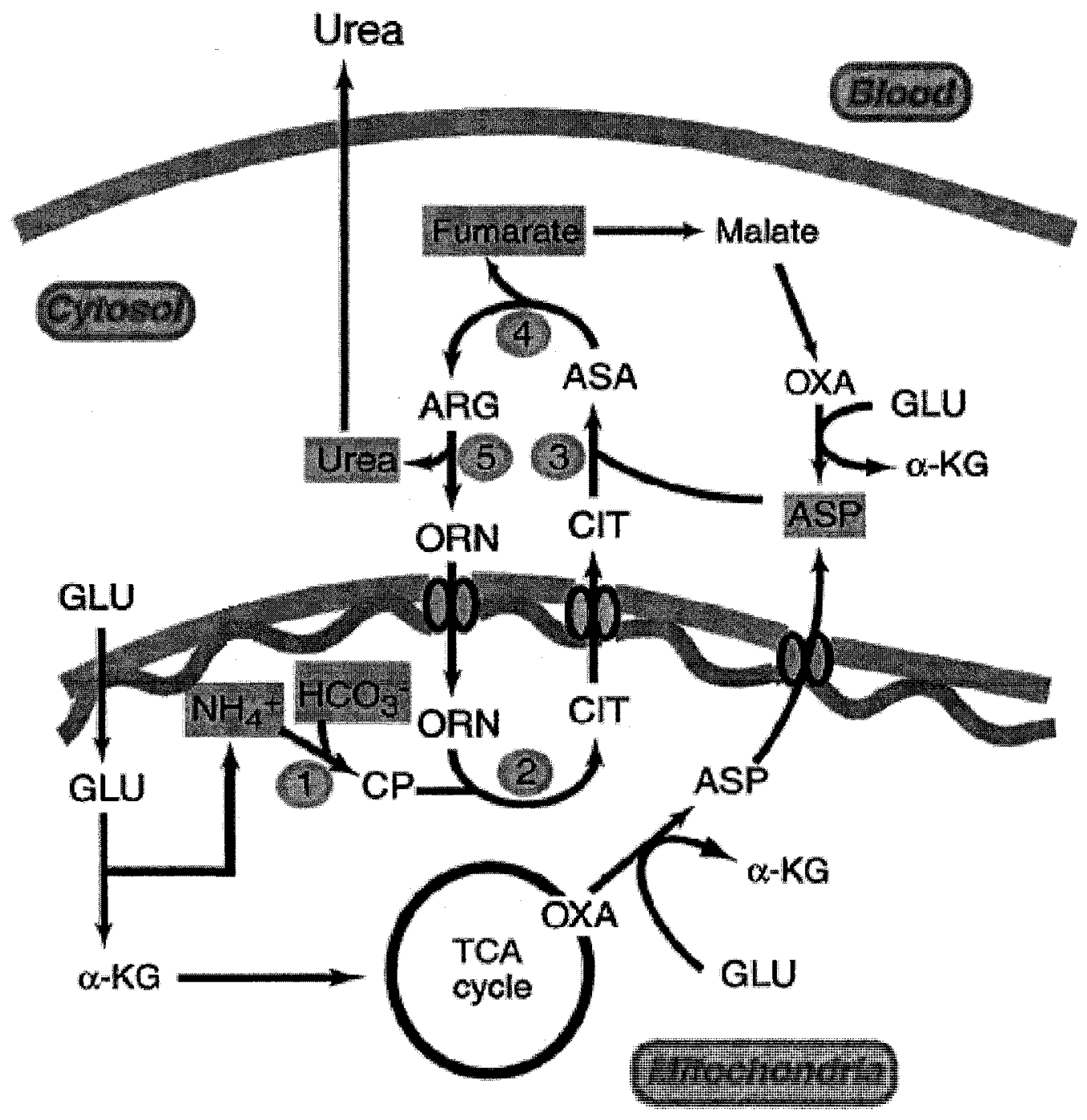


Chapter 2

Regulation of liver glutamate dehydrogenase from a hibernating mammal 


\section{Introduction}

Hibernation is a strategy employed by a variety of mammalian species to survive harsh winter conditions, such as cold temperatures and decreased food availability. This hypometabolic state is characterized by major behavioural, physiological and biochemical changes. For instance, during torpor, body temperature drops drastically to approximately ambient temperature (Carey et al., 2003), heart rate decreases from the normal 200-300 beats/min to only 3-5 beats/min (Zatzman, 1984), and respiration is reduced from 100-200 to 4-6 breaths/min (McArthur and Milsom, 1991). In addition, there are major biochemical alterations that allow these mammals to survive. This includes a strong reduction of metabolic rate, typically to just $1-5 \%$ of the euthermic value (Geiser, 2004), a reprioritization of cellular energy use, altered expression of many proteins, and differential regulation of many enzymes to aid long term survival during torpor (Storey, 2003).

Richardson's ground squirrels (Spermophilus richardsonii) are well-studied hibernators and are the model species examined in this chapter. The species occurs across the prairies of the central and northern United States and southern Canada, and typically hibernates from September to January, February, or March depending on their location. To prepare for hibernation, these squirrels increase body fat stores by eating excessively (hyperphagia) during the late summer and early autumn. As the weather gets colder, the squirrels move into underground burrows that are sufficiently below the surface so that the ambient temperature typically remains slightly above $0^{\circ} \mathrm{C}$ even when outside air temperatures are far below $0^{\circ} \mathrm{C}$ in midwinter (Geiser, 1988). Once in the hibernaculum, ground squirrels soon begin to undergo short periods of shallow torpor (body temperature 
dropping just a few degrees) that progressively become longer and deeper until in midwinter torpor bouts last for about two weeks and body temperature drops to near ambient. These prolonged torpor bouts are interspersed with short periods (several hours) of arousal, where the animal re-establishes normal physiological functioning and re-warms to typical endotherm body temperature $\left(\sim 36^{\circ} \mathrm{C}\right.$; Carey et al., 2003). Rewarming depends primarily on nonshivering thermogenesis in brown adipose tissue with additional contributions from shivering thermogenesis in skeletal muscle once the body is partially rewarmed (above about $15^{\circ} \mathrm{C}$ ).

Particularly important to this study are the metabolic changes that occur during mammalian hibernation. Suppression of carbohydrate oxidation and the activation of lipolysis, amino acid oxidation, and gluconeogenesis are all part of the metabolic reorganization that occurs during hibernation. For instance, the regulatory glycolytic enzymes (glycogen phosphorylase, phosphofructokinase-1, and pyruvate kinase) are all suppressed during hibernation (Storey, 1987a). Furthermore, liver gluconeogenic capacity increases in ground squirrels by $60-100 \%$ during torpor (Storey, 2004f). Since carbohydrate oxidation is suppressed, many tissues within a hibernating animal switch to non-carbohydrate fuels to maintain critical cellular processes (Yacoe, 1983; Carey et al., 2003). Energy is derived mainly from an increase in fat catabolism and evidence for this is derived from a number of studies that have shown enhanced gene and/or protein expression of various lipases, other enzymes of fatty acid catabolism and fatty acid transport proteins during hibernation (Wilson et al., 1992; Andrews et al., 1998; Bauer et al., 2001; Hittel and Storey, 2001; Buck et al., 2002).

Lesser known is the role during hibernation of enzymes that control the 
breakdown of amino acids to produce carbon skeletons that can be used for either gluconeogenesis or as oxidative substrates. Principle among these enzymes is glutamate dehydrogenase $(\mathrm{GDH})$, which acts as the gateway for the carbon skeletons of several amino acids to enter the Krebs cycle in the form of $\alpha$-ketoglutarate where they can contribute to energy production or go on to form phosphoenolpyruvate and eventually glucose via gluconeogenesis (Stryer, 1995).

This chapter analyzes liver GDH from Richardson's ground squirrels, comparing and contrasting the kinetic properties of the enzyme from euthermic and hibernating animals, as well as responses of each enzyme form to cellular metabolites, reversible phosphorylation, temperature, and stability against a denaturant.

\section{Materials and Methods}

\section{Animals and Chemicals}

Both male and female Richardson's ground squirrels, S. richardsonii, were captured during the summer in Calgary, Alberta and housed in an animal care facility at the University of Calgary. The animals were kept in separate cages and exposed to a room temperature of $22^{\circ} \mathrm{C}$ and a fall photoperiod ( $10 \mathrm{~h}$ light: $14 \mathrm{~h}$ dark). Following an 8week feeding period to optimize their body lipid reserves, some of the ground squirrels were induced to hibernate by placing them into a $4^{\circ} \mathrm{C}$ cold room in constant darkness. Food was withheld in the cold room but water was available. The squirrels were monitored daily, and hibernators were sampled after 2 days of constant torpor. Both euthermic (maintained at $22^{\circ} \mathrm{C}$ ) and hibernating squirrels were terminated by decapitation. Tissues were immediately excised, frozen in liquid nitrogen, and then 
shipped to Carleton University on dry ice where they were stored at $-80^{\circ} \mathrm{C}$.

All biochemicals were from Sigma Chemical company with a few exceptions. Urea and glycerol were obtained from Fisher Biotech company; $\mathrm{NH}_{4} \mathrm{Cl}$ was from Mallinckrodt $\mathrm{Co}$; $\mathrm{NAD}^{+}$was from Boehringer Mannheim; $\mathrm{CaCl}_{2}$ was purchased from J.T. Baker Chemical company; okadaic acid was from CalBiochem; NaF was from Fisher Scientific, and $\beta$-glycerol phosphate was purchased from BIOSHOP.

\section{Sample Preparation}

Samples of frozen liver were homogenized 1:5 w:v in cold homogenization buffer containing $50 \mathrm{mM}$ Tris- $\mathrm{HCl}, 10 \mathrm{mM}$ 2-mercaptoethanol, $2.5 \mathrm{mM}$ EDTA, $2.5 \mathrm{mM}$ EGTA, $10 \%$ v:v glycerol, $\mathrm{pH}$ 8.0. Homogenization conditions were optimized with respect to the effects of sodium fluoride (NaF) and $\beta$-glycerol phosphate ( $\beta$-GP) on GDH activity and, subsequently, $25 \mathrm{mM} \beta$-GP was included in the homogenization buffer. A few crystals of phenylmethylsulfonyl fluoride (PMSF) were added at the time of homogenization. Homogenates were centrifuged for 30 minutes at $13,500 \mathrm{xg}$ and the supernatant was decanted and held on ice until use.

\section{GDH Assay and Determination of Kinetic Parameters}

GDH activity was assayed at $340 \mathrm{~nm}$ using an MR5000 microplate reader and Biolinx 2.0 software (kinetic reading mode with a reading interval of 12 seconds). The optimum assay conditions for the forward (glutamate-utilizing) reaction for liver GDH from both euthermic and hibernating squirrels were $1.5 \mathrm{mM} \mathrm{NAD}(\mathrm{P})^{+}, 50 \mathrm{mM} \mathrm{L}-$ glutamate and $50 \mathrm{mM}$ Tris-HCl buffer, $\mathrm{pH} 8.0$ in a total volume of $200 \mu \mathrm{L}$ with $5 \mu 1$ of 
liver extract used per assay. For the reverse (glutamate-synthesizing) reaction optimal conditions were $1 \mathrm{mM} \alpha$-ketoglutarate, $100 \mathrm{mM} \mathrm{NH}_{4} \mathrm{Cl}, 0.15 \mathrm{mM} \mathrm{NADH}, 0.5 \mathrm{mM}$ ADP, and $50 \mathrm{mM}$ HEPES buffer, $\mathrm{pH} 7.2$ with $5 \mu \mathrm{L}$ of $5 \mathrm{X}$ diluted liver extract used per assay. Activity was measured in $\mathrm{mU} / \mathrm{mg}$ soluble protein.

$K_{m}$ values for substrates were determined at optimal cosubstrate concentrations. Analysis of the effects of nucleotide activators and inhibitors (GTP, ATP, ADP) was carried out at suboptimal substrate concentrations $(12.5 \mathrm{mM} \mathrm{L}$-glutamate, and $0.5 \mathrm{mM}$ $\mathrm{NAD}(\mathrm{P})^{+}$for the forward reaction and $0.2 \mathrm{mM} \alpha$-ketoglutarate, $50 \mathrm{mM} \mathrm{NH}_{4} \mathrm{Cl}$, and 0.1 mM NADH). Kinetic parameters (e.g. $V_{\max }, K_{m}, K_{a}, I_{50}$ ) were calculated using the Kinetics v.3.5.1 program (Brooks, 1994).

Protein concentration in extracts was determined by the Coomassie blue dyebinding method using the BioRad prepared reagent and bovine serum albumin as the standard.

\section{In vitro Incubations to Stimulate Endogenous Protein Kinases and Phosphatases}

Stimulation of the activities of endogenous protein kinases and phosphatases was used to assess their effects on the activity of GDH. Tissue extracts were prepared in the same manner as described above and then aliquots of the extract were incubated under conditions that would promote the action of endogenous protein kinases or phosphatases. Samples of supernatant were mixed 1:2 v:v with the appropriate solutions. All incubations contained a basic incubation buffer $(50 \mathrm{mM}$ Tris- $\mathrm{HCl}, 10 \%$ v:v glycerol, 10 $\mathrm{mM} \beta$-mercaptoethanol, $\mathrm{pH} 8.0$ ), with additions as follows.

(A) Control Incubations (also denoted as STOP): incubation buffer plus $2.5 \mathrm{mM}$ 
EDTA, $2.5 \mathrm{mM}$ EGTA and 25mM $\beta$-GP.

(B) Stimulation of endogenous protein kinase activities: incubation buffer plus $5 \mathrm{mM}$ $\mathrm{Mg} \cdot \mathrm{ATP}, 30 \mathrm{mM} \beta$-GP and either (1) $1 \mathrm{mM}$ cAMP to stimulate protein kinase A (PKA); (2) $1 \mathrm{mM}$ cGMP to stimulate protein kinase $\mathrm{G}$ (PKG); (3) $1.3 \mathrm{mM} \mathrm{CaCl}_{2}$ $+7 \mu \mathrm{g} / \mathrm{mL}$ phorbol myristate acetate (PMA) to stimulate protein kinase C (PKC);

(4) $1 \mathrm{mM}$ AMP to stimulate AMP-dependent protein kinase (AMPK); or (5) $1 \mathrm{U}$ of calmodulin activity per incubation tube $+1.3 \mathrm{mM} \mathrm{CaCl}_{2}$ to stimulate calciumcalmodulin kinase activity (CaMK).

(C) Stimulation of endogenous protein phosphatase (PPase) activities: incubation buffer plus (1) for protein phosphatase type 1 (PP1): $2.5 \mathrm{nM}$ okadaic acid $+2 \mathrm{mM}$ EDTA $+2 \mathrm{mM}$ EGTA $+5 \mathrm{mM}$ sodium orthovanadate $\left(\mathrm{Na}_{3} \mathrm{VO}_{4}\right) ;(2)$ for stimulation of all serine/threonine phosphatases (Tot SerThre): $5 \mathrm{mM} \mathrm{MgCl}+5$ $\mathrm{mM} \mathrm{CaCl}_{2}+5 \mathrm{mM} \mathrm{Na}_{3} \mathrm{VO}_{4}+1 \mu \mathrm{M}$ okadaic acid; (3) for protein phosphatase type 2B (PP2B): $1 \mu \mathrm{M}$ okadaic acid $+5 \mathrm{mM} \mathrm{CaCl}_{2}+2 \mathrm{mM}$ EDTA $+5 \mathrm{mM}$ $\mathrm{Na}_{3} \mathrm{VO}_{4}$; and (4) for protein phosphatase type 2C (PP2C): $1 \mu \mathrm{M}$ okadaic acid +5 $\mathrm{mM} \mathrm{MgCl} 2+2 \mathrm{mM}$ EGTA $+5 \mathrm{mM} \mathrm{Na}_{3} \mathrm{VO}_{4}$.

Ground squirrel liver extracts were incubated for $4 \mathrm{~h}$ at $\sim 4^{\circ} \mathrm{C}$. Following incubation, $\mathrm{K}_{\mathrm{m}}$ glutamate was determined.

\section{ProQ Diamond Phosphoprotein Staining}

GDH from liver of euthermic and hibernating ground squirrels was partially purified by affinity chromatography. Homogenates were made as described in the Sample Preparation section and $\sim 2 \mathrm{~mL}$ of the extract was applied to a GTP-agarose 
column $(2.5 \times 1 \mathrm{~cm})$ equilibrated in homogenization buffer. Once the extract entered the column, the column was washed with $\sim 10 \mathrm{~mL}$ of homogenization buffer to remove any unbound material prior to beginning a linear salt gradient. GDH was eluted off the column by a $0-1 \mathrm{M} \mathrm{KCl}$ gradient in homogenization buffer and $\sim 750 \mu \mathrm{L}$ fractions were assayed under optimal conditions for the forward reaction. The five fractions with the most activity were pooled and soluble protein content was quantified using the Coomassie blue dye-binding method. Aliquots of the pooled fractions were then mixed 1:1 with SDS loading buffer (100 mM Tris buffer, $\mathrm{pH} 6.8,4 \% \mathrm{w} / \mathrm{v}$ SDS, $20 \% \mathrm{v} / \mathrm{v}$ glycerol, $0.2 \% \mathrm{w} / \mathrm{v}$ bromophenol blue, $10 \% \mathrm{v} / \mathrm{v} 2$-mercaptoethanol) and then boiled for 5 minutes, cooled on ice and frozen at $-20^{\circ} \mathrm{C}$ until use.

Aliquots containing $0.5 \mu \mathrm{g}$ of protein were added to the wells of a $10 \%$ SDSPAGE gel. The gel was run at $180 \mathrm{~V}$ for 45 minutes (running buffer contained: $0.5 \mathrm{M}$ Tris-base, $5 \mathrm{M}$ glycine, $0.5 \% \mathrm{w} / \mathrm{v}$ SDS), after which the gel was removed, washed twice in fixing solution (50\% v:v methanol, $10 \% \mathrm{v}: \mathrm{v}$ acetic acid) and then left overnight in fixing solution at $\sim 4^{\circ} \mathrm{C}$. The following day, the gel was washed three times with $d_{d H_{2}} \mathrm{O}$ for 10 minutes each and then stained with ProQ Diamond Phosphoprotein stain (Invitrogen, Eugene, OR) for 90 minutes. During staining the container holding the gel was covered with tin foil to prevent light from interacting with the light-sensitive stain. The gel remained covered for the remaining steps.

Following staining, the gel was destained by washing twice with ProQ Diamond destaining solution (20\% v:v acetonitrile, $50 \mathrm{mM}$ sodium acetate, $\mathrm{pH}$ 4) for 30 minutes each time. The gel was then washed three times with $\mathrm{ddH}_{2} \mathrm{O}$ for 5 minutes each. The ChemiGenius Bioimaging System (Syngene, Frederick, MD) was used to visualize the 
fluorescence intensity of the bands on the gel and the associated GeneTools software was used for quantification.

\section{Ion exchange chromatography of $G D H$}

Liver extracts were prepared essentially as described in the Sample Preparation section with a modified homogenization buffer: $25 \mathrm{mM}$ MES [2-(N-morpholino) ethanesulfonic acid], $5 \mathrm{mM}$ 2-mercaptoethanol, 1.25 mM EDTA, $1.25 \mathrm{mM}$ EGTA, 5\% $\mathrm{v}: \mathrm{v}$ glycerol, $12.5 \mathrm{mM} \beta-\mathrm{GP}, \mathrm{pH} 6$ (this buffer is referred to as column buffer). A $200 \mu \mathrm{L}$ aliquot of supernatant was applied to a $3 \times 1.8 \mathrm{~cm}(\mathrm{~h} \mathrm{x} \mathrm{d})$ column of $\mathrm{CM}^{-}$cellulose equilibrated in the same buffer. The column was washed with $\sim 10 \mathrm{~mL}$ of column buffer to remove any unbound material and then GDH was eluted with a $0-2 \mathrm{M}$ gradient of $\mathrm{KCl}$ in the buffer. Fractions of $350 \mu \mathrm{L}$ were collected and assayed.

\section{Physical stability of GDH}

To assess possible structural differences between GDH derived from liver of euthermic versus hibernating ground squirrels, enzyme susceptibility to urea denaturation was determined. Tissue extracts were incubated with various concentrations of urea for $24 \mathrm{~h}$ prior to assaying under conditions for maximal GDH activity. $\mathrm{C}_{50}$ values (the concentration of urea that reduced activity by $50 \%$ ) were determined using the Kinetics program.

\section{Temperature Effects on GDH}

To assess the effects of temperature on several GDH kinetic parameters, assays 
were performed at low $\left(5 \pm 1^{\circ} \mathrm{C}\right)$ and high $\left(23 \pm 1^{\circ} \mathrm{C}\right)$ assay temperatures. For $5^{\circ} \mathrm{C}$ assays, the microplate reader and all solutions were held in a temperature-controlled incubator set to $5^{\circ} \mathrm{C}$. After microplates were prepared, they were cooled in the incubator for several minutes before the addition of enzyme. At the end of each assay, the temperature of a random microplate well was determined by placing a telethermometer probe into the well.

GDH response to temperature was also analyzed using Arrhenius plots to determine activation energy $\left(\mathrm{E}_{\mathrm{a}}\right)$. GDH $\mathrm{V}_{\max }$ was measured at $5^{\circ} \mathrm{C}, 9^{\circ} \mathrm{C}, 12^{\circ} \mathrm{C}, 15^{\circ} \mathrm{C}$, $23^{\circ} \mathrm{C}$, and $30^{\circ} \mathrm{C}$, after adjusting incubator temperature to different values and again confirming assay temperature using a telethermometer.

\section{Results}

\section{Initial Kinetic Studies}

Preliminary studies showed that GDH activity in extracts of ground squirrel liver was stable over an extended time. There was no significant loss of activity over $24 \mathrm{~h}$ at $4^{\circ} \mathrm{C}$, but after $48 \mathrm{~h}, \sim 50 \%$ of activity was lost. The $\mathrm{pH}$ optimum of the forward reaction using either $\mathrm{NAD}^{+}$or $\mathrm{NADP}^{+}$was determined to be 8.0 , however, $~ 95 \%$ of activity remained over the range from $\mathrm{pH}$ 7.5-9.0. The $\mathrm{pH}$ optimum for the reverse reaction was $\mathrm{pH} 7.2$, with $\sim 90 \%$ of the maximum GDH activity maintained from $\mathrm{pH}$ 7.0-7.5.

GDH Substrate Kinetics and Temperature Effects with $\mathrm{NAD}^{+}$as the Cofactor

Ground squirrel liver GDH kinetics changed significantly between euthermic and hibernating states in a manner that also depended on the nicotinamide cofactor that was 
used and the assay temperature. Table 2.1 shows that at $23^{\circ} \mathrm{C}$, with $\mathrm{NAD}^{+}$as the cofactor, the $\mathrm{K}_{\mathrm{m}}$ glutamate decreased significantly $(\mathrm{P}<0.05)$ by $24 \%$ for the enzyme from hibernating animals as compared with the euthermic situation. $\mathrm{K}_{\mathrm{m}} \mathrm{NAD}^{+}$did not change between the two physiological states but the maximum activity of GDH was $44 \%$ higher in hibernator liver $(\mathrm{P}<0.05)$ as compared with the euthermic condition.

GDH kinetics at $5^{\circ} \mathrm{C}$ with $\mathrm{NAD}^{+}$as the cofactor showed a similar trend with respect to $\mathrm{K}_{\mathrm{m}}$ glutamate; $\mathrm{K}_{\mathrm{m}}$ decreased by $44 \%(\mathrm{P}<0.05)$ in the hibernating state, as compared with euthermia. In $5^{\circ} \mathrm{C}$ assays, $\mathrm{K}_{\mathrm{m}} \mathrm{NAD}^{+}$was also $44 \%$ lower $(\mathrm{P}<0.05)$ during hibernation (Table 2.1 ) but, unlike the situation at $23^{\circ} \mathrm{C}$, the maximal activity remained the same between euthermic and hibernating states.

It is also interesting to note how the two enzyme forms responded to a drop in assay temperature. Table 2.1 shows that $\mathrm{K}_{\mathrm{m}}$ glutamate and $\mathrm{K}_{\mathrm{m}} \mathrm{NAD}^{+}$of the hibernator form of GDH both decreased significantly when assayed at $5^{\circ} \mathrm{C}$, as compared to $23^{\circ} \mathrm{C}$; $\mathrm{K}_{\mathrm{m}}$ values dropped by 28 and $76 \%$, respectively, for hibernator $\mathrm{GDH}$ at $5^{\circ} \mathrm{C}$. Euthermic GDH also showed a substantial drop (56\%) in $\mathrm{K}_{\mathrm{m}} \mathrm{NAD}^{+}$at the lower temperature.

GDH Substrate Kinetics and Temperature Effects with $\mathrm{NADP}^{+}$as the Cofactor When GDH was assayed with $\mathrm{NADP}^{+}$as the cofactor at $23^{\circ} \mathrm{C}$, several kinetic parameters changed significantly between euthermic and hibernating conditions. Table 2.2 shows the $\mathrm{K}_{\mathrm{m}}$ glutamate decreased by nearly $80 \%$ during hibernation. However, contrary to the kinetics observed with $\mathrm{NAD}^{+}$as the cofactor, $\mathrm{K}_{\mathrm{m}} \mathrm{NADP}^{+}$was $78 \%$ higher and $\mathrm{V}_{\max }$ was $37 \%$ lower $(\mathrm{p}<0.05)$ for the hibernator form of GDH when compared to euthermic GDH. When the assay temperature decreased to $5^{\circ} \mathrm{C}, \mathrm{K}_{\mathrm{m}}$ glutamate, $\mathrm{K}_{\mathrm{m}}$ 
$\mathrm{NADP}^{+}$and $\mathrm{V}_{\text {max }}$ did not change significantly between euthermic and hibernating conditions.

Again, euthermic and hibernator GDH responded differently to decreases in assay temperature when utilizing $\mathrm{NADP}^{+}$in the redox reaction. Hibernator GDH displayed a varied response to cold temperature when utilizing $\mathrm{NADP}^{+}$, with a significant increase in $\mathrm{K}_{\mathrm{m}}$ glutamate, a 3-fold decrease in $\mathrm{K}_{\mathrm{m}} \mathrm{NADP}^{+}$, and a 56\% drop in maximal velocity (Table 2.2). The euthermic form of the enzyme, using $\mathrm{NADP}^{+}$, showed significant decreases in $\mathrm{K}_{\mathrm{m}}$ glutamate, $\mathrm{K}_{\mathrm{m}} \mathrm{NADP}^{+}$and $\mathrm{V}_{\max }$ when assayed at $5^{\circ} \mathrm{C}$ as compared to assays at $23^{\circ} \mathrm{C}$.

The effect of temperature on GDH activity was further investigated by looking at the maximal GDH velocity (with $\mathrm{NADP}^{+}$as the cofactor) over a range of temperatures. Data were evaluated by Arrhenius plots (Figure 2.1). The plots were linear over the range of temperatures used $\left(5-30^{\circ} \mathrm{C}\right)$. Activation energy, $\mathrm{E}_{\mathrm{a}}$, was determined from the slope of the line and values for euthermic $(30 \pm 4 \mathrm{KJ} / \mathrm{mol})$ and hibernating $(38.9 \pm 0.9 \mathrm{KJ} / \mathrm{mol})$ GDH were not significantly different.

GDH Kinetics in the Reverse (Glutamate-synthesizing) Direction

GDH was also assayed in the reverse, glutamate-synthesizing, direction at $23^{\circ} \mathrm{C}$ and there were several significant differences between kinetic parameters under euthermic and hibernator conditions. The enzyme was assayed with and without ADP, an activator of the enzyme. Table 2.3 shows that in the absence of ADP, $K_{m} \alpha-$ ketoglutarate and $\mathrm{K}_{\mathrm{m}} \mathrm{NH}_{4}{ }^{+}$decreased by $\sim 44 \%$ and $\sim 39 \%$ respectively, during hibernation. In the presence of $0.5 \mathrm{mM}$ ADP the $\mathrm{K}_{\mathrm{m}} \alpha$-ketoglutarate increased for both 
the euthermic and hibernating enzyme (but was still lower for the hibernator enzyme) whereas $\mathrm{K}_{\mathrm{m}} \mathrm{NH}_{4}{ }^{+}$of euthermic GDH decreased in the in the presence of ADP. There were no significant changes in GDH $V_{\max }$ between euthermic and hibernating states, both with and without ADP. However, the euthermic GDH maximal velocity increased significantly in the presence of ADP, whereas the hibernator GDH did not.

Comparing the $\mathrm{V}_{\max }$ for the forward reaction, using $\mathrm{NAD}^{+}$as the cofactor at room temperature, and the reverse reaction $\mathrm{V}_{\max }$, using $\mathrm{NADH}$ as the cofactor, it is clear that large differences were present. The reverse reaction velocities for euthermic and hibernator GDH were $\sim 11$ - and $\sim 7$-fold greater than the corresponding forward reaction $\mathrm{V}_{\max }$ values.

\section{Effectors of GDH}

The effects of common intracellular molecules on the forward reaction of GDH were determined by measuring enzyme activity at various concentrations of the effector molecules. Similar to the other kinetic parameters, the effects of these molecules depended on the cofactor being used as well as the assay temperature. With $\mathrm{NAD}^{+}$as the cofactor and assays at $23^{\circ} \mathrm{C}, \mathrm{K}_{\mathrm{a}} \mathrm{ADP}$ decreased by $54 \%$ for hibernator $\mathrm{GDH}$ as compared with the euthermic condition (Table 2.1). Furthermore, under these conditions, ADP activation of GDH was 3.5 fold for the hibernator enzyme but just 1.6 fold for the euthermic enzyme. ADP effects on GDH were very different at $5^{\circ} \mathrm{C}$. At low temperature, hibernator GDH was less sensitive to $\operatorname{ADP}\left(K_{a} 2\right.$ fold higher) than the euthermic enzyme. Furthermore, the hibernator $\mathrm{K}_{\mathrm{a}} \mathrm{ADP}$ was increased significantly at $5^{\circ} \mathrm{C}$ compared with its value at $23^{\circ} \mathrm{C}$, whereas the $\mathrm{K}_{\mathrm{a}} \mathrm{ADP}$ of euthermic GDH decreased 
by $>50 \%$ at $5^{\circ} \mathrm{C}$ compared with the value at $23^{\circ} \mathrm{C}$ (Table 2.1 ).

Similar to the situation with $\mathrm{NAD}^{+}$, hibernator $\mathrm{GDH}$ assayed with $\mathrm{NADP}^{+}$at $23^{\circ} \mathrm{C}$ showed a $\mathrm{K}_{\mathrm{a}} \mathrm{ADP}$ that was $33 \%$ lower than the euthermic value (Table 2). Moreover, hibernator GDH showed a greater fold activation ( 4.4 fold) by ADP than did euthermic GDH (1.9 fold) when ADP was added to the reaction at room temperature. At $5^{\circ} \mathrm{C}$, the affinity of GDH for ADP did not change significantly between euthermic and hibernator states or when compared to the corresponding values for $23^{\circ} \mathrm{C}$ assays. However, at low temperature, both euthermic and hibernator GDH showed a significantly greater fold activation by ADP than at $23^{\circ} \mathrm{C}$.

Similar to the situation for the forward reaction of GDH, the reverse reaction was also activated by ADP. Table 2.3 shows that the affinity of GDH for ADP did not change significantly between euthermic and hibernating conditions. However, the euthermic enzyme displayed a significantly greater fold activation by ADP.

The effects of two high-energy molecules (GTP and ATP) were assessed on the forward GDH reaction with $\mathrm{NAD}^{+}$as the cofactor. ATP, tested at concentrations up to 10 $\mathrm{mM}$, had no significant effect on either euthermic or hibernator GDH. However, GTP was a strong inhibitor with an $\mathrm{I}_{50}$ value of just $1.8 \mu \mathrm{M}$ for $\mathrm{GDH}$ from both euthermic and hibernating liver.

\section{Reversible Phosphorylation of GDH}

To determine if the stable kinetic changes in GDH between euthermic and hibernating ground squirrels were due to reversible phosphorylation of the protein, crude extracts were incubated with activators of specific endogenous protein phosphatases and 
protein kinases, and then the $\mathrm{K}_{\mathrm{m}}$ glutamate was revisited (Figures 2.2 and 2.3). Incubation conditions that inhibited both kinases and phosphatases (STOP) resulted in a high $\mathrm{K}_{\mathrm{m}}$ for euthermic GDH and a significantly lower one for the hibernator enzyme, similar to the results reported in Table 2.1 but with somewhat lower absolute values. The incubations that facilitated protein phosphatase actions lead to $28-50 \%$ decreases $(\mathrm{p}<0.05)$ in the $\mathrm{K}_{\mathrm{m}}$ glutamate for euthermic GDH (Fig. 2.2). The phosphatases responsible were PP2B and PP2C, as well as conditions that stimulated all serine/threonine phosphatases. Similarly, for the hibernating form of GDH, stimulation of total serine/threonine phosphatases led to a 24\% decrease $(\mathrm{p}<0.05)$ in $\mathrm{K}_{\mathrm{m}}$ glutamate compared to the STOP condition (Fig. 2.2).

In general, the incubations that stimulated the action of endogenous protein kinases had the opposite effect, producing significant increases $(\mathrm{p}<0.05)$ in $\mathrm{K}_{\mathrm{m}}$ glutamate compared to the STOP condition (Fig. 2.3). For euthermic GDH, the stimulation of selected endogenous kinases, namely PKA and PKC, produced $31-42 \%$ increases in $\mathrm{K}_{\mathrm{m}}$ glutamate compared to the control situation. Similarly, actions of endogenous protein kinases on hibernator GDH resulted in $44-76 \%$ increases in the $K_{m}$ glutamate. Hibernator GDH responded to stimulation by PKA, PKC, AMPK and CaMK.

Altering the phosphorylation state of an enzyme changes its net charge and thus allows for the separation of high- and low-phosphate forms of an enzyme by ion exchange chromatography. Figure 2.4 depicts the elution profiles of euthermic and hibernator $\mathrm{GDH}$ activity from a $\mathrm{CM}^{-}$cellulose column using a linear 0-2 $\mathrm{M} \mathrm{KCl}$ gradient. GDH in euthermic extracts eluted in a single, sharp peak of activity early in the gradient. Hibernator GDH activity eluted in two broad peaks with the majority of the activity being in the second peak. Both activity peaks eluted at higher concentration of salts, in 
comparison to the euthermic enzyme.

The difference in phosphorylation state between GDH from the euthermic and hibernator conditions was also investigated by purifying GDH via GTP-agarose chromatography followed by electrophoresis on SDS-PAGE. The resulting gel was stained with ProQ Diamond phosphoprotein stain which detects proteins that are phosphorylated. Having purified GDH using its strong affinity for GTP, most other proteins were removed prior to electrophoresis. Thus, after electrophoresis the single band in the molecular weight range for GDH subunits was attributed to GDH. Subsequent SDS-PAGE gels run with purified commercial bovine liver GDH (Sigma) confirmed this location as the position of GDH subunits. Quantification of band intensities on the stained gel showed that the relative intensities of euthermic GDH bands were significantly stronger $(\mathrm{P}<0.05)$ than the corresponding hibernator bands (Fig. 2.5).

\section{GDH Stability}

Structural differences between enzymes can be elucidated by determining their susceptibility to denaturation by urea. Table 2.1 and 2.2 show that at both $5^{\circ} \mathrm{C}$ and $23^{\circ} \mathrm{C}$ and when assayed with either cofactor, the $\mathrm{C}_{50}$ urea was significantly different when comparing euthermic and hibernator GDH. The hibernator enzyme form was always more susceptible to urea denaturation. Interestingly, a decrease in temperature typically led to a significant increase in $\mathrm{C}_{50}$ urea for both euthermic and hibernator GDH. 
Table 2.1. Comparison of liver GDH kinetic parameters in the forward (glutamateutilizing) direction using $\mathrm{NAD}^{+}$as the cofactor at $5^{\circ} \mathrm{C}$ and $23^{\circ} \mathrm{C}$ for euthermic and hibernator enzymes. Data are means $\pm S E M, n \geq 3$ determinations on independent samples. $K_{m}$ values were determined at optimal cosubstrate concentrations. $K_{a}$ and $I_{50}$ values were determined at suboptimal substrate concentrations (defined in Materials and Methods). ${ }^{a}$ - Significantly different from the corresponding euthermic value at a given temperature using the Student's t-test, $\mathrm{P}<0.05{ }^{\mathrm{b}}{ }^{\mathrm{b}}$ - significantly different from the same parameter at $5^{\circ} \mathrm{C}$.

\begin{tabular}{|c|c|c|c|c|}
\hline & \multicolumn{2}{|c|}{$\mathbf{5}^{\circ} \mathbf{C}$} & \multicolumn{2}{c|}{$\mathbf{3 3}^{\circ} \mathbf{C}$} \\
\hline & Euthermic & Hibernator & Euthermic & Hibernator \\
\hline $\mathrm{K}_{\mathrm{m}}$ Glutamate $(\mathrm{mM})$ & $4.1 \pm 0.4$ & $2.3 \pm 0.3^{\mathrm{a}}$ & $4.2 \pm 0.4$ & $3.2 \pm 0.2^{\mathrm{ab}}$ \\
\hline $\mathrm{K}_{\mathrm{m}} \mathrm{NAD}^{+}(\mathrm{mM})$ & $0.52 \pm 0.04$ & $0.29 \pm 0.04^{\mathrm{a}}$ & $1.17 \pm 0.08^{\mathrm{b}}$ & $1.21 \pm 0.08^{\mathrm{b}}$ \\
\hline $\mathrm{K}_{\mathrm{a}} \mathrm{ADP}(\mu \mathrm{M})$ & $23 \pm 4$ & $48 \pm 5^{\mathrm{a}}$ & $50 \pm 10^{\mathrm{b}}$ & $23 \pm 7^{\mathrm{ab}}$ \\
{$[$ Fold Activation] } & {$[1.6 \pm 0.1]$} & {$[1.44 \pm 0.07]$} & {$[1.61 \pm 0.03]$} & {$\left[3.5 \pm 0.4^{\mathrm{a}}\right]$} \\
\hline $\mathrm{V}_{\max }(\mathrm{mU} / \mathrm{mg})$ & $5.7 \pm 0.2$ & $5.9 \pm 0.3$ & $16 \pm 2^{\mathrm{b}}$ & $23 \pm 2^{\mathrm{ab}}$ \\
\hline $\mathrm{C}_{50}$ Urea $(\mathrm{M})$ & $3.5 \pm 0.1$ & $3.18 \pm 0.05^{\mathrm{a}}$ & $3.8 \pm 0.1$ & $3.14 \pm 0.05^{\mathrm{a}}$ \\
\hline $\mathrm{I}_{50} \mathrm{GTP}(\mu \mathrm{M})$ & - & - & $1.8 \pm 0.2$ & $1.8 \pm 0.2$ \\
\hline
\end{tabular}


Table 2.2. Comparison of liver GDH kinetic parameters in the forward (glutamateutilizing) direction using $\mathrm{NADP}^{+}$as the cofactor at $5^{\circ} \mathrm{C}$ and $23^{\circ} \mathrm{C}$ for both euthermic and hibernator enzymes. Data are means \pm SEM, $n \geq 3$ determinations on independent samples. $\mathrm{K}_{\mathrm{m}}$ values were determined at optimal cosubstrate concentrations. $\mathrm{K}_{\mathrm{a}}$ values were determined at suboptimal substrate concentrations (defined in Materials and Methods). ${ }^{\mathrm{a}}$ - Significantly different from the corresponding euthermic value at a given temperature using the Student's t-test, $\mathrm{P}<0.05 ;^{\mathrm{b}}{ }^{\mathrm{b}}$ - significantly different from the same parameter at $5^{\circ} \mathrm{C}$.

\begin{tabular}{|c|c|c|c|c|}
\hline & \multicolumn{2}{|c|}{$\mathbf{5}^{\circ} \mathbf{C}$} & \multicolumn{2}{c|}{$\mathbf{2 3}^{\circ} \mathbf{C}$} \\
\hline & Euthermic & Hibernator & Euthermic & Hibernator \\
\hline $\mathrm{K}_{\mathrm{m}}$ Glutamate $(\mathrm{mM})$ & $1.2 \pm 0.2$ & $1.1 \pm 0.1$ & $2.8 \pm 0.2^{\mathrm{b}}$ & $0.6 \pm 0.1^{\mathrm{ab}}$ \\
\hline $\mathrm{K}_{\mathrm{m}} \mathrm{NADP}^{+}(\mathrm{mM})$ & $0.29 \pm 0.02$ & $0.27 \pm 0.02$ & $0.41 \pm 0.03^{\mathrm{b}}$ & $0.73 \pm 0.06^{\mathrm{ab}}$ \\
\hline $\mathrm{K}_{\mathrm{a}} \mathrm{ADP}(\mu \mathrm{M})$ & $17 \pm 2$ & $18 \pm 3$ & $21 \pm 1$ & $14 \pm 3^{\mathrm{a}}$ \\
{$[$ Fold Activation] } & {$[4.6 \pm 0.5]$} & {$[5.6 \pm 0.5]$} & {$\left[1.9 \pm 0.1^{\mathrm{b}}\right]$} & {$\left[4.4 \pm 0.5^{\mathrm{a}}\right]$} \\
\hline $\mathrm{V}_{\max }(\mathrm{mU} / \mathrm{mg})$ & $3.8 \pm 0.3$ & $3.6 \pm 0.3$ & $13.2 \pm 0.8^{\mathrm{b}}$ & $8.3 \pm 0.5^{\mathrm{ab}}$ \\
\hline $\mathrm{C}_{50}$ Urea $(\mathrm{M})$ & $4.0 \pm 0.1$ & $3.02 \pm 0.04^{\mathrm{a}}$ & $3.4 \pm 0.2^{\mathrm{b}}$ & $2.76 \pm 0.02^{\mathrm{ab}}$ \\
\hline
\end{tabular}


Table 2.3. Kinetic parameters of liver GDH from euthermic and hibernating ground squirrels in the reverse (glutamate-synthesizing) direction using NADH as the cofactor with assay at $23^{\circ} \mathrm{C} \cdot \mathrm{K}_{\mathrm{a}}$ values were determined at suboptimal substrate concentrations (defined in Materials and Methods). Data are means \pm SEM, $n=3$ determinations on independent samples. ${ }^{a}$-Significantly different from the corresponding euthermic value using the Student's $\mathrm{t}$-test, $\mathrm{P}<0.05{ }^{\mathrm{b}}{ }^{-}$- significantly different from the same parameter measured in the absence of ADP.

\begin{tabular}{|c|c|c|}
\hline & Euthermic & Hibernator \\
\hline $\mathrm{K}_{\mathrm{m}} \alpha$-ketoglutarate $(\mathrm{mM})$ & $0.22 \pm 0.02$ & $0.12 \pm 0.01^{\mathrm{a}}$ \\
\hline $\mathrm{K}_{\mathrm{m}} \alpha$-ketoglutarate $(\mathrm{mM})$ with $0.5 \mathrm{mM}$ ADP & $0.50 \pm 0.07^{\mathrm{b}}$ & $0.30 \pm 0.03^{\mathrm{ab}}$ \\
\hline $\mathrm{K}_{\mathrm{m}} \mathrm{NH}_{4}{ }^{+}(\mathrm{mM})$ & $28 \pm 2$ & $17 \pm 1^{\mathrm{a}}$ \\
\hline $\mathrm{K}_{\mathrm{m}} \mathrm{NH}_{4}{ }^{+}(\mathrm{mM})$ with $0.5 \mathrm{mM}$ ADP & $17 \pm 2^{\mathrm{b}}$ & $14 \pm 1$ \\
\hline $\mathrm{K}_{\mathrm{a}}$ ADP $(\mu \mathrm{M})$ & $37 \pm 4$ & $35 \pm 5$ \\
{$[$ Fold Activation] } & {$[1.60 \pm 0.05]$} & {$\left[1.31 \pm 0.07^{\mathrm{a}}\right]$} \\
\hline $\mathrm{V}_{\max }(\mathrm{mU} / \mathrm{mg})$ & $182 \pm 6$ & $180 \pm 14$ \\
\hline $\mathrm{V}_{\max }(\mathrm{mU} / \mathrm{mg})$ with 0.5 mM ADP & $200 \pm 6^{\mathrm{b}}$ & $190 \pm 13$ \\
\hline
\end{tabular}


Table 2.4. The enzyme efficiency, represented as $V_{\max } / K_{m}$, for both euthermic and hibernator GDH derived from S. richardsonii crude liver extracts. The ratios are calculated by using the maximal velocity of the forward (glutamate-oxidizing) reaction, divided by the $\mathrm{K}_{\mathrm{m}}$ for $\mathrm{NAD}^{+}$or $\mathrm{NADP}^{+}$.

\begin{tabular}{|c|c|c|c|c|}
\hline & \multicolumn{2}{|c|}{ Euthermic } & \multicolumn{2}{c|}{ Hibernator } \\
\hline & $5^{\circ} \mathrm{C}$ & $23^{\circ} \mathrm{C}$ & $5^{\circ} \mathrm{C}$ & $23^{\circ} \mathrm{C}$ \\
\hline $\mathrm{V}_{\max } / \mathrm{K}_{\mathrm{m}}$ with $\mathrm{NAD}^{+}$ & & & & \\
$(\mathrm{mU} / \mathrm{mg} / \mathrm{mM})$ & $11.0 \pm 0.9$ & $14 \pm 2$ & $20 \pm 3$ & $19 \pm 2$ \\
\hline $\mathrm{V}_{\max } / \mathrm{K}_{\mathrm{m}}$ with NADP \\
$(\mathrm{mU} / \mathrm{mg} / \mathrm{mM})$ & $13 \pm 1$ & $32 \pm 3$ & $13 \pm 1$ & $11 \pm 1$ \\
\hline
\end{tabular}


Figure 2.1. Arrhenius plots for liver GDH (using $\mathrm{NADP}^{+}$as the cofactor) from euthermic and hibernating $S$. richardsonii. Data are means \pm SEM, $\mathrm{n}=3$ determinations of separate preparations of enzyme. 
Figure 2.1

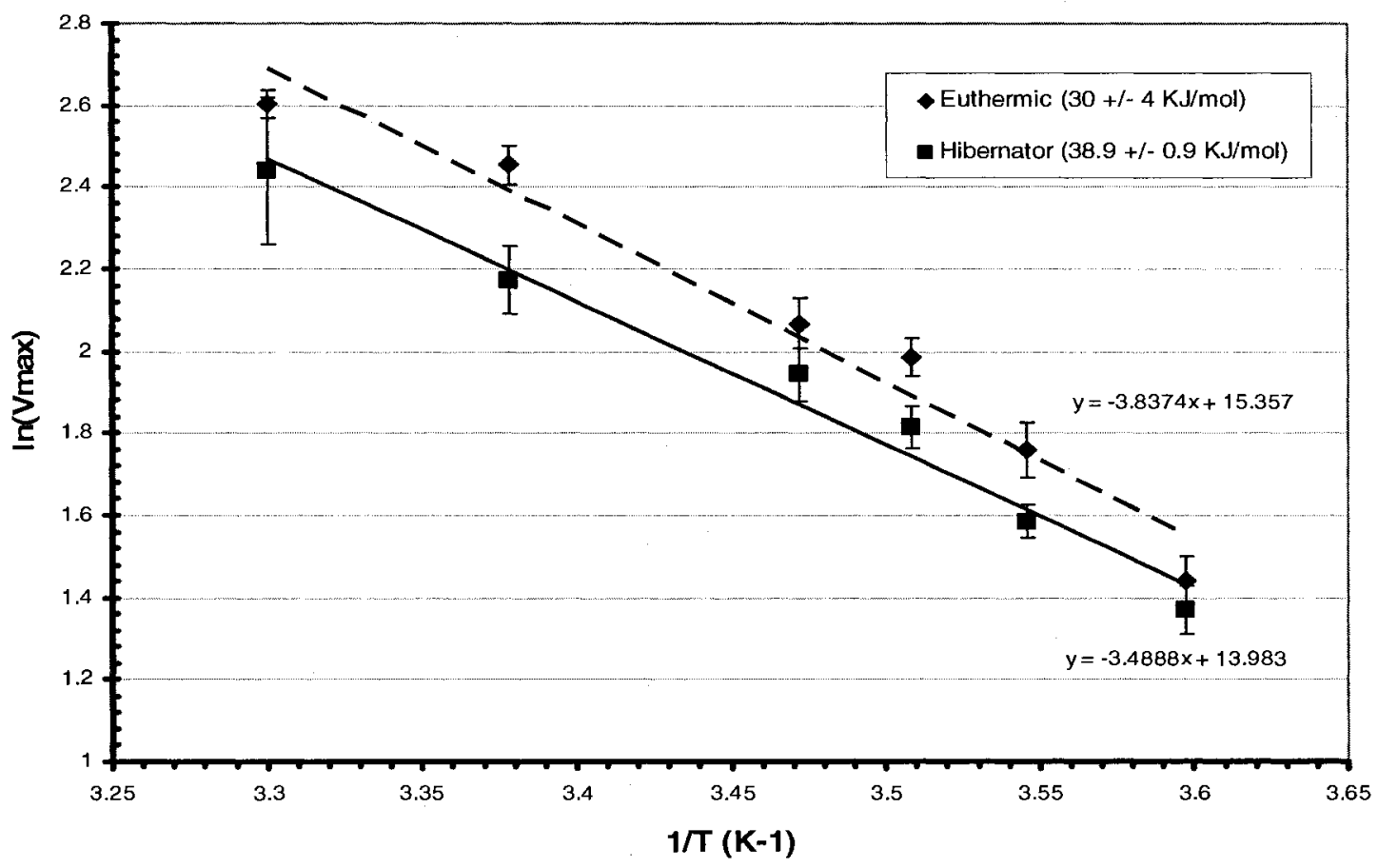


Figure 2.2. Effects of in vitro incubations to stimulate the activities of endogenous protein phosphatases on $\mathrm{K}_{\mathrm{m}}$ glutamate of $S$. richardsonii liver GDH. Crude extracts were incubated for $4 \mathrm{~h}$ before assay at $23^{\circ} \mathrm{C}$. Data are means $\pm \mathrm{SEM}, \mathrm{n}=3$ determinations on separate preparations of enzyme. ${ }^{*}$ - Significantly different from the corresponding euthermic value as determined by the Dunnett's test, $\mathrm{P}<0.05 ; * *$ - significantly different from the corresponding 'STOP' condition, $\mathrm{P}<0.05$. 
Figure 2.2

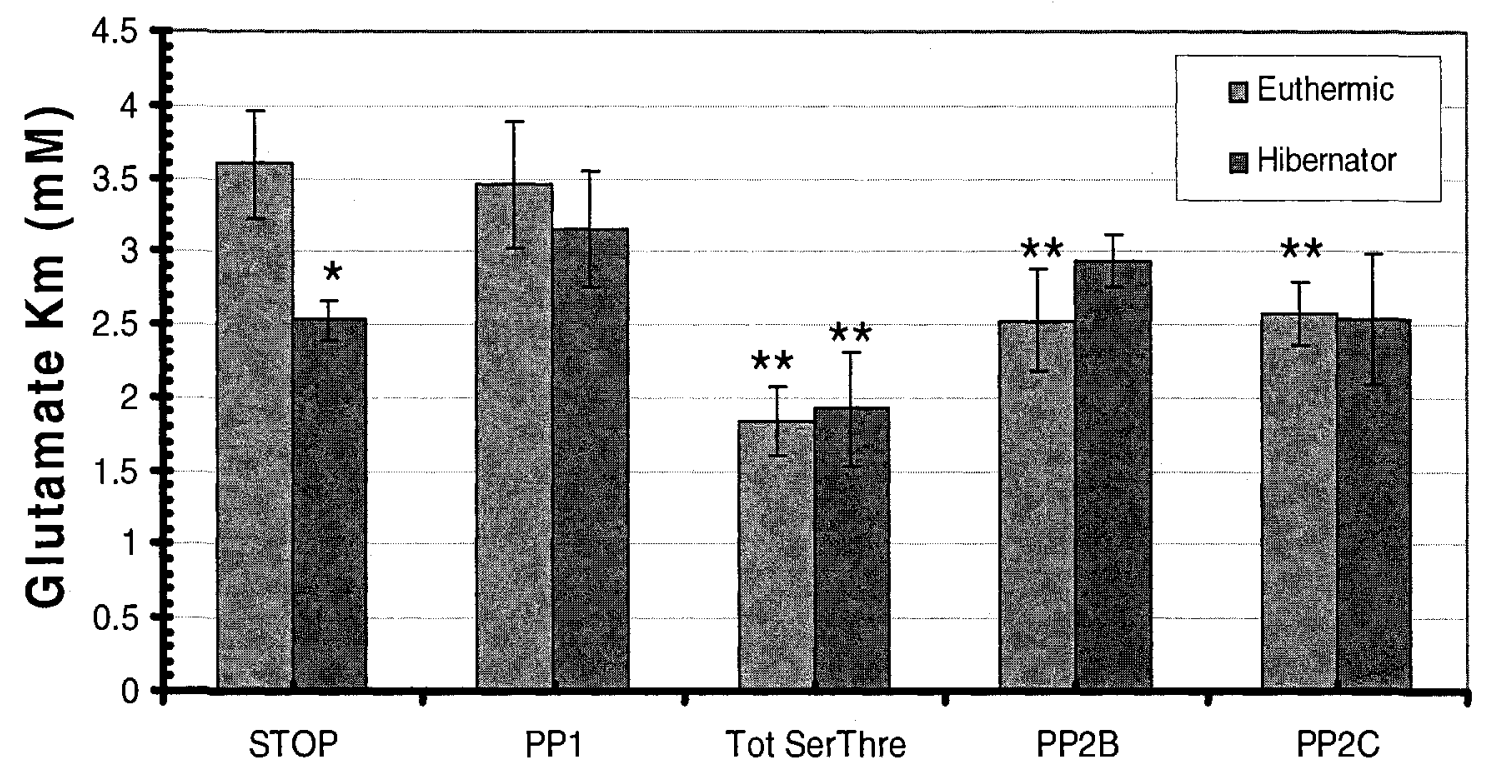


Figure 2.3. Effects of in vitro incubations to stimulate the activities of endogenous protein kinases on $\mathrm{K}_{\mathrm{m}}$ glutamate for liver GDH. Crude extracts were incubated for $4 \mathrm{~h}$ before assay at $23^{\circ} \mathrm{C}$. Data are means $\pm \mathrm{SEM}, \mathrm{n}=3$ determinations on separate preparations of enzyme. *-Significantly different from the corresponding euthermic value via the Dunnett's test, $\mathrm{p}<0.05$. **-Significantly different from corresponding 'STOP' condition, $\mathrm{p}<0.05$. 
Figure 2.3

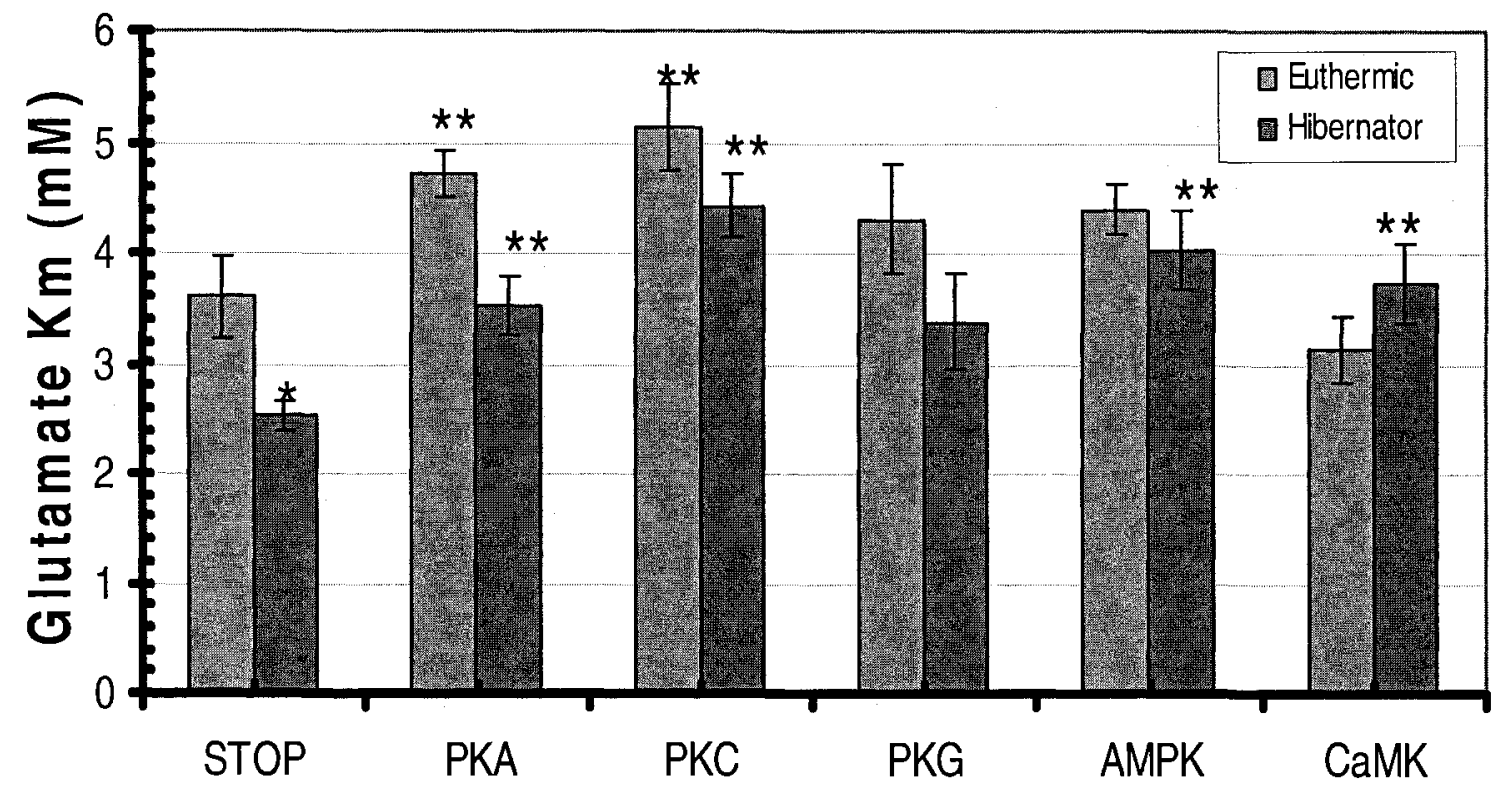


Figure 2.4. $\mathrm{CM}^{-}$cellulose elution profiles for GDH activity from liver of euthermic and hibernating ground squirrels. The enzyme was eluted with a $0-2 \mathrm{M} \mathrm{KCl}$ gradient in column buffer (defined in the Materials and Methods) at $\mathrm{pH}$ 6. The profiles are representative of two other trials that gave comparable results (data not shown). 
Figure 2.4

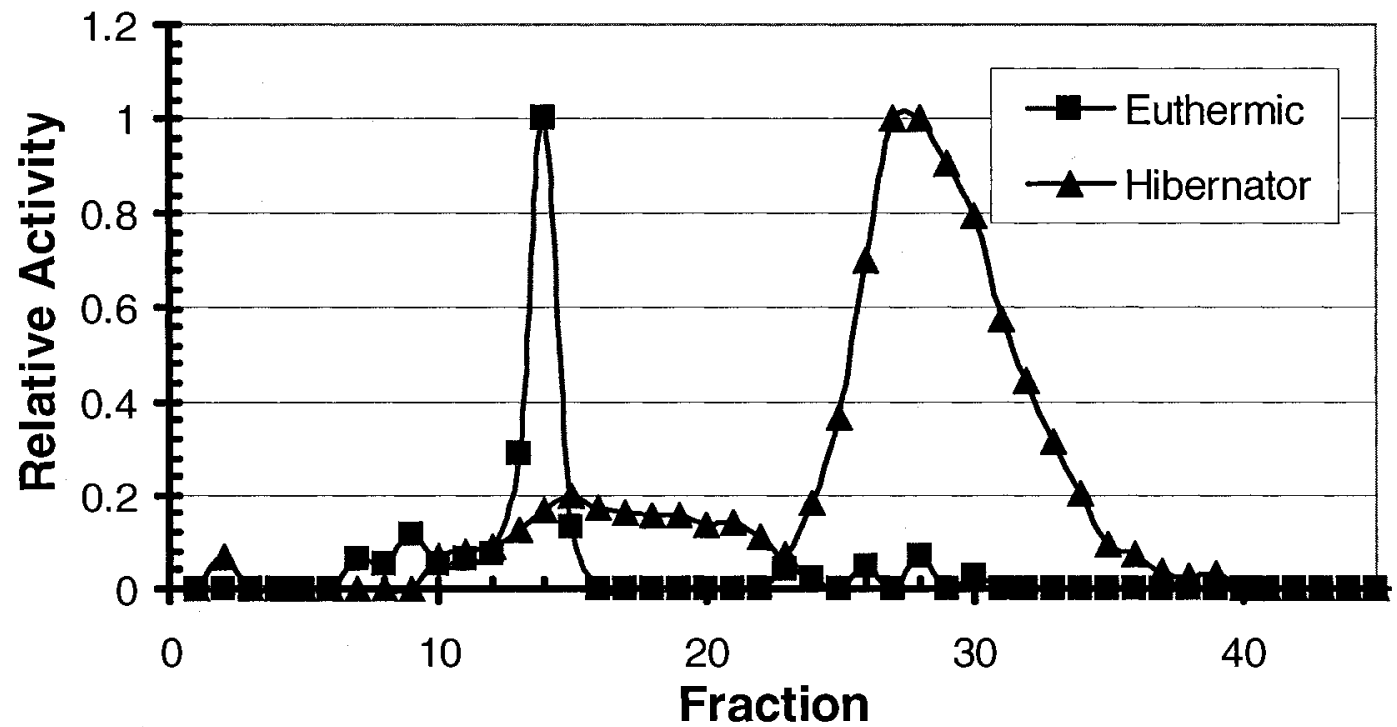


Figure 2.5. The relative band intensity of purified liver GDH from euthermic and hibernating S. richardsonii as assessed on a SDS-PAGE gel stained with ProQ Diamond stain. Data are means $\pm \mathrm{SEM}, \mathrm{n}=3$ independent samples. * - Significantly different from the mean relative band intensity of the euthermic condition, using the one-tailed, equal variance Student's t-test $(\mathrm{P}<0.05)$. 
Figure 2.5

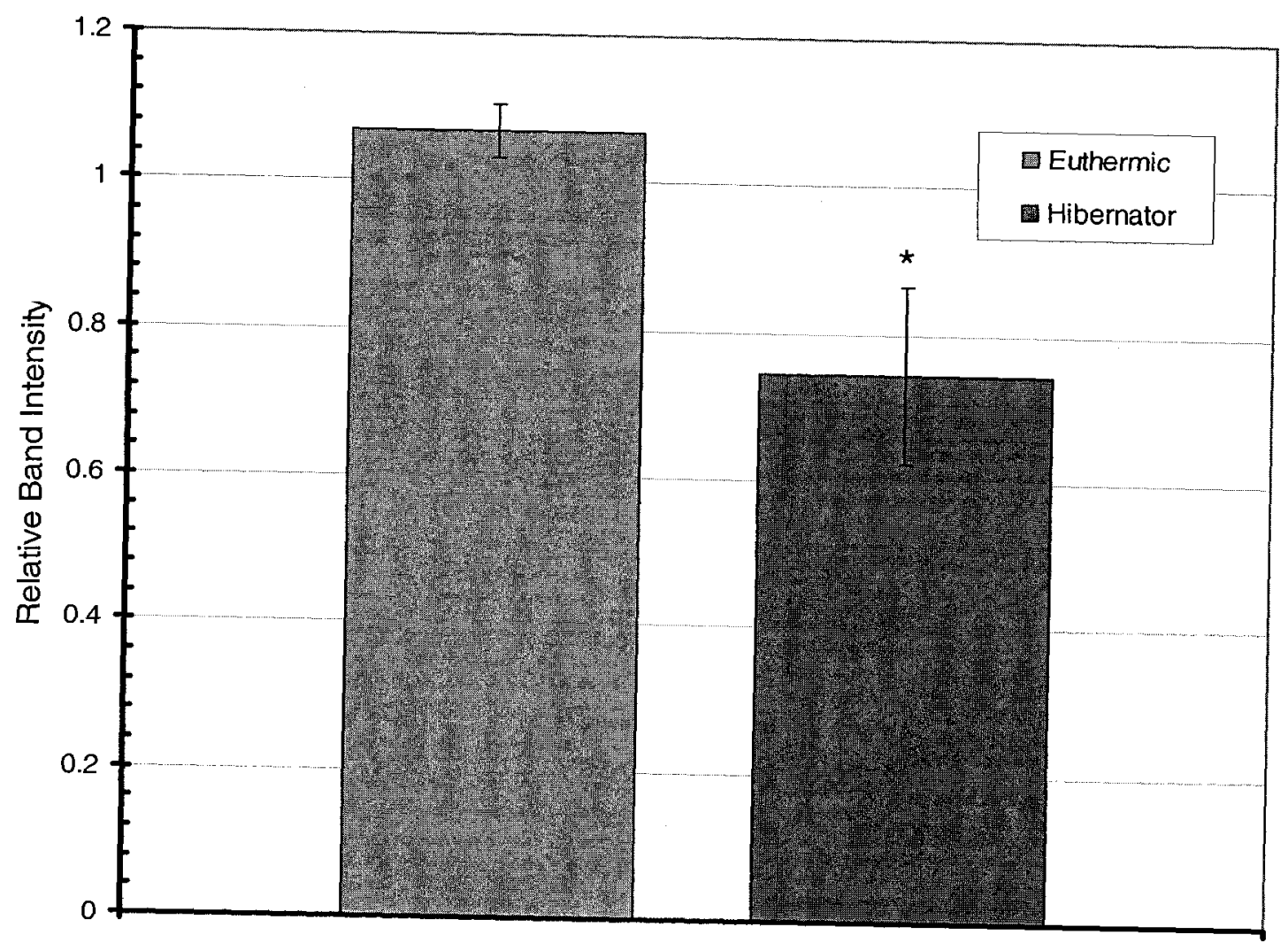




\section{Discussion}

During winter hibernation, mammals primarily use non-carbohydrate fuels to maintain basic cellular and metabolic functioning (Yacoe, 1983; Carey et al., 2003). Although the oxidation of endogenous fat reserves typically constitutes that major fuel for energy production during hibernation, amino acids derived from tissue proteins can also be significant fuels (Storey and Storey, 1990). Thus, the enzymes involved in the deamination and conversion of amino acids into an oxidizable carbon skeleton may be important during hibernation. Glutamate dehydrogenase is the enzyme that forms that major link between carbohydrate and amino acid metabolism, and is responsible for shuttling amino acid carbon skeletons into the Krebs cycle to aid in energy production (Storey et al., 1978). This investigation shows that liver GDH from euthermic and hibernating Richardson's ground squirrels displays markedly different kinetic properties, responses to temperature change, and is interconverted between two forms by reversible phosphorylation.

One apparent difference between euthermic and hibernator GDH is the ability to use $\mathrm{NAD}^{+}$and $\mathrm{NADP}^{+}$in the glutamate-oxidizing reaction. These differences can be exemplified by looking at the $\mathrm{V}_{\max } / \mathrm{K}_{\mathrm{m}} \mathrm{NAD}(\mathrm{P})^{+}$ratio, which is also known as enzyme efficiency, for each enzyme form. The calculated enzyme efficiencies, shown in Table 2.4 , indicate that there is a change in the cofactor preference of GDH operating in the euthermic versus hibernating state. At warm temperature $\left(23^{\circ} \mathrm{C}\right)$, euthermic $\mathrm{GDH}$ has a $>2$-fold higher enzyme efficiency with $\mathrm{NADP}^{+}$as the cofactor compared to the enzyme efficiency with $\mathrm{NAD}^{+}$as the cofactor. This is consistent with the data for bovine liver GDH (a non-hibernating mammal) which showed a preference for $\mathrm{NADP}^{+}$as the cofactor 
when glutamate was being oxidized (Male and Storey, 1982). $\mathrm{NADP}^{+}$preference makes sense in non-hibernating situations where there is decreased reliance on protein oxidation for energy. Alternatively, at a temperature similar to that experienced by the ground squirrel during hibernation, hibernator GDH shows enhanced efficiency when using $\mathrm{NAD}^{+}$as compared with $\mathrm{NADP}^{+}$. Generally speaking, $\mathrm{NAD}^{+}$appears to be the preferred cofactor for the hibernator form of GDH, and $\mathrm{NADP}^{+}$is preferred by euthermic GDH regardless of assay temperature. The increased efficiency of GDH using NAD ${ }^{+}$during hibernation may be associated with a need to facilitate glutamate oxidation as an energy source during torpor. NADH is typically oxidized by the electron transport chain (ETC) for the production of ATP by oxidative phosphorylation, whereas NADPH is used in anabolic processes as well as in antioxidant defence mechanisms. Since anabolic processes in hypometabolic states are at a minimum, it is likely that $\mathrm{NAD}^{+}$becomes more preferable during hibernation. This is supported by the fact that several studies have shown an increase in the activity of ETC enzymes or an up-regulation of genes associated with the ETC during hibernation, which could allow hibernating mammals to optimally use the NADH produced from fatty acid and amino acid oxidation (Hittel and Storey, 2002; Eddy et al., 2006). It is important to note that changes in cofactor preference may reflect a physical difference between euthermic and hibernator enzymes, which may be the result of covalent modification during hibernation.

Common cellular metabolites, such as ADP, ATP and GTP, displayed various effects on euthermic and hibernator GDH. ADP is a well known activator of mammalian GDH, and acts by causing a conformational change in the enzyme that decreases product affinity and thereby increases reaction rate (Smith et al., 2001). In all cases in this study, 
GDH exhibited a $\mathrm{K}_{\mathrm{a}} \mathrm{ADP}$ between $14-50 \mu \mathrm{M}$, which is well within the range of physiological levels of ADP (Table 2.1, 2.2, and 2.3; Thatcher and Storey, 2001). Thus, ADP could play an important role in regulating GDH activity in vivo in both euthermic and hibernating conditions. Generally speaking, it appears that hibernator GDH is more sensitive to ADP at room temperature, whereas euthermic GDH was more sensitive to $\mathrm{ADP}$ at $5^{\circ} \mathrm{C}$. Liver ADP levels during euthermia and hibernation exceed the $\mathrm{K}_{\mathrm{a}} \mathrm{ADP}$ for GDH measured in this study and thus the difference in fold activation of GDH by ADP may be more physiologically relevant during hibernation (Thatcher and Storey, 2001). If this is the case, hibernator GDH displayed a higher fold activation at $23^{\circ} \mathrm{C}$ with either cofactor when compared to the euthermic condition. Furthermore, hibernator GDH fold activation was significantly higher at $5^{\circ} \mathrm{C}$ with $\mathrm{NADP}^{+}$when compared to euthermic GDH.

Although the effect of ADP was extensively examined, the effects of high energy molecules, GTP and ATP, were only investigated in the forward direction and with $\mathrm{NAD}^{+}$as the cofactor. Table 2.1 shows that there were no significant changes in $\mathrm{I}_{50}$ GTP between euthermic and hibernating conditions, but GTP was a very strong inhibitor at low micromolar concentrations, which is consistent with several other studies of animal GDH (Thatcher and Storey, 2001; Lee et al., 2001). Conversely, ATP had a negligible effect on GDH activity at concentrations as high as $10 \mathrm{mM}$. These results coincide with the typical regulatory effects of ATP and GTP on mammalian GDH. GTP binds specifically to an allosteric site via its $\beta$ - and $\gamma$-phosphate groups, and this causes a conformational change that increases GDH affinity for the reaction products and thus slows the reaction (Smith et al., 2001). Similarly, the $\beta$ - and $\gamma$-phosphate groups of ATP 
are capable of binding to the GTP-binding site, but with much less affinity (i.e. GTP is the favoured ligand; Smith et al., 2001). Further complicating the effects of ATP is that higher concentrations of ATP are able to activate GDH via interaction of the adenosine moiety with the ADP binding site (Smith et al., 2001). For these reasons, ATP has a small or negligible net effect on GDH activity in comparison to the effect of GTP. In this study, both euthermic and hibernator forms of GDH had the same response to these two high-energy molecules.

Low temperatures increase the overall rigidity of an enzyme and thereby decrease its activity (Koutsopoulos et al., 2005). However, depending on the intramolecular forces maintaining the enzyme structure, substrate affinities can be preserved, increased or decreased (Malan and Canguilhem, 1989; Kumeta et al., 2003). Generally speaking, ground squirrel GDH seems to adjust to large decreases in temperature very well, as is evidenced by the general pattern of significant decreases in substrate $\mathrm{K}_{\mathrm{m}}$ values at $5^{\circ} \mathrm{C}$ for both enzyme forms (Table 2.1 and 2.2). However, hibernator GDH typically displayed larger reductions in substrate $\mathrm{K}_{\mathrm{m}}$ values at $5^{\circ} \mathrm{C}$ as compared with euthermic GDH. Substrate affinity increases ranged from $28-76 \%$ for hibernator GDH and $29-57 \%$ for the euthermic enzyme. Thus, it appears that the hibernator form of the enzyme may be better suited for low temperature function than euthermic GDH. Other enzymes that have shown increased functioning (i.e. lower substrate $\mathrm{K}_{\mathrm{m}}$ values) during ground squirrel hibernation include adenylate kinase, creatine kinase and protein kinase A (Storey, 2004b).

The kinetic differences outlined above, in addition to the differences in other kinetic parameters shown in Tables 2.1-2.3, indicate that there may be distinct structural 
differences between euthermic and hibernator GDH. Thatcher and Storey (2001) found evidence for different physical forms for ground squirrel GDH using size exclusion chromatography on an HPLC column. One possible explanation for these differences is covalent modification of GDH in the form of reversible phosphorylation. GDH is known to be phosphorylated in several organisms; however, these findings have been confined to yeast (Saccharomyces cerevisiae, Candida utilis) and bacterial (Escherichia coli) species (Hemmings and Sims, 1977; Hemmings, 1978; 1981; Uno et al., 1984; Lin and Reeves, 1994). Although phosphorylation in higher organisms has not been found to date, Thatcher and Storey (2001) suggested that the kinetic and physical differences between purified euthermic and hibernator GDH from the Richardson's ground squirrel liver may be the result of reversible phosphorylation. The present data indicate that indeed ground squirrel GDH is regulated by reversible phosphorylation during hibernation.

In vitro incubations of liver extracts under conditions that would stimulate PP2B, PP2C, and total serine/threonine protein phosphatases resulted in significant decreases in $\mathrm{K}_{\mathrm{m}}$ glutamate for euthermic GDH (Fig. 2.2). Hibernator GDH also responded to stimulation of total serine/threonine protein phosphatases, and the result was again a decrease in $\mathrm{K}_{\mathrm{m}}$ glutamate. It is interesting to note that MacDonald and Storey (2007) found that in the liver of Richardson's ground squirrels, PP2C activity increased significantly during hibernation. Thus, $\mathrm{PP} 2 \mathrm{C}$ may be the prime candidate for the enzyme that dephosphorylates GDH in vivo when ground squirrels enter torpor.

Contrary to the action of endogenous phosphatases, incubations that stimulated protein kinases led to significant increases in $\mathrm{K}_{\mathrm{m}}$ glutamate for both euthermic and hibernator GDH. The kinases found to phosphorylate euthermic GDH were PKA and 
PKC, whereas hibernator GDH was phosphorylated by PKA, PKC, AMPK, and calciumcalmodulin kinase (Fig. 2.3). Several recent studies have investigated the role of some of these kinases during hibernation in ground squirrels. For instance, Horman et al. (2005) found that liver AMPK was much more active in euthermic squirrels as compared to hibernating animals. Thus, it is plausible that AMPK phosphorylates GDH in vivo when the ground squirrel exits torpor and re-establishes normal euthermic functioning. Similarly, ground squirrel PKA activity has been shown to increase rapidly upon arousal from torpor, however, this was only investigated in brown adipose tissue and not liver (MacDonald and Storey, 2007). Additional evidence for the regulation of GDH by reversible phosphorylation comes from an analysis of mammalian GDHs and the putative phosphorylation motifs in their amino acid sequences. Analysis of human, mouse, and rat GDH showed peptide sequences of recognized tyrosine and serine phosphorylation sites, as well as, for human GDH, putative phosphorylation sites for PKA, CaMK and others (Appendix 1; T. Forrest, unpublished).

The results from the protein kinase and phosphatase incubations indicate that both euthermic and hibernator GDH are capable of being phosphorylated in vitro. Since phosphorylation leads to an increase in $\mathrm{K}_{\mathrm{m}}$ glutamate and euthermic GDH has a significantly higher $\mathrm{K}_{\mathrm{m}}$ in its native state, it appears that euthermic GDH is more phosphorylated than hibernator GDH. The fact that both phosphatases and kinases can alter the kinetics of each enzyme form indicates that euthermic and hibernator GDH are phosphorylated to different degrees (ie. high and low phosphate forms), and do not exist in completely phosphorylated or dephosphorylated forms.

To further investigate the possibility that euthermic and hibernator GDH exist in 
two different phosphorylated forms, ion exchange chromatography columns were conducted. The representative elution profile for euthermic and hibernator GDH activity, shown in Figure 2.4, shows that euthermic GDH eluted from the cation exchange column at a lower salt concentration than did hibernator GDH. This fits with the data from the kinase/phosphatase incubation since the more highly phosphorylated euthermic enzyme would harbour a greater negative charge and, thus, would elute off the negatively charged carboxymethyl column more easily. It is interesting to note that the hibernator GDH profile has one major peak as well as a smaller peak in the vicinity of the euthermic GDH peak. This may indicate that during hibernation there is a mixture of GDH forms mainly consisting of the low phosphate form of GDH with a smaller amount of high phosphate enzyme.

ProQ Diamond phosphoprotein staining of purified euthermic and hibernator GDH confirmed the presence of a higher phosphate content in euthermic GDH and a lower amount of phosphate on hibernator GDH (Fig. 2.5). The mean relative band intensity of hibernator GDH was $\sim 25 \%$ less than that of the euthermic enzyme, which coincides with the suggestion that GDH during hibernation is not completely dephosphorylated.

Protein stability, measured by urea denaturation, can also be an indication of a physical difference between two forms of an enzyme. In all cases where ground squirrel GDH was assayed in the forward direction (Table 2.1 and 2.2), the euthermic enzyme showed a $10-34 \%$ higher $\mathrm{C}_{50}$ urea than hibernator GDH which indicates that euthermic GDH was more stable than the hibernator enzyme under the same conditions. These differences most likely derive from different levels of phosphorylation of GDH. 
Hibernator GDH being more sensitive to urea denaturation may mean that it has a more flexible structure that is capable of functioning more effectively at low temperatures, whereas euthermic GDH might have a more rigid structure that suits functions at the higher temperatures in euthermia. Interestingly, an increase in assay temperature generally led to a significant decrease in $\mathrm{C}_{50}$ urea, indicating that euthermic and hibernator GDH are more susceptible to denaturation at higher temperatures. Recent work by Rocco et al., (2008) on the effects of urea and temperature on protein unfolding have elucidated that both of these factors work together via different mechanisms to cause unfolding. Urea affects the secondary structure of proteins and leads to the destabilization of $\beta$-sheets, whereas increases in temperature preferentially disrupt $\alpha$ helices to cause unfolding.

Taken together, the data presented here indicate that GDH from euthermic ground squirrels undergoes incomplete dephosphorylation upon transition into hibernation. The low-phosphate hibernator form of GDH typically showed greater affinity for its substrates as compared to the high-phosphate euthermic form, and seemed well-adapted for function at low temperature. Since hibernation is characterized by a lack of feeding and a decrease in muscle mass (Wang, 1989), it is likely that the metabolic effect of these enhancements of GDH function in the hibernator is not amino acid synthesis, but serve to increase amino acid oxidation during torpor to contribute to energy production and gluconeogenesis.

One potential problem with the increased oxidation of amino acids is the increased production of ammonia, which is toxic to cells if left unattended. Ammonia is typically converted in the mammalian liver to a less toxic form, urea, by a group of 
enzymes that make up the urea cycle. Thus, it is hypothesized that an increase in ammonia production during hibernation would lead to increased levels of urea. Indeed, this has been found for at least one hibernating mammal, the Columbian ground squirrel, which shows elevated blood urea levels during torpor, and increased urea excretion during the periodic arousals in their hibernating cycle (Passmore et al., 1975). To ensure that urea concentrations during torpor do not reach hazardous levels, many hibernators, including Richardson's ground squirrels, use urea recycling (Bintz and Torgerson, 1981; Halfpenny and Ozanne, 1989). This involves the movement of urea from the liver into the blood, which transports it into the saliva and then it is eventually swallowed. Once the urea reaches the intestines, bacteria convert the urea back into ammonia and bicarbonate, and the ammonia gets converted back into amino acids. The complete recycling of ammonia releases acids which combine with the bicarbonate to produce carbon dioxide and water (Halfpenny and Ozanne, 1989).

Another complication of the increased production of ammonia (and therefore urea) as a result of protein catabolism during hibernation is that ureogenesis requires water, and this greatly increases the risk of dehydration. Urea recycling will counteract some of this water loss, however it is likely that the majority of the water lost in urea production is restored through fatty acid oxidation which is elevated during hibernation and which produces metabolic water (Halfpenny and Ozanne, 1989). Thus, it appears that the proposed role of GDH during hibernation coincides with the physiological behaviour of urea during torpor, as well as the known energy and gluconeogenic demands during hibernation. 
Chapter 3

Regulation of liver glutamate dehydrogenase from an anoxia-tolerant freshwater turtle 


\section{Introduction:}

One of the essential requirements for survival of most organisms is oxygen.

Oxygen is necessary for cellular respiration and is the final electron acceptor in the ETC during the production of ATP via oxidative phosphorylation. However, a few organisms are capable of surviving completely without oxygen, or extended periods without oxygen and are called obligate or facultative anaerobes, respectively (Storey and Storey, 2001).

Survival under low oxygen (hypoxia) or no oxygen (anoxia) conditions requires extensive biochemical, behavioral and physiological changes. The behavioral and physiological changes include sluggish movements, large decreases in blood pressure and heart rate, and minimal renal function (Jackson, 2002). Large scale metabolic changes needed to adjust to long term oxygen deprivation include: (i) large reserves of fermentable fuels; (ii) utilizing strategies to buffer or excrete anaerobic metabolic end products that are typically acidic; (iii) utilizing alternative anaerobic routes of substrate fermentation that are linked to enhanced ATP output; (iv) developing good antioxidant defenses in preparation for the reintroduction of oxygen to the body; (v) up-regulating genes that aid anoxia survival, and most importantly, (vi) a strong reduction of metabolic rate (Storey, 2004a). Metabolic rate depression is essential due to the large reduction in ATP production by fermentative pathways in comparison to oxidative metabolism (i.e. conversion of glucose to lactate produces $2 \mathrm{~mol} \mathrm{ATP} / \mathrm{mol}$ glucose, whereas conversion of glucose to $\mathrm{CO}_{2}$ and $\mathrm{H}_{2} \mathrm{O}$ produces $36 \mathrm{~mol} \mathrm{ATP} / \mathrm{mol}$ glucose). With this reduction in ATP output during anoxia, there is typically a coordinated reduction in ATP consuming processes, such as protein synthesis, protein degradation, gluconeogenesis, urea synthesis, and ion motive ATPases (Hochachka et al., 1996). 
Freshwater turtles from the Trachemys and Chrysemys genera are among the few vertebrate species that are capable of surviving extended periods of anoxia. The redeared slider, Trachemys scripta elegans, is a major model for studies of anoxia tolerance, and is the animal investigated in this study. During the winter these turtles can remain submerged in cold water for 3-4 months to escape freezing air temperatures. Red-eared sliders have very limited or no capacity to take up oxygen from water, unlike some other freshwater turtles, and thus alter their metabolism to become facultative anaerobes (Storey, 2004a). Specifically, freshwater turtles typically suppress their metabolic rate to approximately $10-20 \%$ of the corresponding aerobic rate at the same temperature in order to survive anoxia (Herbert and Jackson, 1985). During anoxia these turtles rely completely on glycolysis for energy and have not developed alternative fermentive pathways for increased ATP production as is seen in many other anoxia tolerant species (Storey and Storey, 1990). Instead, the turtles have adapted to withstand very high lactic acid levels (the end product of anaerobic glycolysis) by buffering against $\mathrm{pH}$ change as well as storing lactic acid in their shells to prevent extreme acidosis (Jackson et al., 2000).

As stated above, freshwater turtles generate ATP solely through glycolysis during anoxia. The inability of the Krebs cycle and the electron transport chain (ETC) to participate in energy production suggests that it may be necessary to regulate the enzymes that feed these processes during anoxia. Although few studies have been carried out involving those enzymes that shuttle carbon skeletons into the Krebs cycle, the present study investigates the role of glutamate dehydrogenase (GDH) during anoxia in the freshwater turtle. 
This chapter analyzes liver GDH purified from the freshwater turtle, T. s. elegans, comparing and contrasting forward and reverse reaction kinetics for the enzyme from control and $20 \mathrm{~h}$ anoxic animals, as well as responses of each enzyme form to cellular metabolites, changes in $\mathrm{pH}$, changes in temperature, and reversible phosphorylation.

\section{Materials and Methods}

Animals and Chemicals

Adult red-eared slider turtles, T. s. elegans, were obtained from Wards Natural Science, Mississauga, Ontario and maintained in tanks of dechlorinated water at $7^{\circ} \mathrm{C}$ for three weeks prior to experimentation. Turtles had access to deep water, a small platform, and food in the form of trout pellets, lettuce and egg shells. Control (normoxic) turtles were sampled directly from the tanks, whereas anoxia was imposed by submerging turtles in sealed tanks filled with deoxygenated water (previously bubbled with $100 \%$ nitrogen gas) at $4^{\circ} \mathrm{C}$. A wire mesh placed below the surface of the water prevented the turtles from surfacing. Turtles used in the present study were sampled after $20 \mathrm{~h}$ of anoxic submergence. All turtles were killed by decapitation, via a protocol approved by the university Animal Care Committee and meeting the guidelines of the Canadian Council on Animal Care. Organs were quickly dissected out, frozen in liquid nitrogen and transferred to a $-80^{\circ} \mathrm{C}$ freezer for storage.

The chemicals used for this study came from the same manufacturers as identified in Chapter 2 with the following addition: Blue-agarose was purchased from Sigma Chemical Company. 


\section{Sample Preparation}

Frozen liver tissue samples were homogenized and centrifuged as described in Chapter 2 and the supernatant was stored on ice. The homogenization buffer used previously will be referred to here as buffer A.

\section{Purification of $G D H$}

A $1.7 \mathrm{~mL}$ aliquot of tissue extract (prepared in buffer A) was applied to a Blueagarose column ( $2.5 \times 1.8 \mathrm{~cm} \mathrm{~h} \mathrm{x} \mathrm{d} \mathrm{equilibrated} \mathrm{in} \mathrm{buffer} \mathrm{A})$. The column was then rinsed with $10 \mathrm{~mL}$ of homogenization buffer $\mathrm{A}$ to remove unbound material. Turtle liver GDH was then eluted by a linear salt gradient of $0-0.5 \mathrm{M} \mathrm{KCl}$. Fractions of $\sim 750 \mu \mathrm{L}$ were collected by a Gilson FC203B Fraction Collector. GDH activity was determined by assaying each fraction under optimal conditions (as determined for the crude extract in the forward direction). The five most active fractions were then pooled and held on ice until a GTP-agarose column was prepared.

The GTP-agarose column $(2.8 \times 1.2 \mathrm{~cm} \mathrm{~h} \mathrm{x} \mathrm{d})$ was equilibrated in buffer $\mathrm{A}$ and a $2 \mathrm{~mL}$ aliquot of the pooled eluant from Blue-agarose was then applied. The column was washed with $10 \mathrm{~mL}$ of buffer A to remove any unbound material, and then GDH was eluted with a 0-1 $\mathrm{M}$ linear $\mathrm{KCl}$ gradient. Fractions were assayed using the optimal conditions for GDH, and the five most active fractions were pooled and held on ice until use in kinetic assays.

The purity of the pooled GDH derived from the GTP-agarose column was tested by running a $10 \%$ SDS PAGE gel stained with Coomassie blue. The protein ladder (see Figure 3.1) separated in this gel was used to construct a standard curve from which the 
GDH subunit molecular weight was determined.

GDH Assay

Optimal assay conditions for purified turtle liver GDH in the forward direction were $50 \mathrm{mM}$ L-glutamate, $1.5 \mathrm{mM} \mathrm{NAD}{ }^{+}, 0.5 \mathrm{mM} \mathrm{Mg-ADP}$, and $50 \mathrm{mM}$ Tris- $\mathrm{HCl}$ buffer, pH 8.0 in a total volume of $200 \mu \mathrm{L}$ with $25 \mu \mathrm{L}$ of purified extract used per assay. However, without Mg-ADP, the optimum concentration of L-glutamate was $15 \mathrm{mM}$. In the reverse reaction, the optimal concentrations of substrates were $1 \mathrm{mM} \alpha$-ketoglutarate, $100 \mathrm{mM} \mathrm{NH}_{4} \mathrm{Cl}, 0.1 \mathrm{mM}$ NADH, $0.5 \mathrm{mM} \mathrm{Mg-ADP}, 50 \mathrm{mM}$ HEPES buffer, $\mathrm{pH} 7.2$ with $10 \mu \mathrm{L}$ of purified liver extract used in each assay.

In all cases GDH activity was assayed with a Thermo Labsystems Multiskan spectrophotometer $\left(A_{340}\right)$ and kinetic parameters (e.g. $V_{\max }, K_{m}, K_{a}$, and $I_{50}$ ) were calculated as in Chapter 2. Activity was measured as U/mg soluble protein. Protein concentration in extracts was determined as described in Chapter 2.

\section{Effectors of GDH}

The effect of various metabolites on the forward reaction of GDH was assessed by measuring GDH activity at suboptimal concentrations of all substrates: $2 \mathrm{mM} \mathrm{L-}$ glutamate and $0.5 \mathrm{mM} \mathrm{NAD}^{+}$. The effect GTP, ATP, and ADP on GDH activity was determined by varying the concentration of these effector molecules in the assay wells and calculating $K_{a}$ and $I_{50}$ using the Kinetics v.3.5.1 program (Brooks, 1994). For the reverse reaction, the effect of ADP on GDH activity was assessed with suboptimal substrate concentrations: $0.2 \mathrm{mM} \alpha$-ketoglutarate, $0.05 \mathrm{mM} \mathrm{NADH}$, and $40 \mathrm{mM} \mathrm{NH} 4 \mathrm{Cl}$. 
ProQ Diamond Phosphoprotein Staining

Purified liver GDH from control and $20 \mathrm{~h}$ anoxic turtles were assessed by the ProQ Diamond phosphoprotein staining (Invitrogen, Eugene, OR) as described in Chapter 2. The only modification was that the gel was not left in fixing solution overnight, but was only washed with fixing solution twice and then washed with water the requisite number of times.

Phospho-dephospho Incubations of Purified GDH

GDH purified from control liver was incubated with commercial alkaline or acid phosphatases in an attempt to stimulate dephosphorylation of GDH. Similarly, purified $\mathrm{GDH}$ from $20 \mathrm{~h}$ anoxic turtles was incubated with commercial protein kinase $\mathrm{A}$ to stimulate phosphorylation of GDH. Tissue extracts were prepared in buffer A and incubated for $\sim 24$ hours at $4^{\circ} \mathrm{C}$ in a $1: 2$ ratio with the incubation solution. All incubations contained a basic incubation buffer (50 mM HEPES, 10\% v:v glycerol, 10 $\mathrm{mM} \beta$-mercaptoethanol, $\mathrm{pH}, 7.2)$ with additions as follows.

(A) Control Incubations (also denoted as STOP): incubation buffer plus $2.5 \mathrm{mM}$ EDTA, $2.5 \mathrm{mM}$ EGTA and $25 \mathrm{mM} \beta-$ GP.

(B) Alkaline or Acid Phosphatases: incubation buffer plus $7.5 \mathrm{mM} \mathrm{MgCl} 2,3.75 \mathrm{mM}$ EDTA with either $30 \mathrm{U}$ of alkaline phosphatase or $0.6 \mathrm{U}$ of acid phosphatase.

(C) Protein Kinase A: incubation buffer plus $3.75 \mathrm{mM} \mathrm{Mg} \cdot \mathrm{ATP}, 22.5 \mathrm{mM} \beta-\mathrm{GP}, 0.75$ mM cAMP, and $0.4 \mathrm{pU}$ of PKA holoenzyme.

Following incubation, the $\mathrm{K}_{\mathrm{m}} \alpha$-ketoglutarate in the absence of ADP was determined. 
Effect of $p H$ on the $V_{\max }$ of Forward and Reverse Reactions of Purified GDH

Purified GDH was assayed in both the forward and reverse directions (under optimal assay conditions) at $\mathrm{pH} 6.6$ and $\mathrm{pH}$ 7.4. All of these reactions were done with and without $0.5 \mathrm{mM}$ ADP. $\mathrm{V}_{\max }$ ratios were calculated by dividing the activity of the forward reaction by the activity of the reverse reaction.

\section{GDH Arrhenius Plots}

GDH response to temperature was analyzed using Arrhenius plots to determine activation energy $\left(\mathrm{E}_{\mathrm{a}}\right)$. Crude liver GDH $\mathrm{V}_{\max }$ in the forward direction (the substrate concentrations remained the same as with the purified extracts) was measured at $5^{\circ} \mathrm{C}$, $9^{\circ} \mathrm{C}, 12^{\circ} \mathrm{C}, 15^{\circ} \mathrm{C}, 23^{\circ} \mathrm{C}$, and $30^{\circ} \mathrm{C}$, as described in Chapter 2 .

\section{Results:}

\section{GDH Purification and Molecular Weight Determination}

The purification scheme for liver GDH from control turtles is depicted in Table

3.1. Using a combination of two affinity columns (Blue-agarose and GTP-agarose) GDH was purified 17 -fold with an overall yield of $41 \%$. The specific activity of the final purified control enzyme was $0.157 \mathrm{U} / \mathrm{mg}$ (forward direction). The effectiveness of each step in the purification process was assessed by SDS-polyacrylamide gel electrophoresis with Coomassie blue staining (Fig. 3.1). After purification of GDH by GTP-agarose a single band was seen on the gel, which indicates that the enzyme was purified to homogeneity. The molecular weight of the monomeric subunit of control turtle liver 
GDH was determined to be $\sim 67 \mathrm{kDa}$ as assessed from a standard curve constructed using a protein ladder (not shown). The same purification procedure was used to purify GDH from liver of $20 \mathrm{~h}$ anoxia-exposed turtles. Purified turtle liver GDH remained stable at $4^{\circ} \mathrm{C}$ for more than $24 \mathrm{~h}$, but after $48 \mathrm{~h}$ approximately $40 \%$ of the activity was lost.

\section{GDH Kinetics}

The optimum $\mathrm{pH}$ for purified GDH varied depending on the direction of the reaction. The forward reaction displayed a broad activity peak with $\sim 90 \%$ of the activity being retained from $\mathrm{pH} 8-10$. Activity dropped below $50 \%$ of the maximum activity below $\mathrm{pH} 7$ and above $\mathrm{pH}$ 10.5. For the reverse reaction, the activity peak was also very broad, and $\sim 90 \%$ of the maximal activity was retained from $\mathrm{pH} 7.0-9.5$. Above $\mathrm{pH} 10.5$, GDH activity dropped below $50 \%$ of the maximal activity.

GDH was purified from liver of both aerobic control and anoxic turtles and kinetic properties of the purified enzyme were assessed in both the forward (glutamateutilizing) and reverse (glutamate-synthesizing) directions. In the forward direction, several kinetic parameters that changed significantly $(\mathrm{p}<0.05)$ between control and $20 \mathrm{~h}$ anoxic turtles. The $\mathrm{K}_{\mathrm{m}}$ glutamate was $\sim 69 \%$ higher for the anoxic enzyme when compared to control GDH (Table 3.2). Similarly, the $\mathrm{K}_{\mathrm{m}}$ glutamate in the presence of 0.5 mM ADP was $\sim 45 \%$ higher for anoxic, compared with control GDH. For both control and $20 \mathrm{~h}$ anoxic $\mathrm{GDH}$ the $\mathrm{K}_{\mathrm{m}}$ glutamate increased significantly in the presence of ADP as contrasted with $\mathrm{K}_{\mathrm{m}}$ glutamate without ADP.

Unlike the situation with glutamate, there was no significant difference between control and anoxic $\mathrm{K}_{\mathrm{m}} \mathrm{NAD}^{+}$for purified GDH. However, in the presence of $0.5 \mathrm{mM}$ 
ADP, GDH from anoxic turtles displayed a significantly lower $(\mathrm{p}<0.05) \mathrm{K}_{\mathrm{m}} \mathrm{NAD}^{+}$as compared to the control value (Table 3.2). For purified control GDH, the $\mathrm{K}_{\mathrm{m}} \mathrm{NAD}^{+}$ remained the same with or without ADP but for anoxic GDH the $\mathrm{K}_{\mathrm{m}}$ decreased by $54 \%$ $(\mathrm{p}<0.05)$ in the presence of ADP.

The maximal activity of purified GDH in the forward direction differed significantly between control and $20 \mathrm{~h}$ anoxic states in both the presence and absence of ADP. In the absence of ADP, anoxic GDH exhibited a $V_{\max }$ that was $39 \%$ lower $(\mathrm{p}<0.05)$ than the corresponding control $\mathrm{V}_{\max }$. Similarly, in the presence of $0.5 \mathrm{mM}$ ADP the anoxic GDH maximal activity was $42 \%$ lower than the control $\mathrm{V}_{\max }$ (Table 3.2). Furthermore, the $\mathrm{V}_{\max }$ increased by $70 \%$ and $63 \%$ for control and $20 \mathrm{~h}$ anoxic GDH, respectively, in the presence of $0.5 \mathrm{mM} \mathrm{ADP}$ when compared to assays without ADP.

Similar to GDH kinetics in the forward direction, several kinetic parameters changed significantly in the reverse (glutamate-synthesizing) direction between normoxic and anoxic conditions. For instance, the $\mathrm{K}_{\mathrm{m}} \alpha$-ketoglutarate of purified anoxic GDH was $45 \%$ lower $(\mathrm{p}<0.05)$ in comparison to the same value for aerobic control GDH (Table 3.3). Interestingly, the $K_{m} \alpha$-ketoglutarate increased significantly ( $p<0.05$ ) upon the addition of $0.5 \mathrm{mM}$ ADP, which is similar to the situation observed with $\mathrm{K}_{\mathrm{m}}$ glutamate. GDH substrate affinity for $\mathrm{NH}_{4}{ }^{+}$did not change between control and anoxic conditions without $\mathrm{ADP}$, however, in the presence of $0.5 \mathrm{mM}$ ADP the $\mathrm{K}_{\mathrm{m}} \mathrm{NH}_{4}{ }^{+}$was $\sim 38 \%$ higher for anoxic GDH as compared to control. The $\mathrm{K}_{\mathrm{m}} \mathrm{NH}_{4}{ }^{+}$in the presence of ADP was significantly lower $(\mathrm{p}<0.05)$ for control and anoxic GDH in relation to the corresponding $\mathrm{K}_{\mathrm{m}}$ values in the absence of ADP.

$\mathrm{V}_{\max }$ of the reverse reaction of anoxic GDH was $70 \%$ lower than the value for 
control GDH. Although the activity of both control and $20 \mathrm{~h}$ anoxic GDH increased significantly in the presence of ADP, the control $V_{\max }$ increased by only $33 \%$ whereas the anoxic $\mathrm{V}_{\max }$ increased by $77 \%$ (Table 3.3). Furthermore, the maximum activity for the reverse reaction (without ADP) of purified GDH was $\sim 10$ fold and $\sim 5$ fold higher in comparison to the forward reaction (without ADP) for control and $20 \mathrm{~h}$ anoxic conditions respectively (Table 3.2 and 3.3). In the presence of ADP, the reverse reaction was $\sim 8$ fold and $\sim 5$ fold higher as compared to the forward reaction $V_{\max }$ of control and $20 \mathrm{~h}$ anoxic GDH, respectively.

\section{Effect of Cellular Metabolites on GDH Activity}

The effect of various cellular metabolites on GDH activity (at suboptimal substrate concentrations) was determined for both the forward and reverse reactions of GDH. In the forward direction, ADP acted as an activator of control and $20 \mathrm{~h}$ anoxic GDH. However, both the $K_{\mathfrak{a}}$ and the fold activation of the enzyme were not significantly different between the two conditions (Table 3.2). ATP had very little effect on GDH activity up to $10 \mathrm{mM}$, whereas GTP strongly inhibited liver GDH from both control and $20 \mathrm{~h}$ anoxic turtles. Anoxic GDH was significantly $(\mathrm{p}<0.05)$ more sensitive to GTP inhibition when compared to the control condition ( $\sim 80 \%$ drop in $\mathrm{I}_{50}$ during anoxia).

For the reverse reaction, the $\mathrm{K}_{\mathrm{a}} \mathrm{ADP}$ of GDH increased significantly $(\mathrm{p}<0.05)$ during anoxia (Table 3.3).

\section{Reversible Phosphorylation of GDH}

Stable kinetic changes between an enzyme from two states is often the result of 
posttranslational modification and most commonly reversible phosphorylation. To determine if this mechanism was responsible for the kinetic changes seen between GDH from control and $20 \mathrm{~h}$ anoxic turtles, purified enzyme extracts were run on an SDSPAGE gel and stained with ProQ Diamond phosphoprotein stain. Since GDH was purified to homogeneity the enzyme was easily identified as the only band on the gel. This stain showed a nearly $40 \%$ decrease in the relative band intensity $(\mathrm{p}<0.05)$ for the purified anoxic GDH when compared to the control condition (Fig. 3.2).

To further investigate the possibility of phosphorylation as a regulatory mechanism for turtle GDH during anoxia, purified GDH from control turtles was incubated with commercial alkaline or acid phosphatases whereas purified anoxic GDH was incubated with ATP, cAMP and commercial PKA. $\mathrm{K}_{\mathrm{m}} \alpha$-ketoglutarate values were then assessed. Incubations without any added phosphatases or kinases (denoted STOP) showed $K_{m} \alpha$-ketoglutarate values comparable to those seen for control and anoxic GDH, respectively, in Table 3.3. Incubation of purified control GDH with commercial alkaline or acid phosphatase decreased the $\mathrm{K}_{\mathrm{m}} \alpha$-ketoglutarate by $\sim 46 \%(\mathrm{p}<0.05)$ in comparison to the STOP condition (Fig. 3.3A). Incubation of $20 \mathrm{~h}$ anoxic GDH with commercial PKA did not change $\mathrm{K}_{\mathrm{m}} \alpha$-ketoglutarate (Fig. 3.3B).

\section{GDH Arrhenius Plots}

The maximum activity of crude GDH from aerobic and anoxic turtles was measured in the forward direction at various temperatures to determine activation energy. The activation energies, derived from Arrhenius plots, were not significantly different between control $(26 \pm 3 \mathrm{KJ} / \mathrm{mol})$ and anoxic $(20 \pm 3 \mathrm{KJ} / \mathrm{mol})$ conditions (Fig. 3.4). 


\section{Effect of $p H$ on GDH Activity}

The data presented above was gathered for assays conducted at the optimal $\mathrm{pH}$ for the forward and reverse reactions. However, a key consequence of anoxia in all systems is a gradual decrease in intracellular $\mathrm{pH}$ as anoxia is prolonged and acidic end products accumulate. Anoxia tolerant animals use mechanisms to minimize the $\mathrm{pH}$ decrease but it still occurs. Therefore, it is important to understand how enzyme function changes under the high versus low $\mathrm{pH}$ conditions of the aerobic versus anoxic states. To analyze this, the maximal velocities of both the forward and reverse reactions of purified aerobic and anoxic GDH were measured at two $\mathrm{pH}$ values: $\mathrm{pH} 7.4$ representing normoxic conditions and pH 6.6 representing anoxic conditions. Ratios of activity in the forward vs reverse directions were then calculated for $\mathrm{V}_{\max }$ values measured in the absence versus presence of ADP. As is clear from Table 3.4, regardless of the $\mathrm{pH}$, the maximal velocity in the reverse direction for purified GDH from normoxic or anoxic conditions is greater than the $\mathrm{V}_{\max }$ in the forward direction. For instance, activities measured at $\mathrm{pH} 7.4$ showed a $\sim 10$-fold higher reverse reaction velocity as compared to the velocity in the forward direction. However, the ratio of forward versus reverse reaction maximal velocities between control and anoxic GDH does change with $\mathrm{pH}$. At a normoxic physiological $\mathrm{pH}$ the $V_{\max }$ ratios are essentially the same for control and anoxic GDH. However, at a more acidic $\mathrm{pH}$ typically found during anoxia, anoxic GDH tends to favour the reverse reaction more than control GDH at the same $\mathrm{pH}$; the difference in ratios is significant $(\mathrm{p}<0.05)$. Interestingly, control GDH maintained a similar $\mathrm{V}_{\max }$ ratio when assayed under normoxic, or anoxic $\mathrm{pH}$ conditions. Conversely, anoxic GDH $\mathrm{V}_{\max }$ ratios were more 
sensitive to $\mathrm{pH}$ changes, and favoured the reverse reaction as the $\mathrm{pH}$ decreased. 
Table 3.1. Purification of GDH from the liver of control $T$.s. elegans

\begin{tabular}{|c|c|c|c|c|c|}
\hline $\begin{array}{c}\text { Purification } \\
\text { Step }\end{array}$ & $\begin{array}{c}\text { Total } \\
\text { Protein } \\
\text { (mg) }\end{array}$ & $\begin{array}{c}\text { Total } \\
\text { Activity } \\
\text { (U) }\end{array}$ & $\begin{array}{c}\text { Specific } \\
\text { Activity } \\
\text { (U/mg) }\end{array}$ & $\begin{array}{c}\text { Fold } \\
\text { Purification }\end{array}$ & \% Yield \\
\hline Supernatant & 0.30 & 0.0028 & 0.0093 & - & 100 \\
\hline Blue-Agarose & 0.0074 & 0.0011 & 0.147 & 16 & 78 \\
\hline GTP-Agarose & 0.0039 & 0.00061 & 0.157 & 17 & 41 \\
\hline
\end{tabular}


Figure 3.1. SDS-PAGE with Coomassie blue staining of samples taken at every step in the purification of GDH from the liver of control T. s. elegans. Lanes represent: (1) Crude liver extract, (2) pooled GDH fractions after elution from a blue-agarose column, (3) pooled GDH from a GTP-agarose column, and (4) Biorad Kaleidoscope molecular weight standards $(3 \mu \mathrm{L})$. Molecular weight standards from top to bottom are phosphorylase B, $104 \mathrm{kDa}$; bovine serum albumin, $97 \mathrm{kDa}$; ovalbumin, $50 \mathrm{kDa}$; carbonic anhydrase, $37 \mathrm{kDa}$; and soybean trypsin inhibitor, $29 \mathrm{kDa}$. 
Figure 3.1

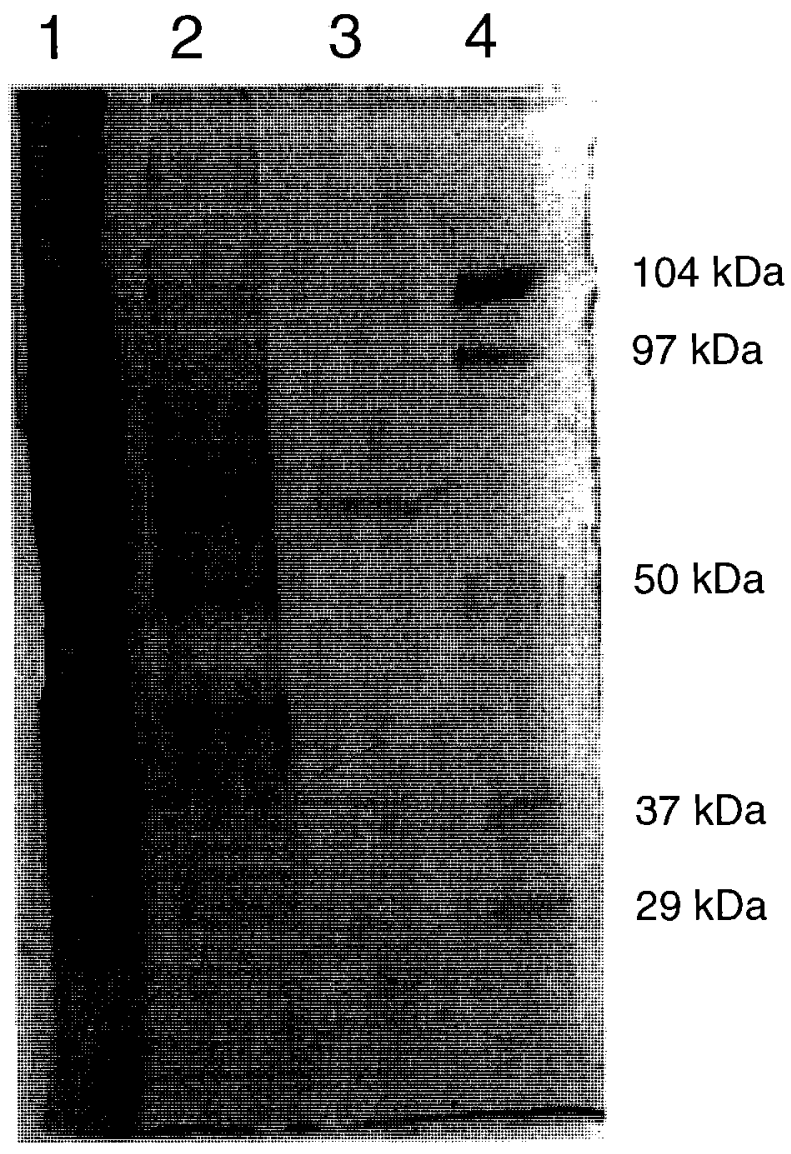


Table 3.2. Comparison of the kinetic parameters of purified liver GDH from control and $20 \mathrm{~h}$ anoxic turtles. GDH was assayed in the glutamate-utilizing (forward) direction using $\mathrm{NAD}^{+}$as the cofactor. Data are means $\pm \mathrm{SEM}, \mathrm{n} \geq 3$ independent determinations on separate preparations of purified enzyme. $\mathrm{K}_{\mathrm{m}}$ values were determined at optimal cosubstrate concentrations. $\mathrm{K}_{\mathrm{a}}$ and $\mathrm{I}_{50}$ values were determined at suboptimal substrate concentrations (defined in Materials and Methods). ${ }^{\text {a }}$-Significantly different from the corresponding control value using the Student's t-test, $\mathrm{P}<0.05 .{ }^{\mathrm{b}}$ - Significantly different from the corresponding value without $\mathrm{ADP}, \mathrm{P}<0.05$.

\begin{tabular}{|c|c|c|}
\hline & Control & $20 \mathrm{~h}$ Anoxic \\
\hline $\mathrm{K}_{\mathrm{m}}$ Glutamate $(\mathrm{mM})$ & $0.71 \pm 0.05$ & $1.20 \pm 0.07^{\mathrm{a}}$ \\
\hline $\mathrm{K}_{\mathrm{m}}$ Glutamate with $0.5 \mathrm{mM}$ ADP $(\mathrm{mM})$ & $1.73 \pm 0.08^{b}$ & $2.5 \pm 0.1^{\mathrm{ab}}$ \\
\hline $\mathrm{K}_{\mathrm{m}} \mathrm{NAD}^{+}(\mathrm{mM})$ & $0.49 \pm 0.03$ & $0.50 \pm 0.04$ \\
\hline $\mathrm{K}_{\mathrm{m}} \mathrm{NAD}^{+}$with $0.5 \mathrm{mM}$ ADP (mM) & $0.45 \pm 0.03$ & $0.23 \pm 0.02^{\mathrm{ab}}$ \\
\hline $\mathrm{K}_{\mathrm{a}} \mathrm{ADP}(\mu \mathrm{M})$ & $28 \pm 7$ & $37 \pm 5$ \\
\hline [Fold Activation] & {$[1.6 \pm 0.1]$} & {$[1.67 \pm 0.05]$} \\
\hline $\mathrm{I}_{50} \mathrm{GTP}(\mu \mathrm{M})$ & $0.59 \pm 0.07$ & $0.109 \pm 0.006^{\mathrm{a}}$ \\
\hline $\mathrm{V}_{\max }(\mathrm{U} / \mathrm{mg})$ & $0.215 \pm 0.005$ & $0.131 \pm 0.004^{\mathrm{a}}$ \\
\hline $\mathrm{V}_{\max }$ with $0.5 \mathrm{mM}$ ADP (U/mg) & $0.365 \pm 0.008^{b}$ & $0.213 \pm 0.005^{\mathrm{ab}}$ \\
\hline
\end{tabular}


Table 3.3 Comparison of the kinetic parameters for purified liver GDH from control and $20 \mathrm{~h}$ anoxic turtles. GDH was assayed in the glutamate-producing (reverse) direction using NADH as the cofactor. Data are means $\pm S E M, n \geq 3$ independent determinations on separate preparations of purified enzyme. $\mathrm{K}_{\mathrm{m}}$ values were determined at optimal cosubstrate concentrations. $\mathrm{K}_{\mathrm{a}}$ values were determined at suboptimal substrate concentrations (defined in Materials and Methods). "-Significantly different from corresponding control value using the Student's t-test, $\mathrm{P}<0.05 .{ }^{\mathrm{b}}$-Significantly different from the corresponding value without $\mathrm{ADP}, \mathrm{P}<0.05$.

\begin{tabular}{|c|c|c|}
\hline & Control & 20 h Anoxic \\
\hline $\mathrm{K}_{\mathrm{m}} \alpha$-ketoglutarate $(\mathrm{mM})$ & $0.128 \pm 0.005$ & $0.070 \pm 0.002^{\mathrm{a}}$ \\
\hline $\mathrm{K}_{\mathrm{m}} \alpha$-ketoglutarate with 0.5 mM ADP (mM) & $0.24 \pm 0.01^{\mathrm{b}}$ & $0.27 \pm 0.05^{\mathrm{b}}$ \\
\hline $\mathrm{K}_{\mathrm{m}} \mathrm{NH}_{4}{ }^{+}(\mathrm{mM})$ & $39 \pm 1$ & $44 \pm 3$ \\
\hline $\mathrm{K}_{\mathrm{m}} \mathrm{NH}_{4}{ }^{+}$with 0.5 mM ADP $(\mathrm{mM})$ & $18 \pm 2^{\mathrm{b}}$ & $29 \pm 3^{\mathrm{ab}}$ \\
\hline $\mathrm{K}_{\mathrm{a}}$ ADP $(\mu \mathrm{M})$ & $17 \pm 4$ & $40 \pm 5^{\mathrm{a}}$ \\
{$[$ Fold Activation] } & {$[1.77 \pm 0.04]$} & {$[1.84 \pm 0.06]$} \\
\hline $\mathrm{V}_{\max }(\mathrm{U} / \mathrm{mg})$ & $2.10 \pm 0.03$ & $0.62 \pm 0.01^{\mathrm{a}}$ \\
\hline $\mathrm{V}_{\max }$ with $0.5 \mathrm{mM} \mathrm{ADP}(\mathrm{U} / \mathrm{mg})$ & $2.80 \pm 0.04^{\mathrm{b}}$ & $1.10 \pm 0.02^{\mathrm{ab}}$ \\
\hline
\end{tabular}


Figure 3.2. The relative band intensity of purified liver GDH from control and $20 \mathrm{~h}$ anoxic $T$. s. elegans as assessed on a SDS-PAGE gel stained with ProQ Diamond phosphoprotein stain. Data are means $\pm \mathrm{SEM}, \mathrm{n}=3$ independent determinations on separate preparations of enzyme. ${ }^{*}$ - Significantly different from controls using the Student's t-test $(\mathrm{p}<0.05)$. 
Figure 3.2

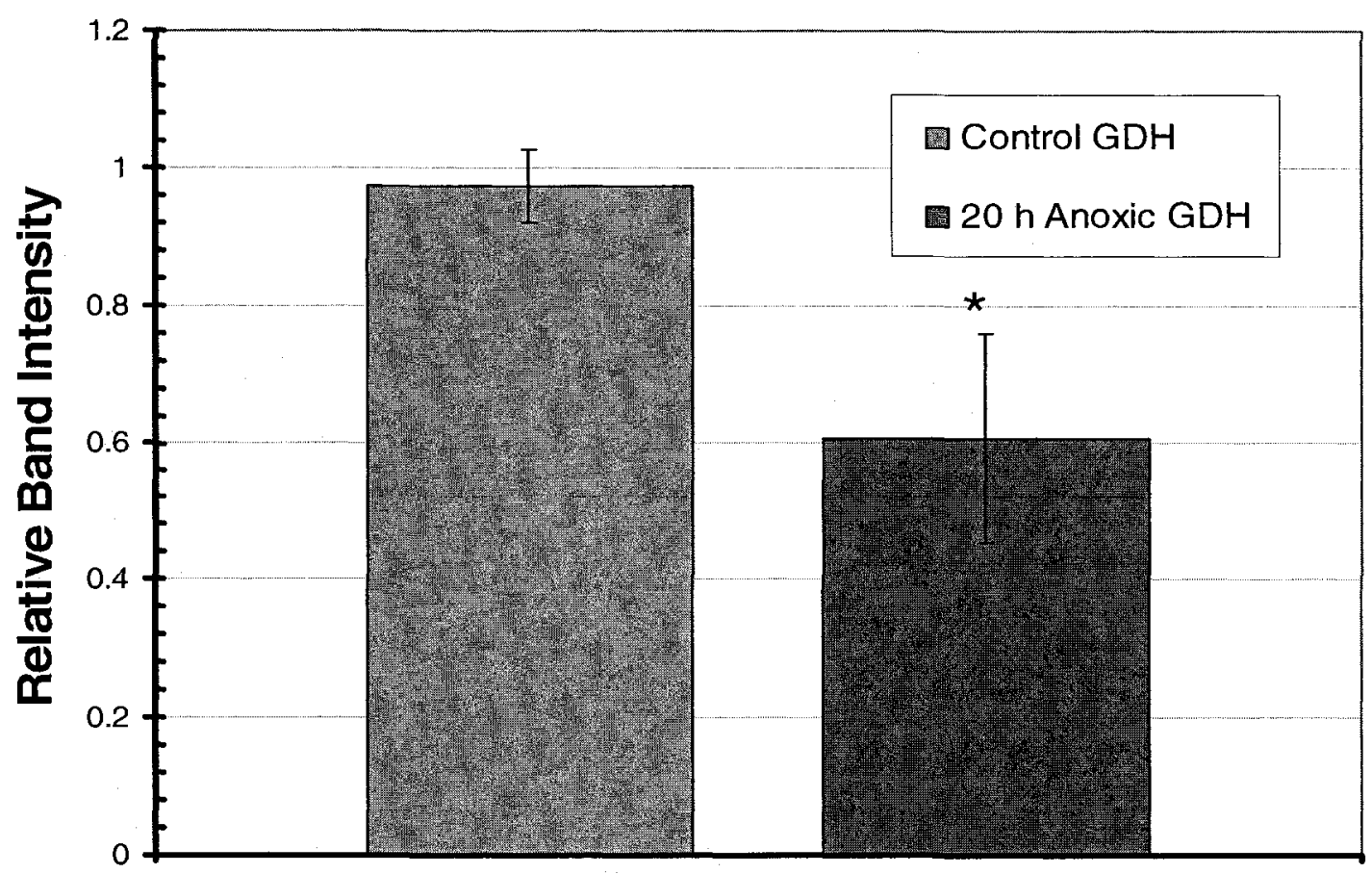


Figure 3.3. Effects of in vitro incubations to stimulate (A) the activities of exogenous alkaline and acid phosphatases, and (B) exogenous PKA on $\mathrm{K}_{\mathrm{m}} \alpha$-ketoglutarate for liver GDH from control (only the phosphatases) and $20 \mathrm{~h}$ anoxic (only PKA) T. s. elegans. Purified extracts were incubated for $\sim 24 \mathrm{~h}$ before assay at $23^{\circ} \mathrm{C}$. Data are means $\pm \mathrm{SEM}$, $\mathrm{n}=3$ independent determinations. ${ }^{*}$-Significantly different from the corresponding STOP value via the Dunnett's test, $\mathrm{p}<0.05$. 
Figure 3.3

A

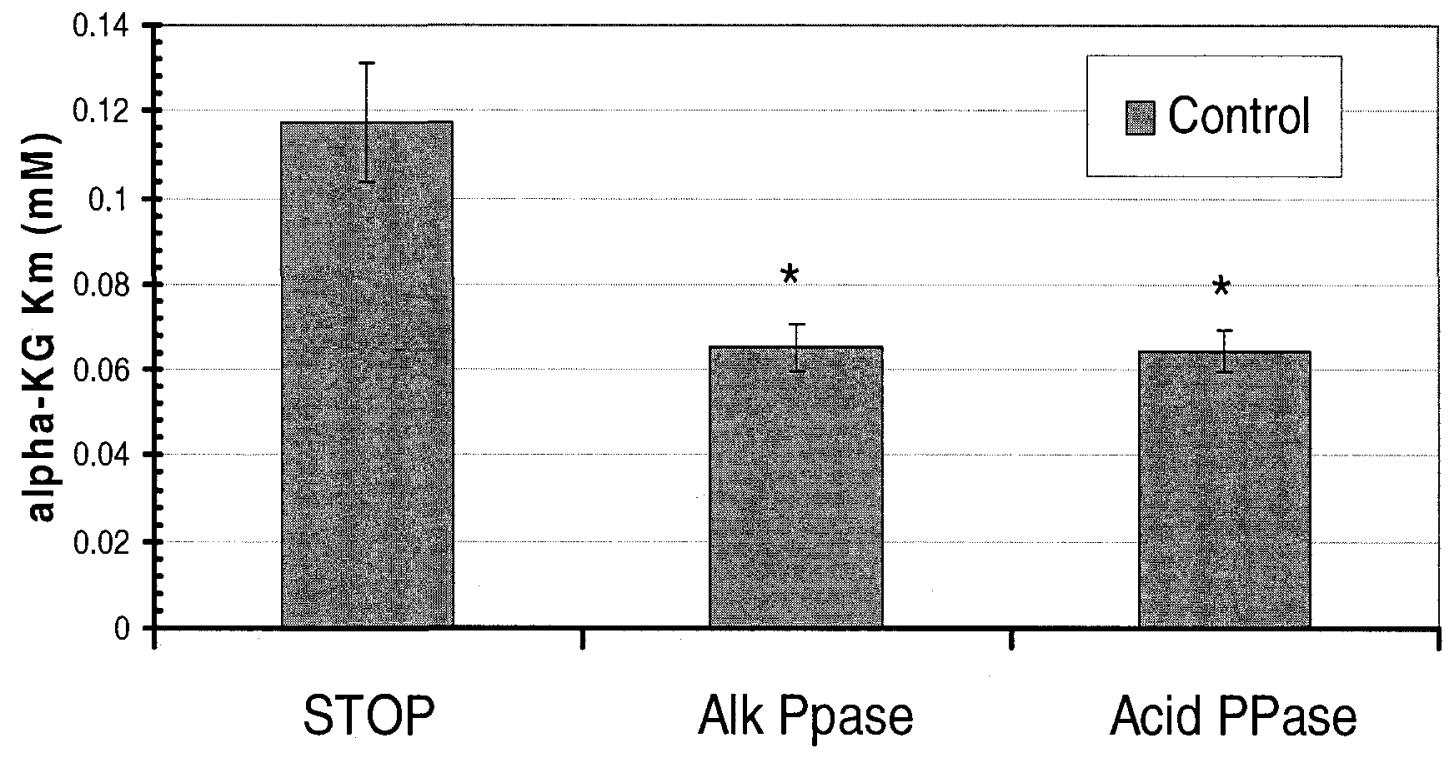

B

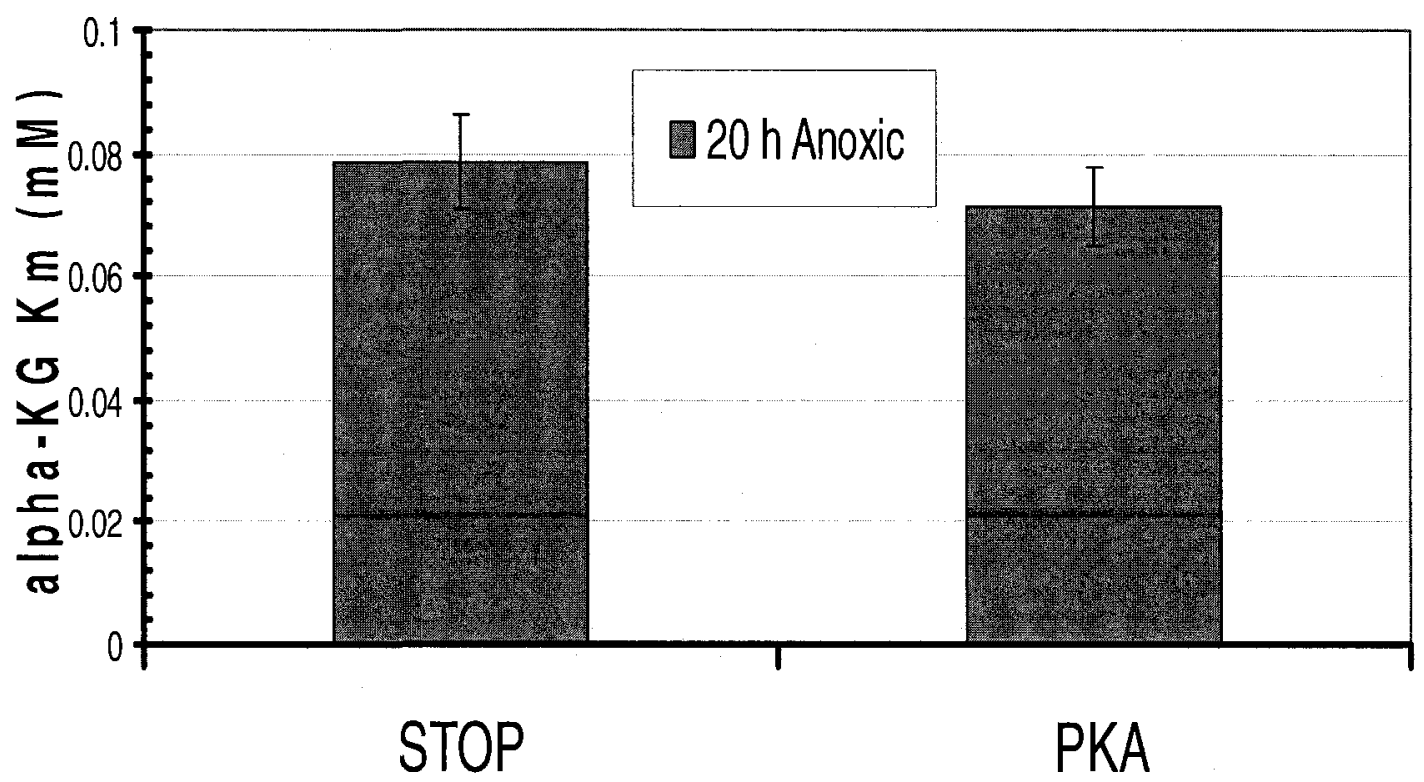


Figure 3.4. Arrhenius plots for liver GDH from control and $20 \mathrm{~h}$ anoxic T. s. elegans. Data and activation energies $\left(E_{a}\right)$ are means \pm SEM, $n=3$ determinations of separate preparations of enzyme. 
Figure 3.4

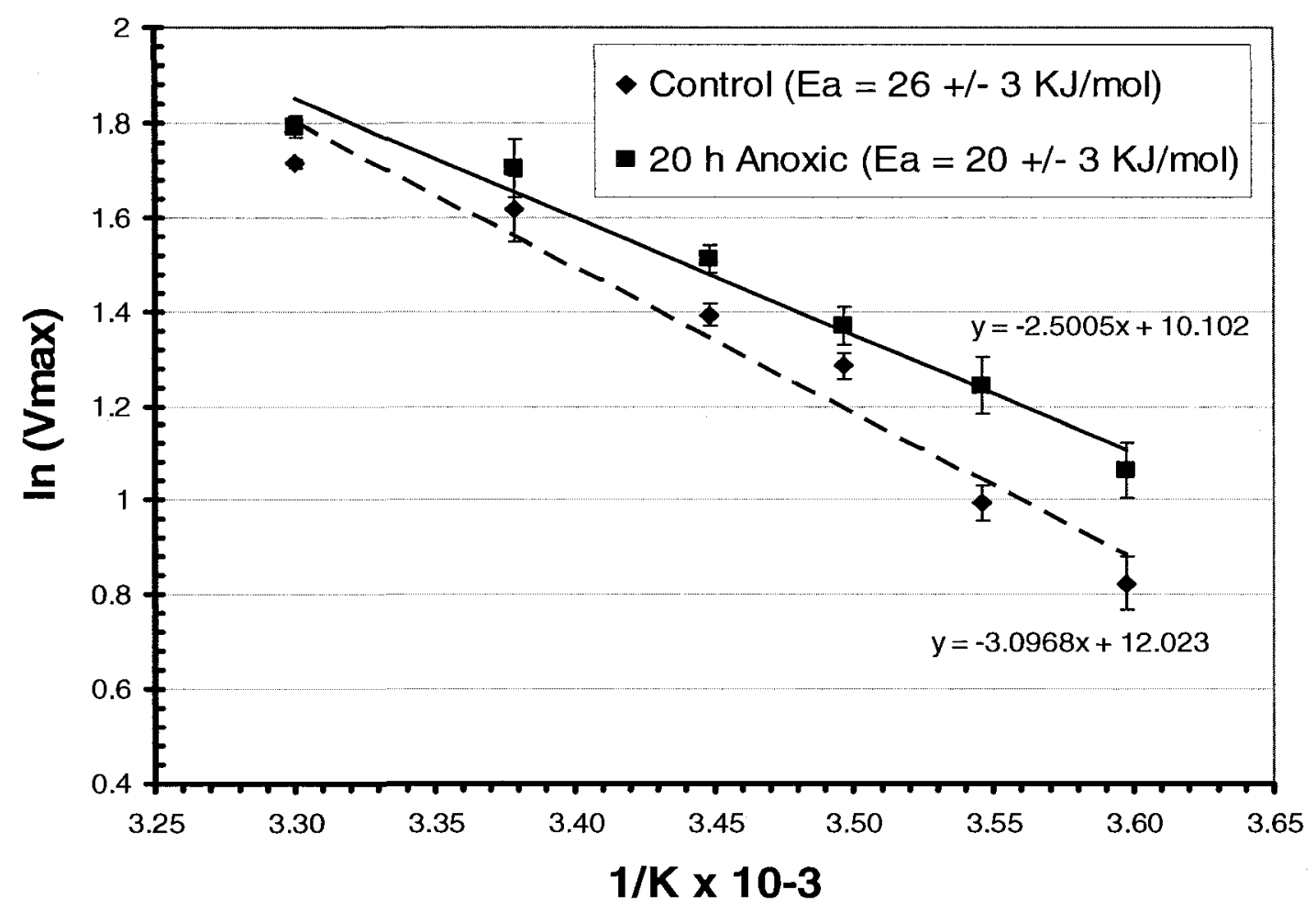


5

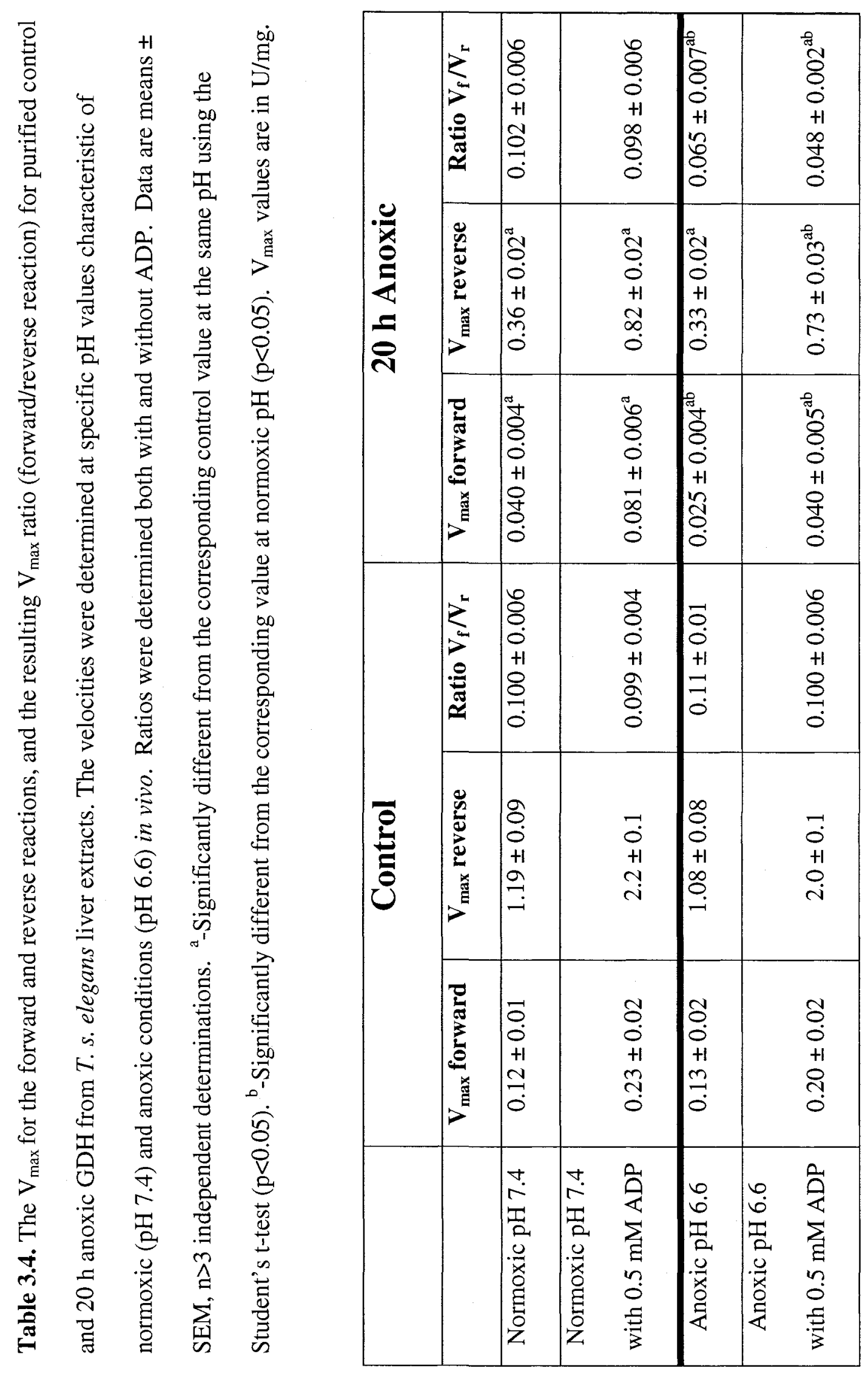




\section{Discussion:}

Dramatic fluctuations in environmental oxygen levels have forced some organisms to develop the capacity for long-term anoxia tolerance. Adaptations to decreased oxygen availability include the expression and suppression of various genes, accumulation of fermentable fuels, alternative routes for anaerobic metabolism, and most importantly, metabolic rate depression (Storey, 2007). The champion of vertebrate facultative anaerobes are species of freshwater turtles, including $T$. s. elegans, which can survive at least 3 months of full anoxia in cold water, conditions that mimic winter hibernation underwater. During anaerobiosis these turtles shut down oxidative metabolism and rely completely on glycolysis for energy production (Storey and Storey, 1990). Such drastic changes to cellular metabolism necessitates some form of regulation for carbohydrate, fatty acid and amino acid oxidation pathways. Glutamate dehydrogenase, a key enzyme in amino acid metabolism that forms the gateway for several amino acids to enter aerobic metabolism, may be an important regulatory site during anoxia in freshwater turtles. The present study shows that purified liver GDH from control and $20 \mathrm{~h}$ anoxic turtles has markedly different kinetics, responses to cellular metabolites and $\mathrm{pH}$, and is present in different phosphorylation states.

SDS-PAGE was used to confirm that GDH was indeed purified by the affinity columns and to determine GDH subunit molecular weight. This method found that the GDH subunit size was $\sim 67 \mathrm{kDa}$ and since GDH is known to be a homohexamer, the predicted native molecular weight of turtle GDH would be $\sim 400 \mathrm{kDa}$. Although the native size of turtle liver GDH was not measured directly, reported molecular weights for bovine liver GDH have ranged from 250-400 kDa (Eisenberg and Reisler, 1970). 
Furthermore, GDH subunit molecular weights have been reported for several other vertebrate species such as rat heart (38 kDa; McDaniel et al., 1984) and ground squirrel liver ( $\sim 60 \mathrm{kDa}$; Thatcher and Storey, 2001). As is clear from the above molecular weights, the size of GDH appears to vary greatly between species. Thus, turtle liver GDH molecular weight determined here may be accurate as it is fairly close to those molecular weights identified above.

The kinetic differences elucidated for purified liver GDH from normoxic and anoxic conditions suggests significant differences in behaviour of this enzyme during anoxia. Generally speaking, the data presented here indicate that control GDH is the more active enzyme form. This can be seen from the GDH kinetics both with and without ADP. For instance, without ADP in the assays, $\mathrm{K}_{\mathrm{m}}$ glutamate increases (i.e. substrate affinity decreases), and $V_{\max }$ decreases (for both forward and reverse reactions) significantly during anoxia (Tables 3.1 and 3.2). Furthermore, in the presence of ADP, there are significant increases in $\mathrm{K}_{\mathrm{m}}$ glutamate, and $\mathrm{K}_{\mathrm{m}} \mathrm{NH}_{4}{ }^{+}$, as well as substantial decreases in forward and reverse reaction maximal velocities for anoxic GDH when compared to control GDH. Taken together this suggests a substantial decrease in both forward and reverse reaction activity in vivo during anoxia.

Shutting down GDH during anoxia corresponds well with the metabolic changes that occur during anoxia in the freshwater turtle. Besides reduced liver glycolytic activity during anaerobiosis (Storey and Storey, 1990), the TCA cycle slows down substantially and oxidative phosphorylation via the ETC ceases. Without these major metabolic pathways functioning to produce ATP, the breakdown of glutamate to $\alpha$-ketoglutarate for energy would be unnecessary and uneconomical. Further evidence supporting 
diminished glutamate oxidation via GDH stems from the known ammonia levels and the degree of ureogenesis and gluconeogenesis in the fully anoxic turtles. Ammonia levels in the anoxic turtles are known to stay constant at fairly low concentrations of $0.13 \mathrm{mM}$ in the blood plasma (Ultsch and Jackson, 1982). Moreover, Hochachka et al. (1996) found that during anoxia freshwater turtles suppress urea and glucose synthesis in the liver by $70 \%$ and $100 \%$, respectively. Thus, it stands to reason that if the metabolic pathways that utilize the products of glutamate oxidation are switched off under anoxic conditions that the forward reaction of GDH be shut down as well.

The constant low-millimolar concentrations of ammonia in the anoxic turtle, not only indicates a slowing of ammonia production, but also a lack of ammonia utilization during anaerobiosis. This observation is consistent with the decreased activity of the ammonia-utilizing/glutamate-producing reaction of GDH seen in this study. Reduced glutamate synthesis seems intuitive since it is well established that protein synthesis is almost completely switched off during anoxia, and thus amino acid synthesis should also be suppressed (Hochachka et al., 1996; Frasor et al., 2001).

Also supporting the idea that GDH activity is reduced during anoxia is the enzyme's response to effector molecules. For instance, Table 3.2 shows that purified anoxic GDH is much more sensitive to GTP inhibition than control GDH. Furthermore, for the glutamate-synthesizing reaction, purified anoxic GDH is significantly less sensitive to activation by ADP when compared to control GDH (Table 3.3). This decreased sensitivity to ADP and increased sensitivity to GTP likely corresponds to decreased GDH activity under anoxia as compared to normoxic conditions.

Although GDH activity appears to be suppressed during anaerobiosis, this does 
not appear to affect the activation energy of the forward reaction. Figure 3.4 illustrates that the Arrhenius plots of control and $20 \mathrm{~h}$ anoxic GDH are nearly identical in slope and their activation energies were not significantly different.

The majority of the kinetic properties assessed were consistent with a less active form of GDH under anoxia, but there are some deviations from this trend. The first to be considered is the substantial decrease in the $\mathrm{K}_{\mathrm{m}} \alpha$-ketoglutarate during anaerobiosis (Table 3.3). However, the apparent activation of GDH that this could offer may be inconsequential in vivo due to two factors. First, estimates from rat hepatocytes under normoxic conditions indicate that mitochondrial $\alpha$-ketoglutarate concentrations are approximately $0.3 \mu \mathrm{mol} / \mathrm{g}$ dry weight $(\sim 0.06 \mathrm{mM}$; Sies et al., 1977), however, this number decreases dramatically during anoxia. For instance, Bowman (1966) reported a 90\% drop in $\alpha$-ketoglutarate concentration during anoxia in rat heart. He proposed that the large decrease in $\alpha$-ketoglutarate was the result of a decrease in the $\mathrm{NAD}^{+}: \mathrm{NADH}$ ratio which consequently inhibited isocitrate dehydrogenase (i.e. NADH inhibits through product inhibition). Furthermore, the typical ammonia concentrations found during anoxia are low whereas the $\mathrm{K}_{\mathrm{m}} \mathrm{NH}_{4}{ }^{+}$is so high that the ability of GDH to synthesize glutamate is very likely limited by ammonia levels. Taken together it is unlikely that the significant decrease in $\mathrm{K}_{\mathrm{m}} \alpha$-ketoglutarate has any physiological significance during anaerobiosis in the freshwater turtle.

Similar to the case with $\alpha-k$ etoglutarate, the $\mathrm{K}_{\mathrm{m}} \mathrm{NAD}^{+}$in the presence of ADP was significantly reduced during anoxia when compared to the normoxic condition (Table 3.2). It is important to note that without added ADP, the $\mathrm{K}_{\mathrm{m}} \mathrm{NAD}^{+}$did not change between control and anoxic conditions. Thus, it appears that ADP binding to purified 
GDH caused a conformational change in the enzyme that increased its affinity for $\mathrm{NAD}^{+}$ during anoxia. Again, the physiological significance of this increased affinity is limited due to the typical mitochondrial concentration of $\mathrm{NAD}^{+}$(4-6 $\mathrm{mM}$ in mitochondria of rat hepatocytes; Tischler et al., 1977). At these NAD ${ }^{+}$concentrations, GDH would be saturated with the cofactor, potentially making the actual $\mathrm{K}_{\mathrm{m}}$ values irrelevant in vivo. However, the kinetic difference identified here as well as other kinetic changes listed above do indicate a structural difference between control and $20 \mathrm{~h}$ anoxic GDH.

As mentioned before, suppression of enzyme activities during anaerobiosis is not uncommon for the freshwater turtles, and is likely an important part of overall metabolic rate depression. Inactivation usually occurs via covalent modification in the form of reversible protein phosphorylation. Examples include regulation of turtle liver glycogen phosphorylase, phosphofructokinase, and pyruvate kinase by phosphorylation under anoxia (Storey, 1996). In order to determine if the kinetic changes in turtle liver GDH were also due to reversible phosphorylation, purified control and anoxic GDH was stained with ProQ Diamond phosphoprotein stain. Figure 3.2 indicates that the less active $20 \mathrm{~h}$ anoxic GDH contained significantly less phosphate than control GDH.

Subsequent incubation of the purified control enzyme with commercial alkaline or acid phosphatase confirmed that control GDH was phosphorylated, and that dephosphorylation stimulated a significant decrease in $\mathrm{K}_{\mathrm{m}} \alpha$-ketoglutarate to a value similar to that of the anoxic enzyme (Fig. 3.3A). However, treatment with exogenous PKA had little effect on $\mathrm{K}_{\mathrm{m}} \alpha$-ketoglutarate of the anoxic form of GDH (Fig. 3.3B), and did not reconvert $\mathrm{K}_{\mathrm{m}} \alpha$-ketoglutarate to a value similar to that of control GDH. This indicates that PKA is not the protein kinase involved in GDH regulation in vivo. 
Although the relevant research into the activities of various protein kinases and phosphatases during turtle anaerobiosis is not extensive, work conducted on other anoxiatolerant animals may provide insight into possible candidates that could act on GDH in vivo. For instance, in the hepatopancreas (liver-like organ) of the anoxia-tolerant crayfish, protein phosphatase 1 and $2 \mathrm{C}$ remain just as active after long $(20 \mathrm{~h})$ anoxia exposures as was seen in control animals. Furthermore, protein phosphatase $2 \mathrm{~A}$ increased in activity during long anoxia exposures in the hepatopancreas of these crayfish (Cowen and Storey, 2001). The activity of these phosphatases during anoxia could suggest a role for these enzymes in the dephosphorylation and inactivation of metabolic enzymes, which is essential for metabolic rate depression during anaerobiosis. It is important to note however that Mehrani and Storey (1995) found that protein phosphatase 1 activity in the turtle liver was suppressed during anoxia and remained low during long anoxic exposures. Thus, PP1 is unlikely to be responsible for the dephosphorylation of GDH during anoxia in T. s. elegans. The role of protein kinases during anoxia has not been extensively studied, but studies found that PKA activity is suppressed during anoxia in the freshwater turtle (Mehrani and Storey, 1995b) and in the crayfish (Cowen and Storey, 2001). If the suppressed activity of PKA during anoxia can be extended to other kinases, then it can be postulated that protein kinases play a role, not in anoxia, but in reestablishing normoxic enzyme activities when oxygen is reintroduced. Although further work on these kinases is necessary, it is important to note that the possible phosphorylation sites on turtle GDH may be the same as those identified in Chapter 2 (Appendix 1; T. Forrest, unpublished) and these provide a good starting point for picking potential kinases that can be tested for their ability to phosphorylate GDH. 
Anaerobic metabolism typically leads to tissue acidification, and low $\mathrm{pH}$ conditions will affect the functioning of all metabolic enzymes (Storey, 1995b). Changes in $\mathrm{pH}$ alter the charge on amino acids and cause changes in enzyme-substrate affinities as well as enzyme conformation (Hochachka and Somero, 1984). Table 3.4 shows the maximal velocities and $\mathrm{V}_{\max }$ ratios (forward reaction $\mathrm{V}_{\max }$ /reverse reaction $\mathrm{V}_{\max }$ ) for turtle liver GDH at pH 6.6 and 7.4. For the high-phosphate control form of GDH, the $\mathrm{V}_{\max }$ ratios with and without ADP did not change significantly between anoxic and normoxic conditions. However, for the low-phosphate anoxic form of GDH, acidification led to a strong decrease in the $\mathrm{V}_{\max }$ ratio. This decrease was the result of a significant decrease in the forward reaction $\mathrm{V}_{\max }$ at anoxic $\mathrm{pH}$ values. A similar effect was seen when the assays of the anoxic enzyme were performed in the presence of ADP. The negative effect of acidification on the forward reaction of anoxic GDH coincides with the fact that under anoxia shuttling carbon skeletons into the Krebs cycle would be uneconomical. The significant differences between $\mathrm{V}_{\max }$ ratios for control and anoxic GDH are further evidence that GDH exists in two distinct enzyme forms.

A possible explanation for the distinct $\mathrm{V}_{\max }$ ratios observed for control and anoxic GDH may stem from the amino acid composition of the active site and the changes that may occur when an enzyme is phosphorylated/dephosphorylated. Charged amino acids in an enzyme active site can be in protonated or deprotonated forms depending on the amino acid $\mathrm{pK}$ as well as the $\mathrm{pH}$ surrounding the enzyme. It is important to note however, that the $\mathrm{pK}$ of an amino acid can change depending on its microenvironment (i.e. the surrounding amino acids; Hochachka and Somero, 1984). Since substrate binding will depend on these charged residues it is usually ideal for enzymes that can 
function in the "forward" and "reverse" directions to have an equal amount of protonated and deprotonated amino acids in the active site so that reversibility can be maintained (Hochachka and Somero, 1984). The significant $\mathrm{V}_{\max }$ ratio difference between control and $20 \mathrm{~h}$ anoxic $\mathrm{GDH}$ at a pH typically found during anoxia, indicates that the microenvironments at the enzymes active site may be different. It may be plausible that dephosphorylation of GDH during anoxia leads to a conformational change that alters the active site microenvironment so as to decrease the enzyme's affinity for forward reaction substrates. It is well established that there are conserved lysine residues that are important for substrate binding for GDH (Peterson and Smith, 1999), and these could be affected by the regulation of GDH in the freshwater turtle during anoxia.

Taken together, the data in this chapter indicate that GDH purified from control versus $20 \mathrm{~h}$ anoxic liver has different kinetic properties, and in general, the anoxic form of GDH was less active in both the forward and reverse directions. Via ProQ Diamond phosphoprotein staining and specific protein kinase/phosphatase incubations it appears that the transition to a less active GDH during anoxia occurs through reversible phosphorylation of the enzyme, the control form being a high phosphate enzyme (that is susceptible to the action of protein phosphatases) and the anoxic form being a low phosphate form. Another significant factor in regulating GDH activity in vivo may by the acidification of tissues during anoxia. A decrease in $\mathrm{pH}$ appears to slow the glutamateoxidizing reaction relative to the glutamate-synthesizing reaction for the anoxic form of GDH and could help to prevent a build-up of Krebs cycle intermediates in vivo under anoxic conditions. Furthermore, an overall suppression of GDH activity under anoxia, affecting both glutamate oxidation and synthesis, coincides with overall metabolic rate 
depression observed during anoxia in the freshwater turtle. 
Chapter 4

Regulation of foot muscle glutamate dehydrogenase

from an estivating land snail 


\section{Introduction:}

Animals that live in seasonally hot and dry environments usually require some mechanism to survive periodic droughts and the scarcity of food that typically follows. One such mechanism is estivation, which is a state of aerobic torpor that is employed by a range of organisms including amphibians, reptiles, small mammals, and land snails (Storey, 2002). Estivation entails major behavioral, physiological, and biochemical adaptations that allow for prolonged survival under these harsh conditions. Particularly important for this study are the biochemical changes which include the reprioritization of energy metabolism, altered expression of many proteins, differential regulation of many enzymes, and a strong reduction in overall metabolic rate (Storey, 2004a). Many of the adaptations seen during this type of aerobic torpor are tailored to retaining water or rationing metabolic fuel reserves; two major problems for estivators.

One of the well-studied estivators is the pulmonate land snail, Otala lactea, which is native to the lands around the Mediterranean Sea. These snails can estivate for many months, and have developed a variety of mechanisms for retaining water and conserving fuel reserves. First, when the snails encounter arid conditions they withdraw into their shells and produce a hardened muscous membrane (epiphragm) that covers their shell opening to prevent evaporative water loss (Rokitka and Herreid, 1975). To further reduce water loss, these snails take breaths only intermittently (i.e. apnoic breathing patterns), when $\mathrm{CO}_{2}$ levels become too high (Barnhart and McMahon, 1987). An additional and crucial mechanism for maintaining a sufficient amount of body water is the accumulation of osmolytes. O. lactea elevate the levels of selected cellular metabolites, in particular urea, to increase the osmolarity of their tissues and retard water 
loss due to the colligative action of high solute levels in body fluids. Land snails can accumulate urea at concentrations as high as $150-300 \mathrm{mM}$ during prolonged estivation (Rees and Hand 1993). The reliance of land snails, as well as other estivating species, on the production of urea increases the importance of nitrogen metabolism during this period.

Long term survival also depends on minimizing the rate of consumption of fixed body reserves of metabolic fuels. This is achieved by two intertwined actions: an overall strong suppression of metabolic rate (ATP turnover) and a reorganization of the priorities for ATP use to minimize ATP consumption by nonessential metabolic processes while sustaining ATP availability for essential functions. For preserving energy, these snails reduce movements, decrease heart rate, and decrease their overall metabolic rate by 70 90\% (Herreid, 1977). Although metabolic rate is greatly depressed, metabolism must continue to provide energy for essential cellular processes. During estivation $O$. lactea uses carbohydrates as the primary source of energy, with amino acid oxidation becoming increasingly more important as carbohydrate stores run out and as dehydration stress demands a build-up of urea (Rees and Hand, 1993). Furthermore, there is a low level lipid oxidation that occurs throughout the dormancy period to also aid in energy production.

Due to the importance of nitrogen metabolism for water retention, and the possibility of amino acids being used for energy during estivation, glutamate dehydrogenase (GDH) was investigated in the foot muscle of $O$. lactea. This chapter compares and contrasts the kinetic properties of GDH from active (control) and estivating animals, as well as responses of each enzyme form to cellular metabolites. The 
possibility of GDH regulation by phosphorylation during estivation was also investigated.

\section{Materials and Methods:}

\section{Animals and Chemicals}

Otala lactea were imported from Morocco and were purchased from local seafood retailer. Snails were placed large plastic tubs lined with damp paper towels. The snails were maintained there for approximately one month and were fed every 2-3 days with shredded cabbage and carrots (sprinkled with crushed chalk). After this period, estivation was induced in some of the snails by placing them in a dry plastic container without food. Active snails remained in the damp container with food and were used as the controls. After 10 days, both control (active) and estivated snails were sacrificed; foot muscle and hepatopancreas were dissected out, quickly frozen in liquid nitrogen and then stored at $-80^{\circ} \mathrm{C}$ until use.

The chemicals used in this study were the same as those used in Chapter 2, with one exception: DEAE ${ }^{+}$Sephadex beads were obtained from Pharmacia Fine Chemicals.

\section{Sample Preparation}

Frozen foot muscle samples were standardly homogenized as described in Chapter 2 (the buffer used will be referred to as homogenization buffer A), except for those extracts made for ion exchange chromatography. The buffer used in those cases (referred to as column buffer) contained $25 \mathrm{mM}$ Tris-HCl, $5 \mathrm{mM}$ 2-mercaptoethanol, 1.25 mM EDTA and 1.25 mM EGTA, 5\% v:v glycerol, and $12.5 \mathrm{mM} \beta$-GP, pH 9. 
Partial Purification of GDH

GDH from O. lactea foot muscle was partially purified as described in the ProQ Diamond Phosphoprotein Staining section of Chapter 2. The five most active fractions collected off of the GTP-agarose column were pooled for use in GDH assays.

\section{GDH Assays}

Optimal assay conditions for the partially purified $O$. lactea foot muscle GDH in the forward direction were $50 \mathrm{mM} \mathrm{L}$-glutamate, $1.5 \mathrm{mM} \mathrm{NAD}^{+}, 0.5 \mathrm{mM} \mathrm{Mg}$-ADP, and $50 \mathrm{mM}$ Tris- $\mathrm{HCl}$ buffer, $\mathrm{pH} 8.0$ in a total volume of $200 \mu \mathrm{L}$ with $50 \mu \mathrm{L}$ of partially purified extract used per assay. In the reverse reaction, the optimal concentrations of substrates were $1 \mathrm{mM} \alpha$-ketoglutarate, $100 \mathrm{mM} \mathrm{NH}_{4} \mathrm{Cl}, 0.2 \mathrm{mM} \mathrm{NADH}, 0.5 \mathrm{mM} \mathrm{Mg}$ ADP, $50 \mathrm{mM}$ HEPES buffer, pH 7.2 with $20 \mu \mathrm{L}$ of partially purified liver extract used in each assay. In all cases GDH activity was assayed with a Thermo Labsystems Multiskan spectrophotometer $\left(\mathrm{A}_{340}\right)$ and kinetic parameters (e.g. $\mathrm{V}_{\max }, \mathrm{K}_{\mathrm{m}}, \mathrm{K}_{\mathrm{a}}$, and $\left.\mathrm{I}_{50}\right)$ were calculated as described in Chapter 2. Activity was measured in $\mathrm{mU} / \mathrm{mg}$ soluble protein. Protein concentration in extracts was determined as described in Chapter 2.

\section{Effectors of $G D H$}

The effect of ADP, ATP, GTP, and citrate on the reverse reaction of GDH was assessed by measuring GDH activity at suboptimal concentrations of all substrates. The suboptimal concentrations were $0.2 \mathrm{mM} \alpha$-ketoglutarate, $0.15 \mathrm{mM} \mathrm{NADH}$, and $40 \mathrm{mM}$ $\mathrm{NH}_{4} \mathrm{Cl}$. The effects of the aforementioned effector molecules on GDH activity were determined by varying the concentration of these molecules in the assay wells and 
ultimately calculating their $\mathrm{I}_{50}$ or $\mathrm{K}_{\mathrm{a}}$. Both $\mathrm{K}_{\mathrm{a}}$ and $\mathrm{I}_{50}$ values were calculated using the Kinetics v.3.5.1 program (Brooks, 1994). For the forward reaction, the effect of ADP on GDH activity was assessed; suboptimal substrate concentrations were $10 \mathrm{mM} \mathrm{L}$ glutamate and $0.5 \mathrm{mM} \mathrm{NAD}{ }^{+}$.

ProQ Diamond Phosphoprotein Staining of GDH

Following the purification of GDH from snail foot muscle, aliquots of the pooled fractions were prepared for SDS-PAGE and run and stained as described in Chapter 2.

\section{Ion Exchange Chromatography of GDH}

Foot muscle extracts were prepared in the column buffer described above. A 500 $\mu \mathrm{L}$ aliquot of supernatant was applied to a $3 \times 1.8 \mathrm{~cm}(\mathrm{~h} \times \mathrm{d})$ column of DEAE ${ }^{+}$Sephadex equilibrated in the same buffer. The column was washed with $\sim 10 \mathrm{~mL}$ of buffer to remove any unbound material and then GDH was eluted with a 0-1 $\mathrm{M}$ gradient of $\mathrm{KCl}$ in column buffer. Fractions of $350 \mu \mathrm{L}$ were collected and assayed under optimal conditions for the forward reaction.

\section{Results:}

GDH Kinetics

After partial purification of $O$. lactea foot muscle GDH via a GTP-agarose column, kinetics in the forward and reverse directions were analyzed. In the forward, glutamate-oxidizing, reaction several kinetic parameters were significantly different $(p<0.05)$ between active and estivated land snails. For instance, $\mathrm{K}_{\mathrm{m}} \mathrm{NAD}^{+}$and $\mathrm{K}_{\mathrm{m}}$ 
glutamate (with ADP) decreased by $36 \%$ and $30 \%$, respectively, during estivation as compared to the control situation (Table 4.1). Furthermore, the $\mathrm{V}_{\max }$ of estivated GDH in the absence of ADP was $>3$-fold higher than the same value for control GDH. Similarly, in the presence of ADP the maximal velocity of estivated GDH was $\sim 2$-fold higher than the $\mathrm{V}_{\max }$ for control GDH.

The reverse reaction also displayed distinctly different kinetics between control and $10 \mathrm{~d}$ estivated land snails. Table 4.2 shows that $\mathrm{K}_{\mathrm{m}} \alpha$-ketoglutarate and $\mathrm{K}_{\mathrm{m}} \mathrm{NH}_{4}{ }^{+}$ were $\sim 3$-fold and 2-fold higher, respectively, for estivated GDH as compared to GDH from active snails. Furthermore, the maximal velocity of GDH in the absence of ADP was $78 \%$ lower during estivation in comparison to the control $\mathrm{V}_{\max }$. The $\mathrm{V}_{\max }$ of GDH in the presence of $\mathrm{ADP}$ also decreased during estivation, with the maximal velocity being $56 \%$ lower than the corresponding control value.

Interestingly, the ratios of maximal velocities (forward reaction $\mathrm{V}_{\max } /$ reverse reaction $\mathrm{V}_{\max }$ ) were very different between control and $10 \mathrm{~d}$ estivated $O$. lactea. The estivated GDH $V_{\max }$ ratio in the absence of ADP was $\sim 14$-fold greater than the corresponding ratio for GDH from active control snails (Table 4.3). Similarly, in the presence of ADP, the $V_{\max }$ ratio for GDH from estivating snails was $\sim 5$-fold greater than the control $\mathrm{V}_{\max }$ ratio.

\section{Effectors of $G D H$}

The effects of common intracellular molecules on the forward and reverse reactions of GDH were determined by measuring enzyme activity at various concentrations of the effector molecules. The only molecule tested on the forward 
reaction was $\mathrm{ADP}$ and it behaved as an activator. Although the $\mathrm{K}_{\mathbf{a}} \mathrm{ADP}$ did not change between control and estivated GDH, the fold activation caused by the addition of ADP was $78 \%$ less for estivated GDH as compared to the control GDH fold activation (Table 4.1).

For the reverse reaction, the effects of AMP, ADP, ATP, GTP, and citrate on foot muscle GDH activity were evaluated. Similar to the situation for the forward reaction, ADP was an activator of GDH. The $\mathrm{K}_{\mathrm{a}} \mathrm{ADP}$ and the corresponding fold activation of GDH were not significantly different between active and estivated conditions (Table 4.2). Table 4.4 shows the actions of the other nucleotides. The addition of AMP to GDH assays activated the control enzyme form at low millimolar concentrations, but GDH from estivated snails was unaffected by AMP at the concentrations tested up to $4.5 \mathrm{mM}$. Similarly, the addition of ATP inhibited the control enzyme while having no effect on estivated GDH up to a concentration of $10 \mathrm{mM}$. On the other hand, GTP inhibited GDH from both the estivated and active conditions. GDH from the estivating snails displayed an $\mathrm{I}_{50}$ GTP that was $56 \%$ lower than the same value for active snails. Lastly, the addition of citrate at concentrations up to $10 \mathrm{mM}$ had no effect on GDH from either control or estivating conditions.

\section{Reversible Phosphorylation of $G D H$}

To determine if the stable kinetic changes in GDH between active and estivating land snails were due to reversible phosphorylation, partially purified extracts were subjected to SDS-PAGE and subsequently stained with ProQ Diamond phosphoprotein stain. Having purified GDH using its strong affinity for GTP, most other proteins were 
removed prior to electrophoresis. Thus, after electrophoresis the single band found at the correct molecular weight range for GDH subunits was attributed to GDH. Furthermore, when purified commercial bovine liver GDH (Sigma) was run on the same SDS-PAGE gels, it gave a band at the same position as the snail GDH subunit after ProQ Diamond staining. Figure 4.1 shows that the quantified band intensity for estivated GDH was $\sim 75 \%$ more intense $(\mathrm{p}<0.05)$ than that observed for control GDH.

Altering the phosphorylation state of an enzyme can change the net charge on that protein, which then allows for the separation of high- and low-phosphate forms of the enzyme. Figure 4.2 illustrates the elution profiles of control and estivated GDH activity from a $\mathrm{DEAE}^{+}$Sephadex column using a linear 0-1 $\mathrm{M} \mathrm{KCl}$ gradient. GDH from the estivated condition eluted off the column at a lower salt concentration than control GDH. Each enzyme form eluted off the column in a single peak of activity. 
Table 4.1. Comparison of foot muscle GDH kinetic parameters from control and 10 day estivated $O$. lactea assayed in the glutamate-utilizing (forward) direction using $\mathrm{NAD}^{+}$as the cofactor. Data are means $\pm S E M, n \geq 3$ independent determinations. $K_{m}$ values were determined at optimal cosubstrate concentrations. $\mathrm{K}_{\mathrm{a}}$ values were determined at suboptimal substrate concentrations (identified in the Materials and Methods). ${ }^{\text {- }}$ Significantly different from the corresponding control value using the Student's t-test, $\mathrm{P}<0.05$. $^{\mathrm{b}}$ - Significantly different from the same condition without ADP, $\mathrm{p}<0.05$.

\begin{tabular}{|c|c|c|}
\hline & Control & 10 Day Estivated \\
\hline $\mathrm{K}_{\mathrm{m}}$ Glutamate $(\mathrm{mM})$ & $0.90 \pm 0.02$ & $0.84 \pm 0.02$ \\
\hline $\mathrm{K}_{\mathrm{m}}$ Glutamate with $0.5 \mathrm{mM}$ ADP $(\mathrm{mM})$ & $3.0 \pm 0.2^{\mathrm{b}}$ & $2.1 \pm 0.2^{\mathrm{ab}}$ \\
\hline $\mathrm{K}_{\mathrm{m}} \mathrm{NAD}^{+}(\mathrm{mM})$ & $0.77 \pm 0.04$ & $0.49 \pm 0.02^{\mathrm{a}}$ \\
\hline $\mathrm{K}_{\mathrm{m}} \mathrm{NAD}^{+}$with 0.5 mM ADP $(\mathrm{mM})$ & $0.159 \pm 0.005^{\mathrm{b}}$ & $0.191 \pm 0.009^{\mathrm{b}}$ \\
\hline $\mathrm{K}_{\mathrm{a}}$ ADP $(\mu \mathrm{M})$ & $4.7 \pm 0.7$ & $3.5 \pm 0.5$ \\
{$[$ Fold Activation] } & {$[13.8 \pm 0.8]$} & {$\left[3.0 \pm 0.4^{\mathrm{a}}\right]$} \\
\hline $\mathrm{V}_{\max }(\mathrm{mU} / \mathrm{mg})$ & $9.4 \pm 0.8$ & $30 \pm 1^{\mathrm{a}}$ \\
\hline $\mathrm{V}_{\max }$ with $0.5 \mathrm{mM} \mathrm{ADP}(\mathrm{mU} / \mathrm{mg})$ & $26.9 \pm 0.2^{\mathrm{b}}$ & $58 \pm 3^{\mathrm{ab}}$ \\
\hline
\end{tabular}


Table 4.2. Comparison of foot muscle GDH kinetic parameters from control and 10 day estivated $O$. lactea assayed in the glutamate-synthesizing (reverse) direction using $\mathrm{NADH}$ as the cofactor. Data are means $\pm \mathrm{SEM}, \mathrm{n} \geq 3$ independent determinations. $\mathrm{K}_{\mathrm{m}}$ values were determined at optimal cosubstrate concentrations. $K_{a}$ values were determined at suboptimal substrate concentrations (defined in the Materials and Methods). ${ }^{a}$ Significantly different from the corresponding control value using the Student's t-test, $\mathrm{P}<0.05$. $^{\mathrm{b}}$ - Significantly different from the same condition without ADP, $\mathrm{p}<0.05$.

\begin{tabular}{|c|c|c|}
\hline & Control & 10 Day Estivated \\
\hline $\mathrm{K}_{\mathrm{m}} \alpha$-Ketoglutarate (mM) & $0.19 \pm 0.03$ & $0.55 \pm 0.05^{\mathrm{a}}$ \\
\hline $\mathrm{K}_{\mathrm{m}} \alpha$-Ketoglutarate with 0.5mM ADP (mM) & $0.22 \pm 0.01$ & $0.27 \pm 0.04^{\mathrm{b}}$ \\
\hline $\mathrm{K}_{\mathrm{m}} \mathrm{NH}_{4}{ }^{+}(\mathrm{mM})$ & $63 \pm 2$ & $126 \pm 3^{\mathrm{a}}$ \\
\hline $\mathrm{K}_{\mathrm{m}} \mathrm{NH}_{4}{ }^{+}$with $0.5 \mathrm{mM}$ ADP $(\mathrm{mM})$ & $36 \pm 1^{\mathrm{b}}$ & $30 \pm 3^{\mathrm{b}}$ \\
\hline $\mathrm{K}_{\mathrm{a}}$ ADP $(\mu \mathrm{M})$ & $36 \pm 4$ & $27 \pm 4$ \\
{$[$ Fold Activation] } & {$[1.83 \pm 0.07]$} & {$[1.63 \pm 0.05]$} \\
\hline $\mathrm{V}_{\max }(\mathrm{mU} / \mathrm{mg})$ & $67 \pm 4$ & $15 \pm 2^{\mathrm{a}}$ \\
\hline $\mathrm{V}_{\max }$ with $0.5 \mathrm{mM}$ ADP $(\mathrm{mU} / \mathrm{mg})$ & $131 \pm 4^{\mathrm{b}}$ & $57 \pm 3^{\mathrm{ab}}$ \\
\hline
\end{tabular}


Table 4.3. The ratios of maximal activity in the glutamate-oxidizing (forward) reaction to the maximal activity in the glutamate-synthesizing (reverse) reaction for GDH from the foot muscle of active and $10 \mathrm{~d}$ estivated $O$. lactea.

\begin{tabular}{|c|c|c|c|}
\hline \multicolumn{2}{|c|}{ Control } & \multicolumn{2}{c|}{ 10 d Estivated } \\
\hline $\mathrm{V}_{\max }$ Ratio & $\mathrm{V}_{\max }$ Ratio & $\mathrm{V}_{\max }$ Ratio & $\mathrm{V}_{\max }$ Ratio \\
(without ADP) & (with ADP) & (without ADP) & (with ADP) \\
\hline $0.14 \pm 0.01$ & $0.205 \pm 0.006$ & $2.0 \pm 0.3$ & $1.01 \pm 0.07$ \\
\hline
\end{tabular}


Table 4.4. The effect of various metabolites on foot muscle GDH activity from control and 10 day estivated $O$. lactea. GDH was assayed in the glutamate-synthesizing (reverse) direction using $\mathrm{NADH}$ as the cofactor. $\mathrm{K}_{\mathrm{a}}$ and $\mathrm{I}_{50}$ values were determined at suboptimal substrate concentrations (defined in the Materials and Methods). Data are means \pm SEM, $\mathrm{n} \geq 3$ independent determinations. *-Significantly different from the corresponding control value using the Student's t-test, $\mathrm{P}<0.05$.

\begin{tabular}{|c|c|c|}
\hline & Control & 10 Day Estivated \\
\hline $\mathrm{K}_{\mathrm{a}}$ AMP $(\mathrm{mM})$ & $0.27 \pm 0.04$ & No Effect (up to 4.5mM) \\
\hline $\mathrm{I}_{50}$ ATP $(\mathrm{mM})$ & $7 \pm 1$ & No Effect (up to $10 \mathrm{mM})$ \\
\hline $\mathrm{I}_{50}$ GTP $(\mu \mathrm{M})$ & $0.34 \pm 0.02$ & $0.15 \pm 0.02^{*}$ \\
\hline
\end{tabular}


Figure 4.1. The relative band intensity of purified foot muscle GDH from active and $10 \mathrm{~d}$ estivated $O$. lactea, as assessed on a SDS-PAGE gel stained with ProQ Diamond phosphoprotein stain. Data are means \pm SEM, $n=3$ independent samples. ${ }^{*}$ - Significantly different from the mean relative band intensity of control GDH using the Student's t-test $(\mathrm{p}<0.05)$. 
Figure 4.1

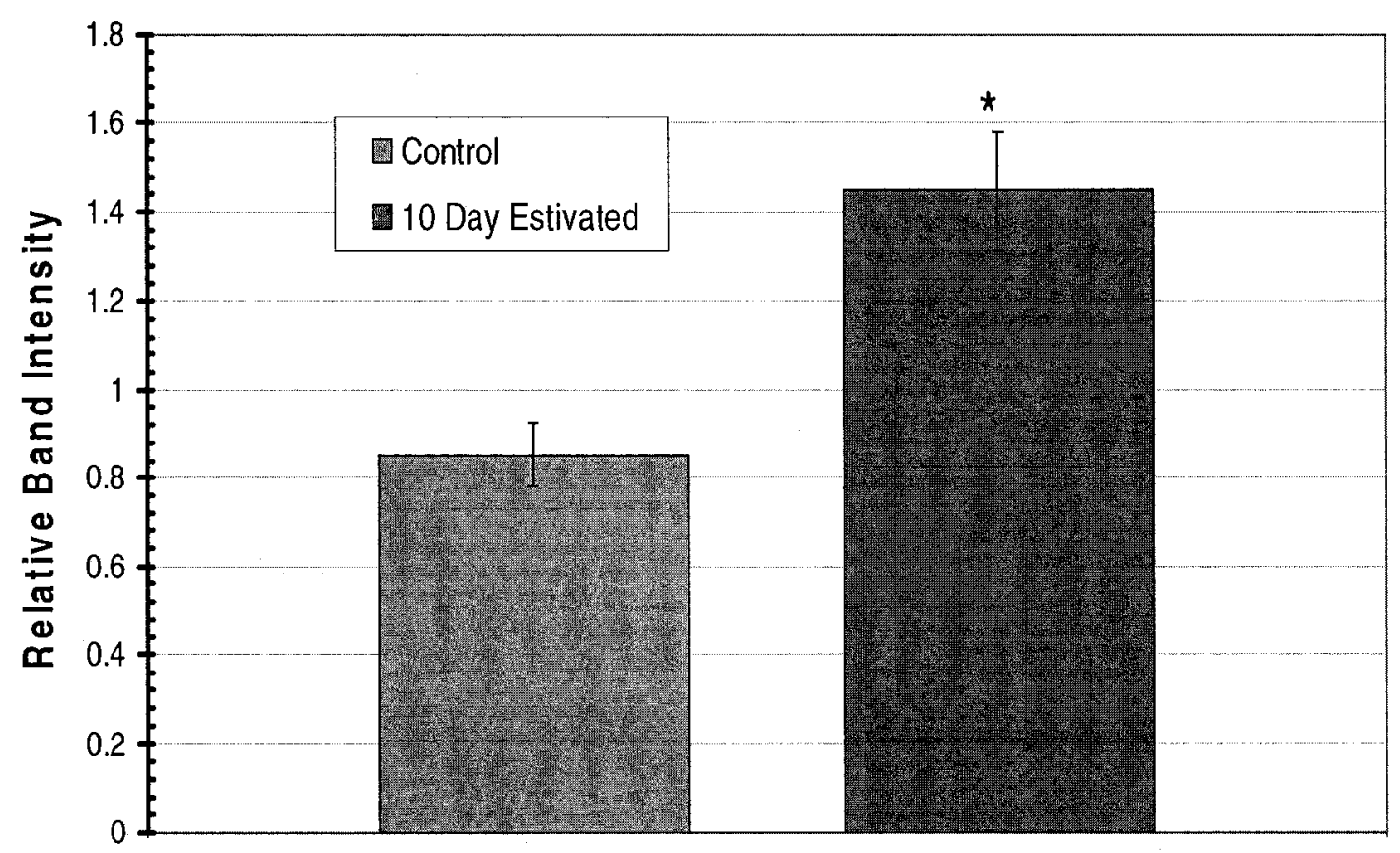


Figure 4.2. Representative $\mathrm{DEAE}^{+}$Sephadex elution profiles for GDH activity from the foot muscle of control and $10 \mathrm{~d}$ estivated $O$. lactea. The enzyme was eluted with a $0-1 \mathrm{M}$ $\mathrm{KCl}$ gradient in column buffer (defined in the Materials and Methods) at $\mathrm{pH} 9$. 
Figure 4.2

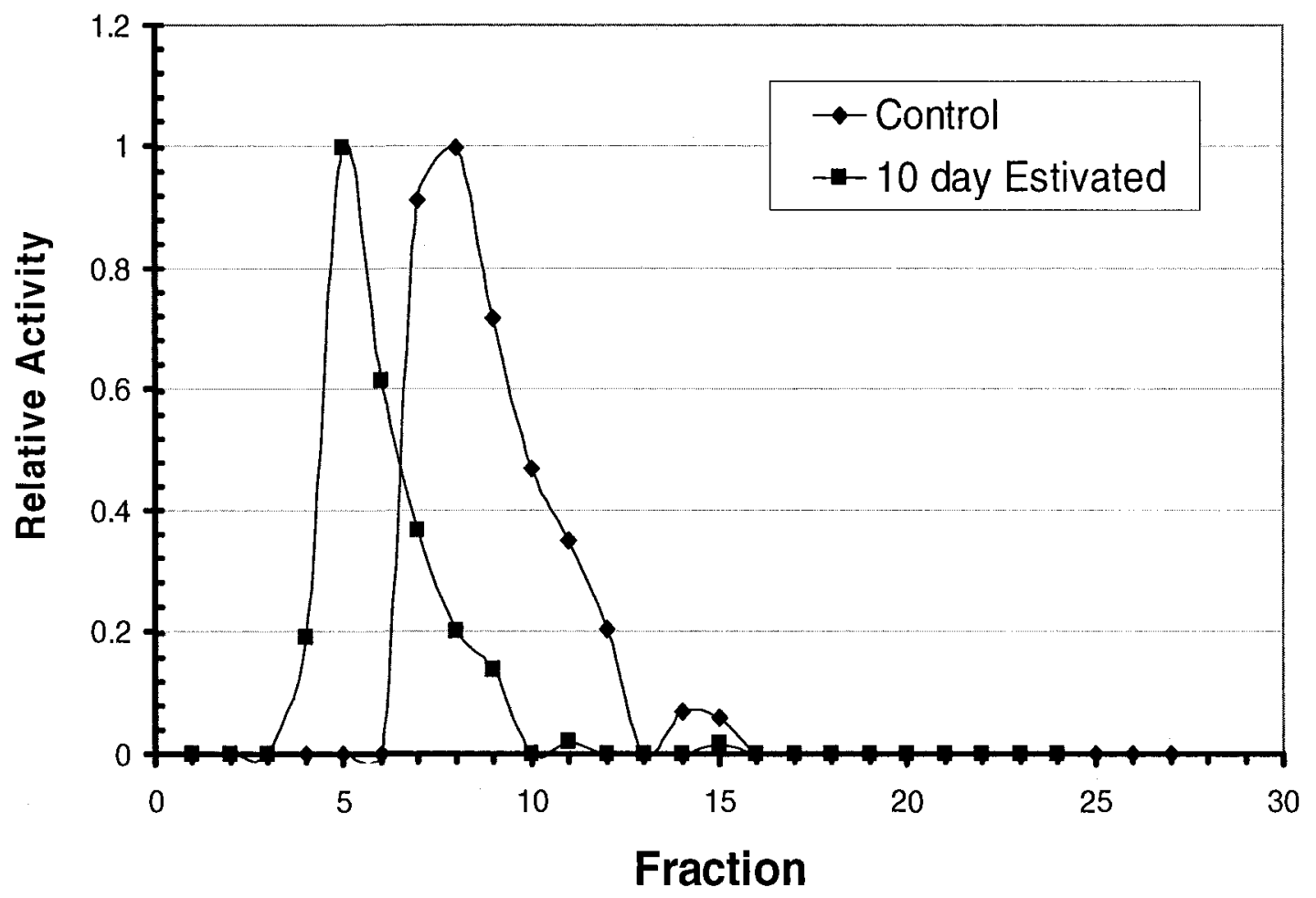




\section{Discussion:}

The land snail, O. lactea, typically inhabits arid lands where the environment can become very dry and food can become scarce (Storey and Storey, 1990). When confronted with these conditions, snails enter into a state of aerobic torpor called estivation. This state is characterized by major biochemical changes which include the reorganization of fuel utilization, and increases in the concentration of osmolytes for water retention (Storey, 2002). An enzyme that may contribute to these processes is glutamate dehydrogenase, which can contribute $\alpha$-ketoglutarate for aerobic energy production and $\mathrm{NH}_{4}{ }^{+}$for ureogenesis. This investigation shows that foot muscle GDH from control and estivating land snails displays markedly different kinetic properties, responses to metabolites, and is interconverted between two forms by reversible phosphorylation.

The initial kinetic studies of GDH revealed distinctly different stories for the forward and reverse reactions. In the forward (glutamate-oxidizing) direction, GDH from the estivating land snail was more active than GDH from the control snails. Estivated GDH displayed a significantly lower $\mathrm{K}_{\mathrm{m}} \mathrm{NAD}^{+}, \mathrm{K}_{\mathrm{m}}$ glutamate (with ADP), as well as significant increases in $\mathrm{V}_{\max }$ both with and without ADP as compared to control (Table 4.1). Conversely, estivated GDH in the reverse direction was significantly less active when compared to control. Evidence for this stems from the significant increases in $K_{m}$ $\alpha$-ketoglutarate, $\mathrm{K}_{\mathrm{m}} \mathrm{NH}_{4}{ }^{+}$, and dramatic decreases in $\mathrm{V}_{\max }$ both with and without ADP for estivated GDH as compared to control GDH (Table 4.2).

The activation of the glutamate-oxidizing reaction for GDH during osmotic stress is not unheard of in species that encounter high-salinity or dry environments. For 
instance, studies with euryhaline anurans have shown that hypersalinity-induced urea biosynthesis was associated with increased GDH activity in the forward direction, in conjunction with increased activity of the urea cycle enzymes (Lee et al., 1982).

Furthermore, Ip et al. (1994) showed that an anoxia-tolerant species of worm (Phascolosoma arcuatum) displayed markedly different GDH kinetics during anoxia. They noted that during anoxia, there were significant increases in $\mathrm{NH}_{4}{ }^{+}$production when compared to the normoxic situation, and they attributed this to the greater deaminating activity of GDH in this state.

The activation of the forward reaction observed in this study during estivation coincides with the biochemical changes that transpire in this hypometabolic state. For example, one of the strategies employed by land snails to survive drought conditions is to accumulate metabolites which increase the osmolarity of body fluids and retain as much water as possible. Typically the increases in osmolarity are mediated by the production of urea, which can reach concentrations as high as $150-300 \mathrm{mM}$ in some land snail species (Rees and Hand, 1993). Urea production by the urea cycle is mainly confined to the liver or hepatopancreas, however there have been recent studies that indicate that extrahepatic urea production is possible. For instance, several fish species including the little skate (Raja erinacea; Steele et al., 2005), the spiny dogfish (Squalus acanthias; Kajimura et al., 2005), the Lake Magadi tilapia (Alcolapia grahami; Lindley et al., 1999) and the largemouth bass (Micropterus dolomieu; Kong et al., 1998) display significant amounts of urea cycle enzyme activity in muscle and/or intestinal tissues. Many of these animals, and several other species, have shown increased extrahepatic urea synthesis during periods of stress. For instance, Saha et al. (1999) proposed that extrahepatic urea 
production may be important in the walking catfish (Clarias batrachus) during habitat drying, similar to that seen during snail estivation. Although the activity of the urea cycle enzymes and the urea content of $O$. lactea foot muscle during estivation are unknown, muscle urea content is known to increase in the estivating Giant African snail, Achatina fulica (Hiong et al., 2005). Since ammonia derived from amino acid catabolism is the main source of ammonia for urea production (Garrett and Grisham, 2005b), it is plausible that activation of the ammonia-producing GDH reaction in the snail foot muscle might contribute to the accumulation of urea for the purpose of water retention during estivation. Further studies on the presence and activity of urea cycle enzymes in $O$. lactea foot muscle would have to be conducted to reveal if this actually occurs in vivo. Another possibility for muscle-borne ammonia is that it could be exported into the hemolymph and transported to another organ for processing into urea. Muscle tissue is generally known to both release and take in ammonia from the blood in vertebrates (Schiff et al., 2006), and this likely extends to invertebrates since ammonia transporters are well known in both prokaryotes and eukaryotes (Andrade and Einsle, 2007). Once transported into the blood the ammonia may be taken up by another organ, such as the hepatopancreas (as occurs in vertebrate liver; Monahan et al., 1972), and subsequently be processed into urea.

In the short term, animals can withstand small increases in ammonia levels without significant adverse effects. In the case of the estivating land snail, the increases in ammonia would serve the same purpose as increases in urea levels (i.e. increasing osmolarity of body fluids to prevent water loss). However, at higher concentrations ammonia becomes toxic. Ammonia is capable of reacting with body water to produce 
ammonium hydroxide which can negatively affect tissues in three ways: (1) the formation of ammonium hydroxide is very exothermic and can lead to significant thermal damage, (2) ammonium hydroxide is a strong base that acts on the tissues and causes liquefaction necrosis, and (3) ammonium hydroxide is known to inhibit the citric acid cycle (Luttrell, 2002). Thus, to prevent these effects, ammonia is typically converted into urea or uric acid, which is a much less toxic nitrogenous compound. Hence, during estivation, the ammonium ion released from GDH-mediated amino acid catabolism will likely lead to a small increase in tissue ammonia levels and a continuous rise in urea synthesis over time.

Although the build-up of urea during estivation is advantageous to prevent water loss, it may negatively affect enzyme function due to its ability to disrupt enzyme secondary structure (as investigated in Chapter 2). Typically those organisms that accumulate urea combat its potentially harmful effects by (1) developing urea-adapted proteins and/or (2) counteracting the effects of urea with other metabolites. In the latter case, the counteracting metabolites are typically methylamines that stabilize macromolecules when present at sufficient levels in the cell (Burg et al., 1999). Direct measurement of methylamines have not been determined for $O$. lactea, however, studies on the estivating Mountain snail indicate that only low levels of counteracting metabolites are present during estivation (Rees and Hand, 1993). Thus, it is likely that the land snails have evolved enzymes that can withstand high concentrations of urea in the absence of any counteracting agents.

In addition to the possible role of foot muscle GDH in urea production, it is likely that the activation of the glutamate-oxidizing reaction contributes to aerobic energy production during estivation. Fuel metabolism during land snail estivation changes over 
time, carbohydrates being oxidized primarily with amino acid catabolism becoming increasingly important as desiccation stress rises and carbohydrate stores are depleted (Rees and Hand, 1993). The tissues used in this study were taken from snails that had been estivating for 10 days. At this early stage in estivation it is likely that the majority of the energy produced in cells was still derived from carbohydrate oxidation with small amounts of energy derived from protein and lipid catabolism. Thus, further activation of GDH may occur in the later stages of estivation, where the snail would rely more heavily on glutamate oxidation for energy production.

As mentioned in Chapter 2, $\alpha$-ketoglutarate produced via the glutamate-oxidizing reaction can be converted to phosphoenolpyruvate and eventually to glucose by the gluconeogenic pathway (Stryer, 1995). However, this pathway is typically relegated to the snail hepatopancreas and is not generally seen in muscle tissue. Thus, activation of foot muscle GDH is unlikely to contribute to the increased gluconeogenic activity seen during land snail estivation (Storey, 2002).

The reduced activity of the reverse reaction during land snail estivation also coincides with the typical biochemical changes observed in this hypometabolic state. For instance, estivation involves a large reduction in metabolic rate, and this typically requires a suppression of most anabolic processes. Particularly important is the suppression of protein synthesis, which if maintained at normal levels during estivation would be impossibly costly (Storey, 2002). Indeed, studies on numerous estivating species including some frogs and pulmonate land snails, show a drastic decrease in protein synthesis (Pakay et al., 2002). Thus, it makes sense that the synthesis of glutamate via GDH, presumably for the eventual synthesis of proteins, is suppressed 
during land snail estivation. It is interesting to note, however, that glutamate levels have been known to rise in some species (i.e. the spadefoot toad) during estivation. However, this increase in glutamate concentration, as well as the concentration of some other amino acids, during estivation is typically associated with protein breakdown rather than amino acid synthesis (Cowen et al., 2000).

The kinetic differences outlined above indicate that there may be distinct structural differences between the control and estivated forms of GDH. To further investigate the structural difference between the two enzyme forms, an anion exchange column was performed. The representative elution profiles of control and estivated GDH on a $\mathrm{DEAE}^{+}$column is shown in figure 4.2 , and indicates that the control enzyme elutes off of $\mathrm{DEAE}^{+}$at a higher salt concentration when compared to estivated GDH. The differences in the elution profiles shows that each enzyme form has a distinct charge distribution. Changes in surface charge distribution can be the result of enzyme regulation by some form of posttranslational modification. Since reversible phosphorylation is the most common form of posttranslational modification, purified GDH from control and estivating foot muscle was run on SDS-PAGE and stained by ProQ Diamond phosphoprotein stain to determine if the enzyme existed in differently phosphorylated states. Figure 4.1 indicates that GDH from the estivating animal is significantly more phosphorylated than the control enzyme. Thus, it appears that the kinetic and structural differences identified in this study may be due to phosphorylation of GDH during estivation.

Regulation of metabolic enzymes through changes in phosphorylation state during O. lactea estivation has been reported previously. Several glycolytic enzymes have been 
found to be regulated in this fashion in the land snail, including glycogen phosphorylase (Brooks and Storey, 1990), phosphofructokinase (Whitwam and Storey, 1991), pyruvate kinase (Whitwam and Storey, 1990), and pyruvate dehydrogenase (Brooks and Storey, 1992). Furthermore, reversible phosphorylation has also been identified as the regulatory mechanism for enzymes outside glycolysis. For instance, glucose-6-phosphate dehydrogenase, a key enzyme in the pentose phosphate pathway, and the $\mathrm{Na}^{+} / \mathrm{K}^{+}$-ATPase membrane ion pump are regulated in this fashion during estivation (Ramnanan and Storey, 2006ab). Many of these enzymes exist in a high-phosphate form during estivation, which corresponds to the inactivation of these enzymes during hypometabolism. This correlates well with the phosphorylation of foot muscle GDH during land snail estivation found in this study. The existence of these enzymes in a high-phosphate form during estivation suggests that protein kinases must be active during the early stages of estivation, and possibly throughout the prolonged dormant period. Although the individual protein kinases that act on GDH in vivo have not been investigated in this study, previous studies on protein kinases in $O$. lactea indicate which kinases may phosphorylate GDH during estivation. For instance, Brooks and Storey (1996) determined that the levels of cyclic GMP rise during estivation in O. lactea. An increased cGMP level subsequently activates protein kinase $\mathrm{G}(\mathrm{PKG})$ making it a possible regulator of GDH activity. Alternatively, protein kinase A appears to decrease in activity during estivation and is unlikely to be part of GDH regulation in vivo (Brooks and Storey, 1994).

Similar to the situation with the protein kinases, very little work has been done on the role of protein phosphatases during estivation in $O$. lactea. Work on estivation in the 
spadefoot toad could suggest the role of protein phosphatases during this hypometabolic state, however, the protein phosphatases displayed varied responses to estivation, which not only depended on the type of phosphatase but also the tissue in which it was located (Storey, 2002). Unfortunately, few phosphatases were investigated in the skeletal muscle of the toad and thus would have a limited applicability to the phosphatases in the foot muscle of $O$. lactea.

In addition to the effect of phosphorylation on GDH substrate kinetics, phosphorylation of GDH also altered the enzyme's responses to common cellular intermediates. For instance, both control and estivating GDH showed similar affinities for ADP in the forward reaction, however, the fold activation by ADP was significantly higher for the low-phosphate control form of GDH (Table 4.1). This difference may reflect the energy requirements in the two states; in the control state, cellular energy needs are high and a decrease in the energy state of the cell could necessitate a much greater GDH response to enhance glutamate oxidation as a fuel, mediated by ADP as a signal of low energy. Alternatively, during estivation where energy needs are low, a dramatic increase in GDH activity would likely cause a backup of the TCA cycle as oxygen consumption, and therefore ETC activity, is reduced during estivation (Barnhart, 1986). This large increase in fold activation for the control form of GDH was not seen for the reverse reaction of this enzyme. Furthermore, the $\mathrm{K}_{\mathrm{a}} \mathrm{ADP}$ measured in the reverse reaction was not significantly different between active and estivating snails (Table 4.2). Muscle ADP concentrations are typically above the $\mathrm{K}_{\mathrm{a}}$ values for both control and estivated GDH observed here, and thus are likely a factor in regulating GDH activity in vivo. 
In addition to ADP, the effect of other cellular energy molecules was assessed on the reverse reaction of GDH. For instance, estivated GDH was relatively unresponsive to the addition of AMP to the assays, whereas control GDH was activated at low millimolar concentrations. The AMP concentration in O. lactea foot muscle is known to be 0.34 $\mu \mathrm{mol} / \mathrm{g}$ wet weight under control conditions $(\sim 0.34 \mathrm{mM})$, and $0.23 \mu \mathrm{mol} / \mathrm{g}$ wet weight during dormancy ( $\sim .23 \mathrm{mM}$; Churchill and Storey, 1989). Based on these results, the intracellular foot muscle AMP concentrations would be high enough to activate the control enzyme but not the estivated enzyme in this study. In response to ATP, control GDH displayed an $\mathrm{I}_{50}$ ATP of $7 \mathrm{mM}$ whereas estivated GDH was uninhibited at concentrations up to $10 \mathrm{mM}$. The ATP concentrations reported by Churchill and Storey (1989) indicate that land snail muscle ATP concentrations are appoximately $0.83 \mu \mathrm{mol} / \mathrm{g}$ wet weight $(\sim 0.83 \mathrm{mM})$ under control conditions, and $1.16 \mu \mathrm{mol} / \mathrm{g}$ wet weight $(\sim 1.16 \mathrm{mM})$ during estivation. With the control $\mathrm{I}_{50}$ ATP being so high it is likely that both of these enzymes are unaffected by ATP in vivo. Alternatively, GDH was highly responsive to GTP, and both control and estivated GDH was inhibited at low micromolar concentrations. It is important to note that estivated GDH displayed a significantly lower $\mathrm{I}_{50}$ GTP in comparison to the control enzyme. Although the in vivo concentration of GTP is unknown, sensitive measurements of guanylate levels in Helix aspersa maxima muscle showed undetectable amounts of GTP (Rac et al., 2007). Thus, the importance of GTP for regulating GDH in vivo is unknown. That being said, the unresponsiveness of the reverse reaction of estivated GDH to AMP and the significantly higher sensitivity to GTP inhibition coincides with a shutdown of the glutamate-synthesizing reaction during estivation. 
Another metabolite tested on the reverse reaction of GDH was citrate, a common product of lipid oxidation. Since, a constant and low level of lipid oxidation occurs in $O$. lactea during estivation, citrate accumulates to appreciable amounts. Citrate is known to inhibit some metabolic enzymes, such as phosphofructokinase and glucose-6-phosphate dehydrogenase in the land snail during estivation and anoxia (Whitwam and Storey, 1991; Ramnanan and Storey, 2006a). Citrate is thought to bind to allosteric sites on PFK which have a similar structure to allosteric ADP binding sites (Li et al., 1999). Knowing the effect of citrate on some metabolic enzymes found in the land snail and its possible binding to ADP-binding sites, I investigated the effects of this metabolite on GDH activity in this study. Table 4.3 shows that neither control nor estivated GDH showed any significant response to the addition of citrate up to $10 \mathrm{mM}$, and therefore this metabolite does not appear to be a significant regulator of GDH activity in vivo.

The kinetic changes elucidated in this study strongly suggest that foot muscle GDH exists in two different forms under control and estivating conditions in the land snail, O. lactea. As revealed by ProQ Diamond phosphoprotein staining and ion exchange chromatography, these kinetic changes appear to be due to reversible phosphorylation of GDH. The differently phosphorylated forms display distinctly different behaviours, with the forward reaction being activated and the reverse reaction inhibited for estivated GDH in comparison to control GDH. This correlates well with the increased use of amino acids for energy, as well as the increased synthesis of urea for water retention during prolonged estivation. 
Chapter 5

\section{General Discussion}


Animals that have adapted to withstand unforgiving environmental conditions have to deal with drastic decreases in essential resources. In order to survive, they must rely on their endogenous fuel reserves and an establishment of a new balance between ATP-consuming and ATP-producing processes. These requirements necessitate major behavioural, physiological, and biochemical adaptations. Particularly important are the biochemical changes, which include the reprioritization of energy use, altered expression of many proteins, differential regulation of many enzymes, and a strong reduction in overall metabolic rate.

Metabolic rate depression is the key biochemical mechanism that allows organisms to survive in the face of harsh environmental conditions. Metabolic rates can drop by 70 to nearly $100 \%$ depending on the animal, and this allows sufficient energy savings for prolonged survival during stress. Since environments can change rather quickly these changes must be induced and reversed just as quickly. Changes in metabolic rate are typically mediated by the posttranslational regulation of key metabolic enzymes that control ATP-consuming and ATP-producing pathways. The regulatory mechanism usually responsible for such alterations is reversible protein phosphorylation. Indeed, protein phosphorylation has been known to regulate glycolysis, fatty acid catabolism, nucleotide biosynthesis, protein synthesis, ion channel functioning as well as other major biochemical pathways in various hypometabolic organisms (Frank et al., 1998; Frerichs et al., 1998; Ramnanan and Storey, 2006ab; Storey and Storey, 1990; Storey and Storey, 2004). Given that phosphorylation is one of the most prevalent and powerful regulatory mechanisms for metabolic regulation, the research in this thesis explored the role of reversible phosphorylation in the regulation of amino acid 
metabolism within organisms that transition into hypometabolic states. Glutamate dehydrogenase is a key component in amino acid metabolism and is the enzyme investigated in this study.

The studies presented in this thesis involve three organisms that depress their metabolic rate in response to vastly different environmental stressors. Richardson's ground squirrels enter into a state of aerobic torpor, called hibernation, to survive cold winters where their food (e.g. grasses, herbs, seeds, insects) is lacking. Freshwater turtles, on the other hand, enter into a state of anaerobic hypometabolism when submerged in cold water during the winter and/or during prolonged diving at other seasons. Lastly, pulmonate land snails enter an aerobic dormancy in response to arid conditions (often at high temperatures) and the corresponding stresses of dehydration and decreased food availability. Although all of these animals suppress their metabolic rate overall, each animal displays selective enhancement or suppression of various biochemical pathways depending on the needs of the organism during hypometabolism.

\section{The role of GDH during Richardson's ground squirrel hibernation}

Richardson's ground squirrels (S. richardsonii) enter into hibernation when confronted with harsh winter conditions. Hibernation is composed of torpor bouts that can eventually reach as long as several weeks, interspersed with short periods of arousal where the squirrel re-establishes normal euthermic functioning (Carey et al., 2003). During torpor, squirrels reprioritize cellular energy use by suppressing carbohydrate oxidation and activating fatty acid and amino acid breakdown, as well as 
gluconeogenesis. Although lipolysis is the main energy source during hibernation, a significant portion of cellular energy may be derived from amino acid oxidation.

In analyzing the kinetics of liver glutamate dehydrogenase from euthermic and hibernating ground squirrels, it was evident that there were significant differences between the two states. In general, the hibernator form of GDH was significantly more active than the euthermic enzyme form. Incubations that stimulated endogenous protein kinases (PKA, PKC, AMPK, and CaMK) and phosphatases (PP2B, PP2C, and total serine/threonine phosphatases) indicated that these kinetic changes were likely mediated by reversible phosphorylation. Indeed, ProQ Diamond phosphoprotein staining of GDH from both conditions confirmed that the hibernator enzyme was significantly less phosphorylated than euthermic GDH. Both kinases and phosphatases were capable of acting on both enzyme forms, indicating that euthermic and hibernator GDH are phosphoenzymes, however, they are phosphorylated to different degrees under the two conditions. Since hibernation is characterized by a decrease in muscle mass (Wang, 1989), the activation of GDH during hibernation likely leads to an increase in amino acid catabolism rather than an increase in amino acid synthesis during torpor. The breakdown of glutamate into $\alpha$-ketoglutarate and ammonia contributes to energy production and gluconeogenesis via the Krebs cycle.

Another important factor to consider when assessing GDH during hibernation is its ability to function at low temperatures. The studies conducted in this thesis suggest that the hibernator form of GDH is well suited for function at $\sim 5^{\circ} \mathrm{C}$, which is close to the typical core body temperature of ground squirrels during torpor. 


\section{The role of GDH in anoxia-tolerant turtles}

The freshwater turtle, $T$. s. elegans, survives cold winters by becoming a facultative anaerobe while submerged underwater for prolonged periods of time. Their inability to take up oxygen from the surrounding water necessitates a strong suppression of their metabolic rate and reorganization of several metabolic pathways (Storey, 2004a). For instance, during this anaerobic torpor, the turtles completely rely on glycolysis for energy production and shutdown oxygen-related processes such as the Krebs cycle and the electron transport chain (Storey and Storey, 1990).

The study of purified turtle liver GDH indicated that the enzyme from $20 \mathrm{~h}$ anoxic turtles was significantly less active in both the forward and reverse directions as compared to the control condition. Specific phosphatase incubations and phosphoprotein staining suggested that the inactivation of GDH during anoxia was mediated by reversible phosphorylation. These studies showed that the anoxic form of GDH was substantially less phosphorylated than its counterpart from the control condition. Decreased GDH activity in the glutamate-oxidizing direction during anoxia coincides with reduced functioning of the Krebs cycle and ETC, as shuttling $\alpha$-ketoglutarate into the Krebs cycle would be useless and uneconomical during anaerobiosis. Furthermore, decreased GDH activity in the glutamate-synthesizing direction corresponds with the fact that synthetic processes are largely shutdown during hypometabolism.

Another factor to consider in the regulation of GDH during anoxia is the substantial acidification that occurs during this period due to the build up of intracellular lactic acid. The drop in $\mathrm{pH}$ appeared to have a negative affect on the glutamate-oxidizing 
reaction for anoxic GDH, further decreasing the likelihood of glutamate catabolism (and a resulting build-up of Krebs cycle intermediates) during anoxia.

\section{The role of GDH during land snail estivation}

The pulmonate land snail, $O$. lactea, survives seasonally high temperatures and arid conditions by entering into an aerobic dormancy called estivation. Many of the adaptations possessed by these estivators are tailored to retaining body water and conserving metabolic fuel reserves. For instance, these land snails preserve water by producing a hardened mucous membrane over their shell opening, apnoic breathing patterns, and the accumulation of osmolytes (Rokitka and Herreid, 1975; Barnhart and McMahon, 1987; Rees and Hand 1993). Particularly important to the present research is the appreciable accumulation of urea during estivation, which indicates an increased reliance on amino acid metabolism during this dormancy.

The present study investigated GDH from the foot muscle of $O$. lactea. Initial kinetic studies revealed that GDH displayed substantially different behaviours when taken from the active and estivating conditions. The kinetics indicated that the glutamate-oxidizing reaction becomes activated and the glutamate-synthesizing reaction becomes suppressed during estivation. This would support amino acid oxidation during estivation both as a fuel source and for the production and accumulation of the osmolyte, urea. The kinetic changes appear to be the result of regulation by reversible phosphorylation as evidenced by ProQ Diamond phosphoprotein staining and DEAE ${ }^{+}$ion exchange chromatography. GDH from estivating snails was present in a more highly phosphorylated state as compared to controls. 


\section{GDH in hypometabolic states}

The fact that GDH affects important cellular processes such as energy production and nitrogen metabolism necessitates some form of regulation during dormancy. The present study has shown that various factors could regulate GDH in vivo during hypometabolism. In all studies undertaken in this thesis, ADP was a potent activator and GTP was a potent inhibitor of GDH activity, and depending on the intramitochondrial concentrations, these molecules could be factors in regulating GDH activity during dormancy. In addition to the effects of these small allosteric effector molecules, GDH activity was affected by other conditions that are specific to particular hypometabolic states. For instance, low temperatures experienced during ground squirrel hibernation can greatly affect metabolic enzyme activity, and was shown to increase substrate affinities for ground squirrel liver GDH. Furthermore, tissue acidification that typically develops due to anaerobic metabolism in the freshwater turtle increased the suppression of the glutamate-oxidizing reaction of liver GDH. Thus, it is likely that numerous factors work in concert to regulate GDH in vivo during hypometabolism.

Although those factors identified above may be significant regulators of GDH activity, one of the most important mechanisms that controls major changes in the activity states of enzymes during transitions to and from a hypometabolic state is reversible protein phosphorylation. Indeed, in the present study, GDH was found to be regulated by reversible phosphorylation during hibernation, anoxia and estivation, however the regulation of GDH was slightly different in each state. During ground squirrel hibernation and freshwater turtle anoxia, GDH was present in a low-phosphate 
form that led to the activation and suppression of GDH activity, respectively, as compared with the corresponding aroused or aerobic states. Alternatively, GDH from foot muscle of the land snail was present in a high-phosphate form during estivation and this led to activation of the glutamate-oxidizing reaction and a suppression of the glutamate-synthesizing reaction.

It has been well established that protein phosphorylation can lead to the activation or suppression of enzyme activity. Although most would assume the effects of phosphorylation on a particular enzyme would be the same regardless of species, a review of the literature reveals that this is not the case. Indeed, phosphorylation of some enzymes can have both inhibitory and stimulatory effects. For instance, Xenopus oocyte $\mathrm{Na}^{+} / \mathrm{K}^{+}$-ATPase is known to be activated by PKA phosphorylation, whereas PKA stimulation of this enzyme in mouse $\mathrm{LTK}^{-}$and human HeLa cells led to a decrease in pump activity (Cheng et al., 1999). Furthermore, rat renal proximal tubule $\mathrm{Na}^{+} / \mathrm{K}^{+}$ ATPase is known to be both activated and inhibited by phosphorylation mediated by PKC (Cheng et al., 1999). The differences in the effect of phosphorylation are at least in part due to various tissue preparation and assay conditions, however, species-specific differences in phosphorylation effects cannot be completely discounted. Additionally, recent studies on glucose-6-phosphate dehydrogenase (G6PDH), a key enzyme in the pentose phosphate pathway, have shown species-specific differences in the effects of phosphorylation. G6PDH from liver of the freeze-tolerant wood frog, Rana slyvatica, was shown to be in a low-phosphate and less active form when assayed from the frozen state, whereas G6PDH from the anoxia-tolerant marine snail, Littorina littorea, was in a low-phosphate and more active form during anoxia (C. Dieni, unpublished; J. Lama, 
unpublished). Furthermore, the effects of phosphorylation on the activity of AMP deaminase (AMPD) vary for several hypometabolic organisms. For instance, muscle AMPD is phosphorylated and activated during anoxia exposure of turtles (Zhou, 2006), whereas AMPD in the muscle of wood frogs was phosphorylated and inactivated during frog freezing (Dieni and Storey, 2008). These examples indicate that the effects of phosphorylation on an enzyme can vary in response to different stresses, as is seen with GDH in the present study.

Phosphorylation-induced inhibitory and stimulatory effects on enzymes may be the result of protein phosphorylation at different sites. Site-specific phosphorylation typically requires various protein kinases, as each kinase binds to certain amino acid sequences on a protein. Glycogen synthase provides evidence for an enzyme with multiple phosphorylation sites, and an enzyme that may be acted on by various protein kinases. An early review on this enzyme identified numerous kinases such as phosvitin kinase, a cAMP-independent protein kinase, PKA, PKG, as well as others that were capable of phosphorylating glycogen synthase (Krebs and Beavo, 1979). Some kinases were more effective in altering synthase activity than others (i.e. phosvitin kinase did not change synthase activity as much as some of the other kinases), which indicates that the location of phosphorylation is an important factor in the regulation of enzyme activity (Krebs and Beavo, 1979). Another interesting study on the site-specific effects of enzyme phosphorylation was conducted on rat epididymal fat pads, where differences in acetyl-CoA carboxylase phosphorylation patterns were investigated in response to insulin and epinephrine (Witters et al., 1983). These researchers found that exposure to insulin or epinephrine led to different site-specific phosphorylations of acetyl-CoA carboxylase. 
Moreover, they found that acetyl-CoA carboxylase phosphorylation in response to epinephrine caused a significant decrease in enzyme activity, whereas exposure to insulin caused an increase in enzyme activity. This increase, however, could not be confirmed to be due to phosphorylation because the increase in activity did not survive purification procedures, and thus may have been due to outside factors. Nevertheless, this study provides an interesting example of an enzyme that is differently phosphorylated in response to outside stimuli.

Another factor to consider when looking at the various affects of phosphorylation on GDH is the possibility of tissue-specific regulation of this enzyme. This is important when comparing the effects of phosphorylation on liver GDH (from the ground squirrel and turtle) to muscle GDH (for the land snail). Organ-specific regulation of enzymes is a well established phenomenon in many animal species. For instance, the human pyruvate dehydrogenase complex (PDC) appears to be regulated in a tissue-specific manner via phosphorylation. This regulation is mediated by the tissue-specific expression of pyruvate dehydrogenase kinases which phosphorylate PDC in a site-specific manner (Bowker-Kinley et al., 1998). Another example was recently elucidated in the marine snail, Littorina littorea, which displays organ-specific regulation of the glycolytic enzyme, hexokinase (J. Lama, unpublished). Other examples include the organ-specific regulation of phosphofructokinase, pyruvate kinase, and glycogen phosphorylase in the marine whelk during anaerobiosis (Storey et al., 1990), and the tissue-specific regulation of glycogen phosphorylase in the anoxia-tolerant goldfish (Storey, 1987b). Furthermore, studies with wood frogs have demonstrated that there is a substantial difference in the anaerobic energy requirements of different organs during freezing, indicating that there is 
likely tissue-specific regulation of metabolism and possibly tissue-specific needs for amino acids as fuel sources during this period (Storey, 1987c). Taken together these examples indicate that the energetic needs of every organ are different during hypometabolism, and therefore require tissue-specific regulation of key metabolic enzymes.

\section{Conclusion}

In conclusion, in this thesis, I have demonstrated that GDH may play an important, yet varied, role in the survival of several organisms that enter into hypometabolic states. GDH was found to be regulated by reversible phosphorylation during hibernation, anaerobiosis, and estivation; however, the effects of regulation depended on the specific cellular needs in each hypometabolic state. GDH from Richardson's ground squirrels displayed a propensity to oxidize glutamate during hibernation to aid in energy production and contribute to gluconeogenesis. Similarly, the estivating land snail, $O$. lactea, activated the glutamate-oxidizing reaction of GDH during dormancy to aid in energy production, and contribute to urea biosynthesis. By contrast, the glutamate-oxidizing and glutamate-producing reactions of liver GDH of freshwater turtles were suppressed during anoxia in conjunction with the inhibition of oxygen-based metabolism.

\section{Future Directions}

The studies described in this thesis identified the effects of GDH regulation in several hypometabolic states; however, these studies also reveal new directions which 
may be pursued in the future. Of course there is a large amount of work that can be performed on GDH from the animals studied in this thesis as well as on other animals that use hypometabolism to survive a wide range of environmental stresses that include different demands on amino acid metabolism. These studies would include kinetic analyses of the enzyme in the forward and reverse directions with both $\mathrm{NAD}(\mathrm{P})^{+}$and $\mathrm{NAD}(\mathrm{P}) \mathrm{H}$ used as cofactors, respectively. These investigations may also include the determination of activator or inhibitor constants for various adenine and guanine nucleotides as well as other species-specific molecules that may build up in their hypometabolic state.

Aside from additional studies on GDH itself, there are several future studies, linked to the present research that could be pursued. Some important new directions are outlined below:

\section{Signal Transduction}

As stated previously, organisms that are capable of entering into a hypometabolic state to survive harsh environmental conditions require quick adjustments to cellular metabolism without major reorganization of cellular biochemistry. These rapid alterations are typically mediated by reversible phosphorylation, which is brought about by the action of protein kinases and protein phosphatases. The study presented here on the regulation of ground squirrel GDH by phosphorylation identified possible candidate kinases and phosphatases that may regulate the enzyme in vivo. A look into the physical and kinetic properties of these kinases and phosphatases may be important in developing an overall picture of the biochemical events that occur during hypometabolism. Selected protein kinases can be assayed radioactively through the use of ${ }^{32} \mathrm{P}-\mathrm{ATP}$ and specific 
peptide substrates, whereas the activity of protein phosphatases can be measured using a dye-binding assay that detects phosphate release (i.e. malachite green assay). Studies could include kinetic analyses, temperature effects, and the determination of conformational stability for phosphatases from both euthermic and hibernating ground squirrels. Although the specific kinases and phosphatases that acted on turtle liver GDH and land snail foot muscle GDH were not identified here, the kinases and phosphatases found for the ground squirrel may be important regulators for those animals as well. Thus, these studies may be conducted in the various animals used in this thesis.

Indeed, preliminary studies on protein phosphatase 2C from liver of Richardson's ground squirrel showed significant activation of the enzyme during hibernation. The $K_{m}$ for the PP2C peptide and $\mathrm{K}_{\mathrm{a}} \mathrm{MgCl}_{2}$ decreased substantially during hibernation, which coincides with the significant increase in PP2C activity found by MacDonald and Storey (2007) for these ground squirrels during torpor. Activation of PP2C during hibernation makes this enzyme a potential regulator of liver GDH activity in vivo.

\section{Urea Cycle}

The urea cycle is essential to the conversion and detoxification of ammonia that is produced through amino acid catabolism. In two of the studies conducted in this thesis, specifically on ground squirrel and land snail GDH, there was an activation of the glutamate-oxidizing reaction of GDH which would mean an increased production of intracellular ammonia. This increased ammonia production suggests that the urea cycle may also become activated during hibernation and estivation to compensate for the increased amino acid breakdown. Carbamoyl phosphate synthase I (CPSI) is the rate- 
limiting enzyme for the urea cycle and catalyzes the conversion of ATP and bicarbonate to carbamoyl phosphate and ADP. To determine the activity of CPSI the reaction is coupled to ornithine transcarbamoylase, which produces citrulline (Davis et al., 2000). Citrulline can be measured colorimetrically via the use of diacetylmonoxime and a strongly acidic solution, with spectrophotometric measurement at $490 \mathrm{~nm}$ (Archibald, 1944). A study of CPSI would be particularly interesting in conjunction with the activation of the glutamate-oxidizing reaction of GDH in land snail foot muscle, since extrahepatic urea production is rare and typically only seen to date in organisms undergoing osmotic stress. Studies of this urea cycle enzyme could also be conducted on the freshwater turtle, with the prediction that this energy expensive process would be suppressed during anoxia. 


\section{References}

Andrade, S.L., and Einsle, O. (2007). The Amt/Mep/Rh family of ammonium transport proteins. Mol. Membr. Biol. 24(5-6): 357-365.

Andrews, M.T., Squire, T.L., Bowen, C.M., and Rollins, M.B. (1998). Low-temperature carbon utilization is regulated by novel gene activity in the heart of a hibernating mammal. Proc. Natl. Acad. Sci. USA 95: 8392-8397.

Archibald, R.M. (1944). Determination of citrulline and allantoin and demonstration of citrulline in blood plasma. J. Biol. Chem. 156(1): 121-142.

Barnhart, M.C. (1986). Respiratory gas tensions and gas exchange in active and dormant land snails Otala lactea. Physiol. Zool. 59: 733-745.

Barnhart, M.C. and McMahon, BR. (1987). Discontinuous $\mathrm{CO}_{2}$ release and metabolic depression in dormant land snails. J. Exp. Biol. 128: 123-138.

Bauer, V.W., Squire, T.L., Lowe, M.E., and Andrews, M.T. (2001). Expression of a chimeric retroviral-lipase mRNA confers enhanced lipolysis in a hibernating mammal. Am. J. Physiol. Regul. Integr. Comp. Physiol. 281: R1186-R1192.

Bintz, G.L., and Torgerson, G.E. (1981). The metabolism of $\left[{ }^{14} \mathrm{C}\right]$ urea by control and starved Richardson's ground squirrels. Comp. Biochem. Physiol. A. 69: 551-555.

Bowker-Kinley, M.M., Davis, W.I., Wu, P., Harris, R.A., and Popov, K.M. (1998). Evidence for existence of tissue-specific regulation of the mammalian pyruvate dehydrogenase complex. Biochem. J. 329: 191-196.

Bowman, R.H. (1966). Effects of diabetes, fatty acids, and ketone bodies on tricarboxylic acid cycle metabolism in the perfused rat heart. J. Biol. Chem. 241(13): 30413048.

Brooks, S.P.J. (1994) A program for analyzing enzyme rate data obtained from a microplate reader. BioTechniques 17, 1155-1161.

Brooks, S.P.J. and Storey, K.B. (1990). Glycolytic enzyme binding and metabolic control in estivation and anoxia in the land snail Otala lactea. J. Exp. Biol. 151: 193-204.

Brooks, S.P.J. and Storey, K.B. (1992). Properties of pyruvate dehydrogenase from the land snail, Otala lactea: control of enzyme activity during estivation. Physiol Zool. 65: 620-633.

Brooks, S.P.J. and Storey, K.B. (1992). Protein kinase involvement in land snail aestivation and anoxia: protein kinase A kinetic properties and changes in second messenger compounds during depressed metabolism. Mol. Cell. Biochem. 156(2): 
$153-161$.

Brooks, S.P.J. and Storey, K.B. (1994). Metabolic depression in land snails: in vitro analysis of protein kinase involvement in pyruvate kinase control in isolated $O$. lactea. Can. J. Zool. 72: 856-862.

Buck, M.J., Squire, T.L., and Andrews, M.T. (2002). Coordinate expression of the PDK4 gene: a means of regulating fuel selection in a hibernating mammal. Physiol. Genomics 8: 5-13.

Burg, M.B., Peters, E.M., Bohren, K.M. and Gabbay, K.H. (1999). Factors affecting counteraction by methylamines of urea effects on aldose reductase. Proc. Natl. Acad. Sci. U.S.A. 96(11): 6517-6522.

Campbell, N.A., and Reece, J.B. (2002). Water balance and waste disposal In: Biology ( $6^{\text {th }}$ Edition). Pearson Education Inc. San Francisco, CA. USA. Pg 936-938.

Carey, H.V., Andrews, M.T., and Martin, S.L. (2003). Mammalian hibernation: cellular and molecular responses to depressed metabolism and low temperature. Physiol. Rev. 83: 1153-1181.

Cheng, S.X.J., Aizman, O., Nairn, P., Greengard, P., and Aperia, A. (1999). $\left[\mathrm{Ca}_{2}{ }^{+}\right]_{\mathrm{I}}$ determines the effects of protein kinases $\mathrm{A}$ and $\mathrm{C}$ on activity of rat renal $\mathrm{Na}^{+}, \mathrm{K}^{+}$ATPase. J. Physiol. 518(1): 37-46.

Churchill, T.A., and Storey, K.B. (1989). Intermediary energy metabolism during dormancy and anoxia in the land snail Otala lactea. Physiol. Zool. 62(5): 10151030 .

Cowen, K.J., MacDonald, J.A., Storey, J.M., and Storey, K.B. (2000). Metabolic reorganization and signal transduction during estivation in the spadefoot toad. EBO 5(1): 61-85.

Cowen, K.J., and Storey, K.B. (2001). Protein kinase and phosphatase responses to anoxia in crayfish, Orconectes virilis: Purification and characterization of cAMPdependent protein kinase. Comp. Biochem. Physiol. B 130: 565-577.

Davis, J.A., Greer, F.R., and Benevenga, N.J. (2000). Comparison of Total Body Urea Production Potential with Total Body Carbamoyl Phosphate Synthetase (CPS-1) Activity in Newborn Piglets Infused with Alanine at 50\% of Resting Energy Expenditure for 36 Hours. J. Nutr. 130(8): 1978-1983.

Dieni, C.A. and Storey, K.B. (2008). Regulation of 5'-adenosine monophosphate deaminase in the freeze tolerant wood frog, Rana sylvatica. BMC Biochem. 9:12.

Eddy, S.F., Morin Jr., P., and Storey, K.B. (2006). Differential expression of selected 
mitochondrial genes in hibernating little brown bats, Myotis lucifugus. J. Exp. Zool. 305(8): 620-630.

Eisenberg, H., and Reisler, E. (1970). A physical model for the structure of glutamate dehydrogenase. Biopolymers 9(1): 113-115.

Frank, C.L., Brooks, S.P.J., Harlow, H.J., and Storey, K.B. (1998). The influence of hibernation patterns on the critical enzymes of lipogenesis and lipolysis in prairie dogs. Exp. Biol. Online 3(9): 1-8.

Frasor, K.P., Houlihan, D.F., Lutz, P.L., Leone-Kabler, S., Manuel, L., Brechin, J.G. (2001). Complete suppression of protein synthesis during anoxia with no postanoxia protein synthesis debt in the red-eared slider turtle, Trachemys scripta elegans. J. Exp. Biol. 204: 4353-4360.

Frerichs, K.U., Smith, C.B., Brenner, M., DeGarcia, D.J., Krause, G.S., Marrone, L., Dever, T.E. and Hallenbeck, J.M. (1998). Suppression of protein synthesis in brain during hibernation involves inhibition of protein initiation and elongation. Neurobiology 95(24): 14511-14516.

Garrett, R.H., and Grisham, C.M. (2005a). What is gluconeogenesis, and how does it operate? In: Biochemistry ( $3^{\text {rd }}$ Edition). Thomson Learning Inc. pg 706-712.

Garrett, R.H., and Grisham, C.M. (2005b). Nitrogen acquisition and amino acid metabolism In: Biochemistry ( $3^{\text {rd }}$ Edition). Thomson Learning Inc. pg 825-828.

Geiser, F. (1988). Reduction of metabolism during hibernation and daily torpor in mammals and birds: temperature effect or physiological inhibition? J. Comp. Physiol. B 158(1): 25-37.

Geiser, F. (2004). Metabolic rate and body temperature reduction during hibernation and daily torpor. Annu. Rev. Physiol. 66: 239-274.

Halfpenny, J.C., and Ozanne, R. (1989). Physiological responses In: Winter: An Ecological Handbook. Big Earth Publishing, pp 114-116.

Hemmings, B.A. (1978). Phosphorylation of NAD-dependent glutamate dehydrogenase from yeast. J. Biol. Chem. 253: 5255-5258.

Hemmings, B.A. (1981). Reactivation of the phospho form of the NAD-dependent glutamate dehydrogenase by a yeast protein phosphatase. Eur. J. Biochem. 116: 47-50.

Hemmings, B.A. and Sims, A.P. (1977). The regulation of glutamate metabolism in Candida utilis. Evidence for two interconvertible forms of NAD-dependent glutamate dehydrogenase. Eur. J. Biochem. 80: 143-151. 
Herbert, C.V., and Jackson, D.C. (1985). Temperature effects on the responses to prolonged submergence in the turtle Chrysemys picta belli. II. Metabolic rate, blood acid-base and ionic changes, and cardiovascular function in aerated and anoxic water. Physiol. Zool. 58: 670-681.

Herreid, C.F. (1977). Metabolism of land snails (Otala lactea) during dormancy, arousal and activity. Comp. Bioc. Physiol. A56: 211-215.

Hiong, K.C., Loong, A.M., Chew, S.F. and Ip, Y.K. (2005). Increases in urea synthesis and the ornithine urea-cycle capacity in the Giant African snail, Achatina fulica, during fasting or aestivation, or after the injection of ammonium chloride. J. Exp. Zool. 303A: 1040-1053.

Hittel, D.S. and Storey, K.B. (2001). Differential expression of adipose- and heart-type fatty acid binding proteins in hibernating ground squirrels. Biochim. Biophys. Acta. 1522(3): 238-243.

Hittel, D.S., and Storey, K.B. (2002). Differential expression of mitochondria-encoded genes in a hibernating mammal. J. Exp. Biol. 205: 1625-1631.

Hochachka, P.W., Buck, L.T., Doll, C.J., and Land, S.C. (1996). Unifying theory of hypoxia tolerance: Molecular/metabolic defense and rescue mechanisms for surviving oxygen lack. Proc. Natl. Acad. Sci. 93: 9493-9498.

Hochachka, P.W. and Somero, G.N. (1984). Water-solute adaptations In: Biochemical Adaptation. Princeton University Press. pp. 337-351.

Horman, S., Hussain, N., Dilworth, S.M., Storey, K.B., and Rider, M.H. (2005). Evaluation of the role of AMP-activated protein kinase and its downstream targets in mammalian hibernation. Comp. Biochem. Physiol. B 142(4): 374-382.

Ip, Y.K., Peng, K.W., Chew, S.F., Lim, R.W., and Tan, G.Q. (1994). Ammonia production and kinetic properties of glutamate dehydrogenase in the sipinculid Phascolosoma arcuatum exposed to anoxia. Marine Biology 119(2): 261-266.

Jackson, D.C. (2002). Hibernating without oxygen: Physiological adaptations of the painted turtle. J. Physiol. 543(3): 731-737.

Jackson, D.C., Crocker, C.E., and Ultsch, G.R. (2000). Bone and shell contribution to lactic acid buffering of submerged turtles Chrysemys picta bellii at $3^{\circ} \mathrm{C}$. Am. J. Physiol. Regulatory Integrative Comp. Physiol. 278: R1564-R1571.

Kajimura, M., Walsh, P.J., Mommsen, T.P. and Wood, C.M. (2005). The dogfish shark (Squalus acanthias) increases both hepatic and extrahepatic ornithine urea cycle enzyme activities for nitrogen conservation after feeding. Physiol. Biochem. Zool. 
79: 602-613.

Kong. H., Edberg, D.D., Korte, J.J., Salo, W.L., Wright, P.A., and Anderson, P.M. (1998). Nitrogen excretion and expression of carbamoyl phosphate synthetase III activity and mRNA in extrahepatic tissues of the largemouth bass (Micropterus salmoides) Arch. Biochem. Biophys. 350: 157-168.

Koutsopoulos, S., vand der Oost, J., and Norde, W. (2005). Temperature-dependent structural and functional features of a hyperthermostable enzyme using elastic neutron scattering. Proteins: Structure, Function, and Bioinformatics 61: 377384.

Krebs, E.G. and Beavo, J.A. (1979). Phosphorylation-dephosphorylation of enzymes. Ann. Rev. Biochem. 48: 923-959.

Kumeta, H., Miura, A., Kobashigawa, Y., Miura, K., Oka, C., Nemoto, N., Nitta, K., and Tsuda, S. (2003). Low-temperature-induced structural changes in human lysozyme elucidated by three-dimensional NMR spectroscopy. Biochemistry 42(5): 1209-1216.

Lee, A.R., Lilove, M., Katz, U., and Balinsky, J.B. (1982). Urea cycle enzymes and glutamate dehydrogenase in Xenopus laevis and Bufo viridis adapted to high salinity. J. Exp. Zool. 221: 169-172.

Lee, E., Yoon, H., Ahn, J., Choi, S.Y., and Cho, S. (2001). Identification of the GTP binding site of the human glutamate dehydrogenase by cassette mutagenesis and photoaffinity labelling. J. Biol. Chem. 276(51): 47930-47936.

Li, Y., Rivera, D., Ru, W., Gunasekara, D., and Kemp, R.G. (1999). Identification of allosteric sites in rabbit phosphofructo-1-kinase. Biochemistry 38: 16407-16412.

Lin, H.P. and Reeves, H.C. (1994). In vivo phosphorylation of NADP ${ }^{+}$glutamate dehydrogenase in Escherichia coli. Curr. Microbiol. 28(2): 63-65.

Lindley, T.E., Scheiderer, C.L., Walsh, P.J., Wood, C.M., Bergman, H.I., Bergman, A.I., Laurent, P., Wilson, P., and Anderson, P.M. (1999). Muscle as the primary site of urea cycle enzyme activity in an alkaline lake-adapted tilapia, Oreochromis alcalicus grahami. J. Biol. Chem. 274: 29858-29861.

Luttrell, W. (2002). Toxic tips: Ammonia. Chemical Health and Safety 9(3): 30-31.

MacDonald, J.A., and Storey, K.B. (2007). The effect of hibernation on protein phosphatases from ground squirrel organs. Arch. Biochem. Biophys. 468:234243.

Malan, A., and Canguilhem, B. (1989). Temperature and enzyme structure. In: Living in 
the Cold ( $2^{\text {nd }}$ International Symposium). John Libbey Eurotext pp. 160-161.

Male, K.B., and Storey, K.B. (1982). Regulation of coenzyme utilization by bovine liver glutamate dehydrogenase: Investigations using thionicotinamide analogues of NAD and NADP in a dual wavelength assay. Int. J. Biochem. 14: 1083-1089.

McArthur, M.D. and Milsom, W.K. (1991). Changes in ventilation and respiratory sensitivity associated with hibernation in Columbian (Spermophilus columbianus) and golden-mantled (Spermophilus lateralis) ground squirrels. Physiol. Zool. 64: 940-959.

McDaniel, H.G., Yeh, M., Jenkins, R., Freeman, B., and Simmons, J. (1984). Glutamic dehydrogenase activity in rat heart: demonstration of two forms of enzyme activity. Am. J. Physiol. Heart Circ. Physiol. 246: H483-H490.

Mehrani, H., and Storey, K.B. (1995). Effect of anoxia on protein phosphatase in turtle organs: purification and properties of protein phosphatase type-1 from turtle liver. Arch. Biochem. Biophys. 316(2): 836-843.

Mehrani, H., and Storey, K.B. (1995b). cAMP-dependent protein kinase and anoxia survival in turtles: Purification and properties of liver PKA. Mol. Cell. Biochem. 145(1): 81-88.

Monahan, W.G., Tilbury, R.S., and Laughlin, J.S. (1972). Uptake of ${ }^{13} \mathrm{~N}$-labeled ammonia. Soc. Nucl. Med. 13(4): 274-277.

Nakasako, M. (2001). Large-Scale Domain Movements and Hydration Structure Changes in the Active-Site Cleft of Unligated Glutamate Dehydrogenase from Thermococcus profundus Studied by Cryogenic X-ray Crystal Structure Analysis and Small-Angle X-ray Scattering. Biochemistry 40: 3069-3079.

Pakay, J.L., Withers, P.C., Hobbs, A.A., and Guppy, M. (2002). In vivo downregulation of protein synthesis in the snail Helix aspersa during estivation. Am. J. Physiol. Regulatory Integrative Comp. Physiol. 283: R197-R204.

Passmore, J.C., Pfeiffer, E.W., and Templeton, J.R. (1975). Urea excretion in hibernating Columbian ground squirrel (Spermophilus columbianus). J. Exp. Zool. 192(1): 83-86.

Peterson, P.E., and Smith, T.J. (1999). The structure of bovine glutamate dehydrogenase provides insights into the mechanism of allostery. Structure 7: 769-782.

Rac, M.E., Safranow, K., Dolegowska, B., and Machoy, Z. (2007). Guanine and inosine nucleotides, nucleosides and oxypurines in snail muscles as potential biomarkers of fluoride toxicity. Folia Biologica (Krakow) 55: 153-160. 
Ramnanan, C.J., and Storey, K.B. (2006a). Glucose-6-phosphate dehydrogenase regulation during hypometabolism. Biochem. Biophys. Res. Comm. 339: 7-16.

Ramnanan, C.J., and Storey, K.B. (2006b). Suppression of $\mathrm{Na}^{+} / \mathrm{K}^{+}$-ATPase activity during estivation in the land snail Otala lacteal. J. Exp. Biol. 209: 677-688.

Rees, B.B., and Hand, S.C. (1993). Biochemical correlates of estivation tolerance in the mountain snail Oreohelix (Pulmonata: Oreohelicidae). Biol. Bull. 184: 230-242.

Rokitka, M.E., and Herreid, C.F. (1975). Formation of epiphragm by the land snail Otala lactea (Muller) under various environmental conditions. Nautilus 89: 27-32.

Saha, N., Das, L., and Dutta, S. (1999). Types of carbamoyl phosphate synthetases and subcellular localization of urea cycle and related enzymes in air-breathing walking catfish, Clarias batrachus. J. Exp. Biol. 283: 121-130.

Schiff, E.R., Sorrell, M.F., Maddrey, W.C. (2006). Consequences of liver disease In: Schiff's Diseases of the Liver (10 ${ }^{\text {th }}$ Edition). Lippincott Williams and Wilkens. Philadelphia, PA, USA. pg 572.

Schmidt, E.S., and Schmidt, F.W. (1988). Glutamate dehydrogenase: biochemical and clinical aspects of an interesting enzyme. Clinica Chimica Acta 43: 43-56.

Sies, H., Akerboom, T.P.M., and Tager, J.M. (1977). Mitochondrial and cytosolic NADPH systems and isocitrate dehydrogenase indicator metabolites during ureogenesis from ammonia in isolated rat hepatocytes. Eur. J. Biochem. 72: 301307.

Smith, T.J., Peterson, P.E., Schmidt, T., Fang, J., and Stanley, C.A. (2001). Structures of bovine glutamate dehydrogenase complexes elucidate mechanism of purine regulation. J. Mol. Biol. 307: 707-720.

Steele, S.L., Yancey, P.H., and Wright, P.A. (2005). The little skate Raja erinacea exhibits an extrahepatic ornithine urea cycle in the muscle and modulates nitrogen metabolism during low-salinity challenge. Physiol. Biochem. Zool. 78: 216-226.

Storey, K.B. (1987a). Regulation of liver metabolism by enzyme phosphorylation during mammalian hibernation. J. Biol. Chem. 262: 1670-1673.

Storey, K.B. (1987b). Tissue-specific controls on carbohydrate catabolism during anoxia in goldfish. Physiol. Zool. 60: 601-607.

Storey, K.B. (1987c). Organ-specific metabolism during freezing and thawing in a freeze-tolerant frog. Am. J. Physiol. 253: R292-R297.

Storey, K.B. (1996). Metabolic adaptations supporting anoxia tolerance in reptiles: 
Recent advances. Comp. Biochem. Physiol. A 113(1): 23-35.

Storey, K.B. (2002). Life in the slow lane: Molecular mechanisms of estivation. Comp. Bioc. Physiol. A 133: 733-754.

Storey, K.B. (2003). Mammalian hibernation: transcriptional and translational controls. Adv. Exp. Biol. Med. 543: 21-38.

Storey, K.B. (2004a). Oxygen limitation and metabolic rate depression In: Functional Metabolism: Regulation and Adaptation. Wiley-Liss, Hoboken, pp. 421-431.

Storey, K.B. (2004b). Temperature effects on hibernator metabolism. In: Functional Metabolism: Regulation and Adaptation. Wiley-Liss, Hoboken, NJ, pp. 454-460.

Storey, K.B. (2004c). Isoform/isozyme properties. In: Functional Metabolism: Regulation and Adaptation. Wiley-Liss, Hoboken, NJ, pp. 393-398.

Storey, K.B. (2004d). Human energy metabolism in health and disease. In: Functional Metabolism: Regulation and Adaptation. Wiley-Liss, Hoboken, pp. 261.

Storey, K.B. (2004e). The mitochondria: Powerhouse of the cell. In: Functional Metabolism: Regulation and Adaptation. Wiley-Liss, Hoboken, pp. 214.

Storey, K.B. (2004f) Mammalian hibernation: Biochemical adaptation and gene expression In: Functional Metabolism: Regulation and Adaptation. Wiley-Liss, Hoboken, NJ, pp. 458.

Storey, K.B. (2007). Anoxia tolerance in turtles: Metabolic regulation and gene expression. Comp. Biochem. Physiol. A 147(2): 263-276.

Storey, K.B., Fields, J.H.A., and Hochachka, P.W. (1978). Purification and properties of glutamate dehydrogenase from mantle muscle of the squid, Loligo pealeii. Role of the enzyme in energy production. J. Exp. Zool. 205(1): 111-118.

Storey, K.B., Kelly, D.A., Duncan, J.A., and Storey, J.M. (1990). Anaerobiosis and organ-specific regulation of glycolysis in the marine whelk. Can. J. Zool. 68: 974980.

Storey, K.B. and Storey, J.M. (1990). Metabolic rate depression and biochemical adaptation in anaerobiosis, hibernation, and estivation. Quart. Rev. Biol. 65(2): 145-174.

Storey, K.B., and Storey, J.M. (2001). Hibernation: poikilotherms. Encyclopedia of Life Sciences, MacMillan Reference Ltd., London: Nature Publishing Group. 
Storey, K.B. and Storey, J.M. (2004). Metabolic rate depression in animals: transcriptional and translational controls. Biol. Rev. Camb. Philos. Soc. 79(1): 207-233.

Stryer, L. (1995). Metabolic energy. In: Biochemistry $\left(4^{\text {th }}\right.$ Edition). W.H. Freeman and Company pp. 638.

Thatcher, B.J. and Storey, K.B. (2001). Glutamate dehydrogenase from liver of euthermic and hibernating Richardson's ground squirrels: Evidence for two distinct enzyme forms. 79: 11-19.

Tischler, M.E., Friedrichs, D., Coll, K., and Williamson, J.R. (1977). Pyridine nucleotide distributions and enzyme mass action ratios in hepatocytes from fed and starved rats. Arch. Biochem. Biophys. 184(1): 222-236.

Ultsch, G.R., and Jackson, D.C. (1982). Long-term submergence at $3^{\circ} \mathrm{C}$ of the turtle Chrysemys picta bellii in normoxic and severely hypoxic water: Effects of changes in ambient $\mathrm{PO}_{2}$ and subsequent air breathing. J. Exp. Biol. 97: 87-99.

Uno, I., Matsumoto, K., Adachi, K., and Ishikawa, T. (1984). Regulation of NADdependent glutamate dehydrogenase by protein kinases in Saccharomyces cerevisiae. J. Biol. Chem. 259: 1288-1293.

Whitten, B.K., Schrader, L.E., Huston, R.L., and Honold, G.R. (1970). Hepatic polyribosomes and protein synthesis: seasonal changes in a hibernator. Int. J. Biochem. 1: 406-408.

Whitwam, R.E. and Storey, K.B. (1990). Pyruvate kinase and the land snail Otala lactea: regulation by reversible phosphorylation during estivation and anoxia. J. Exp. Biol. 154: 321-337.

Whitwam, R.E. and Storey, K.B. (1991). Regulation of phosphofructokinase during estivation and anoxia in the land snail Otala lactea. Physiol. Zool. 64: 595-610.

Wilson, B.E., Deeb, S., and Florant, G.L (1992). Seasonal changes in hormone-sensitive and lipoprotein lipase mRNA concentrations in marmot white adipose tissue. Am. J. Physiol. Regul. Integr. Comp. Physiol. 262: R177-R181.

Witters, L.A., Tipper, J.P., and Bacon, G.W. (1983). Stimulation of site-specific phosphorylation of acetyl Coenzyme A carboxylase by insulin and epinephrine. $J$. Biol. Chem. 258(9): 5643-5648.

Yacoe, M.E. (1983). Adjustments of metabolic pathways in the pectoralis muscles of the bat, Eptesicus fuscus, related to carbohydrate sparing during hibernation. Physiol. Zool., 56(4): 648-658. 
Zatzman, M.L. (1984). Renal and cardiovascular effects of hibernation and hypothermia. Cryobiology. 21: 593-614.

Zhou, J. (2006). Regulation of enzymes of energy metabolism - AMP deaminase and creatine kinase - in an anoxia tolerant turtle. M.Sc. thesis, Dept. Biology, Carleton University. 


\section{Appendix 1}

Table 1: The serine/threonine phosphorylation sites which were common among more than one of the prediction tools for human glutamate dehydrogenase (P00367), their sequence and the matching binding motif. Phosphorylated residues are underlined.

\begin{tabular}{|c|c|c|c|c|c|}
\hline \multicolumn{3}{|c|}{ Serine } & \multicolumn{3}{|c|}{ Threonine } \\
\hline Location & Sequence & Binding Motif & Location & Sequence & Binding Motif \\
\hline 54 & RRHYSEAVA & CAMK2 & 144 & SQHRTPCKG & $\begin{array}{l}\text { CDK2, CDK1, } \\
\text { cdc2, MAPK }\end{array}$ \\
\hline 79 & DRGASIVED & CK2, CAMK2 & 154 & IRYSTDVSV & CAMK2 \\
\hline 94 & RTRESEEQK & PKA & T169 & ASLMTYKCA & CK1, PKC \\
\hline 128 & RDDGSWEVI & PLK1 & 206 & TRRFIMELA & $\begin{array}{l}\text { PKA, CAMK2, } \\
\text { PKD, Aurora-A, } \\
\text { CHK1 }\end{array}$ \\
\hline 153 & GIRYSTDVS & PKA, GSK3 & 410 & NGPTTPEAD & CK2, ERK, MAPK \\
\hline 157 & STDVS VDEV & $\begin{array}{l}\text { CK1, CK2, } \\
\text { PLK, PLK1 }\end{array}$ & 455 & YGRLIFKYE & PKA \\
\hline 227 & APDMSTGER & CK2 & & & \\
\hline 234 & EREMSWIAD & $\begin{array}{c}\text { CAMK2, } \\
\text { PLK1 }\end{array}$ & & & \\
\hline 261 & GKPISQGGI & ATM & & & \\
\hline 270 & HGRISATGR & PKA & & & \\
\hline
\end{tabular}

*Prediction tools used were Disphos, ELM, NetPhos, Scansite, Phosida, KinasePhos, and PhosphoSite.

Table 2: The annotated serine and tyrosine phosphorylation sites (phospho-residues underlined) found for human glutamate dehydrogenase from PhosphoSite.

\begin{tabular}{|c|c|c|c|c|}
\hline Enzyme & $\begin{array}{c}\text { SwissProt } \\
\text { ID }\end{array}$ & $\begin{array}{l}\text { Site } \\
\text { info }\end{array}$ & $\begin{array}{c}\text { Phosphorylation } \\
\text { Sites }\end{array}$ & $\begin{array}{c}\text { Other organisms } \\
\text { with the same } \\
\text { phosphorylation } \\
\text { site }\end{array}$ \\
\hline \multirow{5}{*}{$\begin{array}{l}\text { Glutamate } \\
\text { Dehydrogenase }\end{array}$} & \multirow{5}{*}{ P00367 } & S79 & GFFDRGASIVEDKLV & mouse and rat \\
\hline & & $\mathrm{S} 128$ & PIRRDDGSWWEVIEGY & mouse and rat \\
\hline & & Y451 & KNLNHVSYGRLTFKY & mouse and rat \\
\hline & & $\mathrm{Y} 464$ & KYERDSNYHLLMSVQ & mouse and rat \\
\hline & & $\mathrm{Y} 512$ & IVHSGLAYTMERSAR & mouse and rat \\
\hline
\end{tabular}

